Arthur Nicolaus Fendrich

Análise de custo-eficácia dos Pagamentos por Serviços Ambientais em paisagens fragmentadas: estudo de caso de São Paulo

São Carlos, SP

2017 

Arthur Nicolaus Fendrich

\section{Análise de custo-eficácia dos Pagamentos por Serviços Ambientais em paisagens fragmentadas: estudo de caso de São Paulo}

Dissertação apresentada à Escola de Engenharia de São Carlos, Universidade de São Paulo, como parte dos requisitos para obtenção do título de Mestre em Ciências - Programa de Ciências da Engenharia Ambiental

Universidade de São Paulo

Orientador: Prof. Dr. Victor Eduardo Lima Ranieri

São Carlos, SP

2017 
AUTORIZO A REPRODUÇÃO TOTAL OU PARCIAL DESTE TRABALHO, POR QUALQUER MEIO CONVENCIONAL OU ELETRÔNICO, PARA FINS DE ESTUDO E PESQUISA, DESDE QUE CITADA A FONTE.

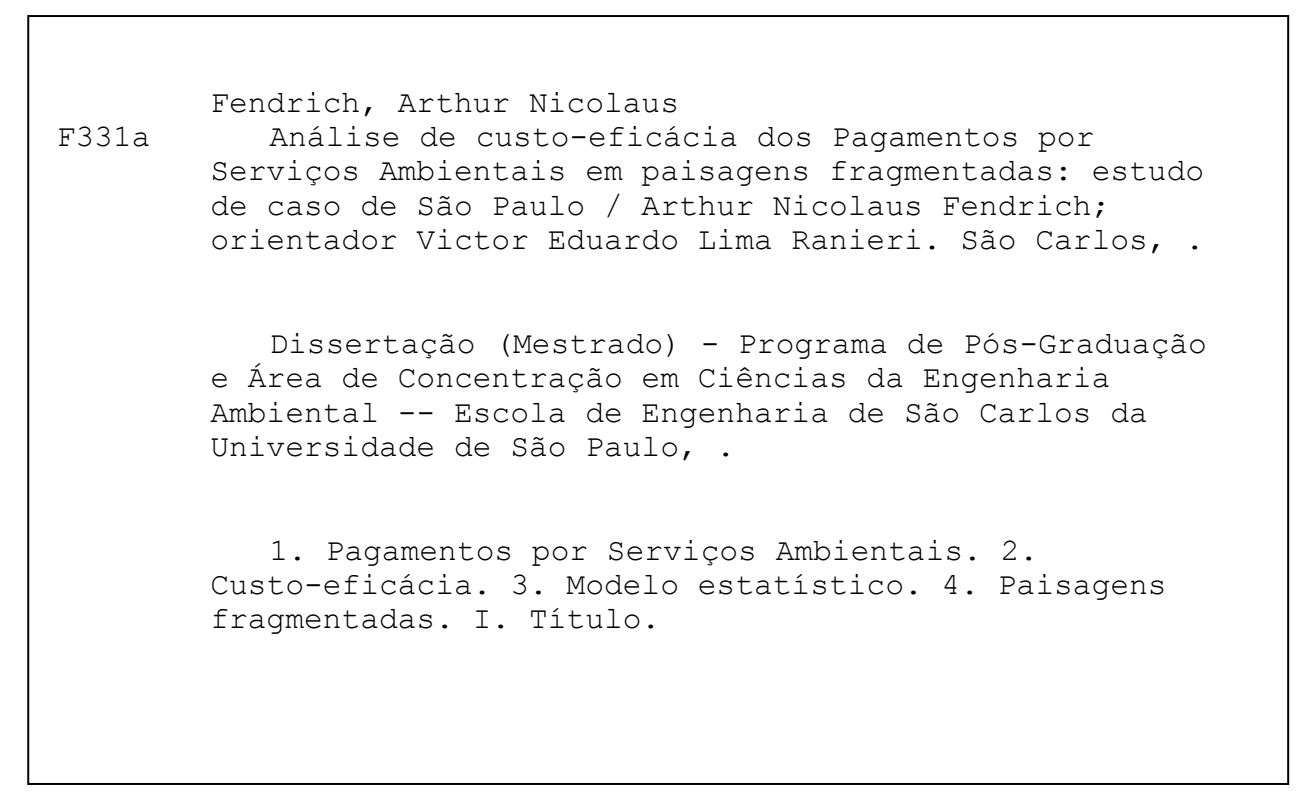


Candidato: Engenheiro ARTHUR NICOLAUS FENDRICH

Título da dissertação: "Análise de custo-eficácia dos pagamentos por serviços ambientais em paisagens fragmentadas: estudo de caso de São Paulo".

Data da defesa: 14.11.2017

\section{Comissão Julgadora:}

Prof. Associado Victor Eduardo Lima Ranieri (Orientador) (Escola de Engenharia de São Carlos/EESC)

Prof. Titular Gerd Sparovek

(Escola Superior de Agricultura "Luiz de Queiroz"/ESALQ-USP)

Profa. Dra. Fernanda De Bastiani

(Universidade Federal de Pernambuco/UFPE)
Resultado:
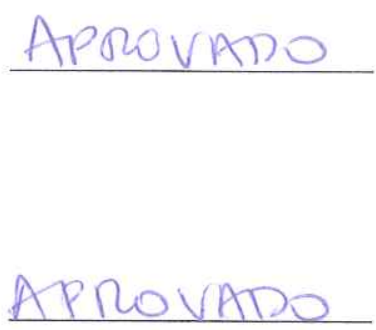

APROVADO

Coordenador do Programa de Pós-Graduação em Ciências da Engenharia Ambiental:

Prof. Associado Frederico Fabio Mauad

Presidente da Comissão de Pós-Graduação:

Prof. Associado Luís Fernando Costa Alberto 



\section{Agradecimentos}

Agradeço inicialmente ao Prof. Dr. Victor Eduardo Lima Ranieri por conceder a oportunidade de desenvolver esta pesquisa sob sua orientação, por todo o tempo dedicado à análise da dissertação, pelas contribuições dadas em todas as etapas da pesquisa, por todos os esforços que despende em proporcionar oportunidades para mim e para todos seus orientandos, e por todas as conversas que tivemos e que contribuíram muito para minha formação.

A todos os proprietários e as proprietárias rurais que dedicaram parte de seu tempo a responder ao questionário e confiaram a mim o bom uso das informações fornecidas.

A todos que se dedicam a contribuir para o desenvolvimento, utilização e divulgação de software livre em pesquisas acadêmicas, pois considero que o compartilhamento da pesquisa ao amplo acesso e a construção do conhecimento de forma livre, independente e cooperativa são fundamentais para a humanidade. Essa pesquisa foi desenvolvida com utilização dos recursos computacionais do Centro de Ciências Matemáticas Aplicadas à Indústria (CeMEAI) financiados pela FAPESP e além desse agradecimento formal, gostaria de agradecer também aos membros da Comissão Gestora do Cluster Euler, que foram sempre atenciosos.

Aos professores e professoras: Dr. Alexandre Toshiro Igari, pela contribuição teórica dada à pesquisa. À Dra. Juliana Cobre, por apontar alternativas que melhoraram muito a proposta metodológica inicial. Ao Dr. Mário de Castro Andrade Filho, por esclarecer minhas dúvidas e opinar sobre os resultados parciais. À Dra. Fernanda De Bastiani, pelas contribuições ao texto e à sugestão de perspectivas futuras para a pesquisa. Ao Dr. Gerd Sparovek, pela ampla contribuição dada à pesquisa.

A todos os colegas do NEPA desde que entrei no Mestrado - Carol, Eleri, Erica, Ligia, Marcio, Maridelia, Karina e Lucas -, pela qualidade das discussões sobre assuntos correlatos e pelas contribuições dadas nesta pesquisa nas apresentações de resultados parciais.

À Marina, pelo amor, confiança e compreensão que foram fundamentais nos (muitos) momentos em que achei que algo daria errado no desenvolvimento da pesquisa.

À minha família - minha irmã Lorena, minha mãe Silvia e meu pai Alexandre - pelo amor e por sempre apoiarem minhas decisões. 

Na prática, a interrogação central é a seguinte: se Stern estiver mais ou menos certo e se for justificável gastar anualmente o equivalente a 5\% do PIB mundial para evitar uma catástrofe ambiental, temos certeza de que saberemos quais investimentos realizar $e$ como organizá-los? 



\section{Resumo}

Fendrich, A. N. Análise de custo-eficácia dos Pagamentos por Serviços Ambientais em paisagens fragmentadas: estudo de caso de São Paulo. 2017. 125p. Dissertação (Mestrado) - Escola de Engenharia de São Carlos, Universidade de São Paulo, São Carlos, 2017.

Mesmo com o crescimento da dependência da vida humana em relação aos serviços ecossistêmicos, a taxa de perda de diversidade genética no planeta tem alcançado níveis semelhantes à de grandes eventos de extinção, evidenciando a necessidade de ações para a conservação dos recursos naturais. Em adição aos tradicionais instrumentos de comando e controle para a conservação, os instrumentos econômicos têm tido crescente atenção no mundo nos últimos anos, com especial destaque para os Pagamentos por Serviços Ambientais (PSA). A abordagem de pagamentos de incentivos tem crescido na última década e, apesar das potencialidades que o PSA apresenta, muitos programas falham em incorporar o conhecimento científico em sua execução, sendo esse um dos aspectos que podem acarretar baixo desempenho ambiental e econômico. Neste contexto, o presente projeto buscou avaliar a custo-eficácia do PSA em paisagens fragmentadas. A área de estudo é o estado de São Paulo, cuja fragmentação historicamente ocorre pela expansão agropecuária e pelos diversos impactos decorrentes do grande crescimento populacional em seu território. Foram distribuídos questionários para a obtenção das preferências dos proprietários rurais paulistas em relação aos programas de PSA para restauração de vegetação nativa. Os dados coletados foram relacionados a características socioeconômicas e ambientais e um modelo beta inflacionado de zero misto dentro da classe GAMLSS foi utilizado. Em seguida, o modelo foi utilizado para predizer os resultados para os proprietários não entrevistados e a curva de investimento para diferentes retornos para conservação foi construída. Os resultados apontaram que o PSA é uma alternativa muito custosa frente aos orçamentos ambientais paulistas e que traz poucos benefícios para a restauração no estado de São Paulo. A pesquisa possui uma vertente teórica, pois contribui para a compreensão da adequabilidade do PSA em paisagens fragmentadas, e uma vertente prática, pois explicita a quantidade de recursos necessária para a execução dos programas analisados.

Palavras-chave: Pagamentos por Serviços Ambientais; custo-eficácia; modelo estatístico; paisagens fragmentadas. 



\section{Abstract}

Fendrich, A. N. Cost-effectiveness analysis of Payments for Environmental Services in fragmented landscapes: case study in the state of São Paulo. 2017. 125p. Thesis (MS) - Escola de Engenharia de São Carlos, Universidade de São Paulo, São Carlos, 2017.

Although the dependence of human activities on ecosystem services has risen in the past decades, the current rate of genetic diversity loss has substantially declined and reached alarming levels. In addition to the traditional command and control approach for the promotion of conservation, growing attention has been given to economic instruments, especially to Payments for Environmental Services (PES). Despite all potentialities of the PES instrument, many programs fail to introduce scientific knowledge in the execution. Such a lack of foundation may result in low environmental and economic performance. The present research aims at evaluating the cost-effectiveness of PES in fragmented landscapes. The study area is the state of São Paulo, which has been fragmented by the agricultural and pasture expansion, and the impacts linked to the large population growth. A survey with different PES programs was sent to rural landowners and responses were analyzed and linked to socioeconomic and environmental characteristics through a zero-inflated beta mixed model, within the GAMLSS framework. The model was used to predict enrollment of non-respondents in different PES programs. Finally, the relationship between total area for restoration and the amount of resources needed for each program was compared to the environmental budget of the state of São Paulo. Results show that PES is a very costly alternative that can provide only few results for restoration. The present work has a theoretical orientation, as it contributes to the comprehension of the feasibility of PES programs in fragmented landscapes, and a practical orientation, as it quantifies the amount of resources required by the programs analyzed.

Keywords: Payments for Environmental Services; statistical modeling; cost-effectiveness; fragmented landscapes. 



\section{Lista de ilustrações}

Figura 1 - Evolução da população rural do Estado de São Paulo . . . . . . . . . . 32

Figura 2 - Índice dos procedimentos realizados. . . . . . . . . . . . . . . 34

Figura 3 - E-mail enviado aos proprietários rurais e consultores . . . . . . . . 39

Figura 4 - Questionário aplicado. Os valores dos programas A, B, C e D variam a cada atualização da página. . . . . . . . . . . . . . 41

Figura 5 - Sequência de procedimentos para validação das respostas obtidas. . . . 42

Figura 6 - Formas do erro de cobertura. . . . . . . . . . . . . . . . 44

Figura 7 - Mapa contendo os municípios com e sem respostas válidas . . . . . . 59

Figura 8 - Probabilidade espacializada de escolha de uma propriedade aleatória no estado . . . . . . . . . . . . . . . . . 6 60

Figura 9 - Comparação do sexo dos respondentes entre a amostra e a população. Teste realizado: $\chi^{2}$ de Pearson . . . . . . . . . . . . . . 61

Figura 10 - Comparação da idade dos respondentes entre a amostra e a população. Teste realizado: Teste exato de Fisher . . . . . . . . . . . . . 62

Figura 11 - Comparação da uso do solo entre a amostra e a população. Teste realizado: Teste exato de Fisher . . . . . . . . . . . . . . . . 63

Figura 12 - Comparação do uso do solo dos respondentes com o uso do solo dos respondentes do CAR . . . . . . . . . . . . . . . 64

Figura 13 - Gráfico do valor $p$ do teste de Shapiro-Wilk para a normalidade dos resíduos versus a semente aleatória utilizada . . . . . . . . . . 70

Figura 14 - Gráficos de diagnóstico do modelo: à esquerda (a), o histograma dos resíduos e à direita (b), os resíduos plotados versus o índice das observações ............................... 71

Figura 15 - Gráficos de diagnóstico do modelo: à esquerda (a), o QQ-plot dos resíduos e à direita, o worm-plot . . . . . . . . . . . . . 72

Figura 16 - Gráficos de diagnóstico do modelo: worm-plot para diferentes intervalos das variáveis preditoras tempo e pagamento propostos no questionário . 73

Figura 17 - Gráficos de diagnóstico da predição do modelo: à esquerda (a), boxplot dos resíduos puros preditos e à direita (b), a área total predita com o

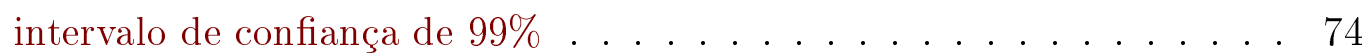

Figura 18 - Predições da disposição à participação espacializadas . . . . . . . . . . 75

Figura 19 - Valores preditos: superfície de participação em função do tempo e pagamento propostos . . . . . . . . . . . . . 76

Figura 20 - Valores preditos: área de participação acumulada em função do pagamento proposto . . . . . . . . . . . . . . 78 
Figura 21 - Valores preditos: curvas de participação para determinados valores fixos de tempo proposto . . . . . . . . . . . . . . . 79

Figura 22 - Valores preditos: curvas de participação sobrepostas a valores notáveis de orçamento ou área para restauração.

A interseção das três curvas indica que um programa proposto pelo tempo representado na curva crescente seria viável para restaurar a quantidade de vegetação representada pela linha horizontal, com os recursos apresentados na curva decrescente. As linhas horizontais representam: a área das Unidades de Conservação de Proteção Integral estaduais do estado de São Paulo (1), a área de restauração necessária para o incremento do percentual de vegetação nativa do estado de São Paulo para 25\% (2), a área aproximada de APPs tornadas desprotegidas com o advento da Lei 12.641/2012 - Novo Código Florestal (3) e a área aproximada de APPs mais Reserva Legal que se tornaram desprotegidas com o advento do Novo Código Florestal (4). As curvas decrescentes representam: o total de investimentos da SMA para a restauração em 2014, o maior dos últimos cinco anos (a), o orçamento destinado para 'pessoal' da Fundação Florestal em 2017 (b), o orçamento total da Fundação Florestal em 2017 (c), o orçamento destinado ao pessoal da SMA em 2017 (d) e, por fim, o orçamento total da SMA em $2017(\mathbf{e}) \ldots \ldots \ldots \ldots$. . . . . . . . . . . . . . 8 80

Figura 23 - Valores preditos: curva de participação de cinco anos divida por dez e sobreposta a valores notáveis de orçamento . . . . . . . . . . 83

Figura 24 - Relação da probabilidade de não participação com o tamanho da propriedade ........................ 85

Figura 25 - Valor médio predito da participação segmentado pelo uso do solo e o tamanho da propriedade . . . . . . . . . . . . . 86 


\section{Lista de tabelas e quadros}

Tabela 1 - Área colhida das principais culturas agrícolas do estado de São Paulo . 32

Tabela 2 - Valores de pagamentos por hectare ano para os proprietários em programas de PSA e na aquisição de Cotas de Reserva Ambiental. . . . . 36

Tabela 3 - Grupos ofertados aos proprietários por meio do questionário. . . . . . . 37

Tabela 4 - Elementos de uma tabela de contingência . . . . . . . . . . . 45

Tabela 5 - Valores utilizados para rejeição das hipóteses nulas . . . . . . . . . 61

Tabela 6 - Coeficientes do modelo estatístico escolhido . . . . . . . . . . . 69

Tabela 7 - Áreas disponíveis na base de predição, separado por cultura e tamanho da propriedade ....................... 87

Tabela 8 - Análise do pressuposto de Banks-Leite et al. (2014): percentual de proprietários que atingiria $30 \%$ da propriedade com vegetação nativa. Tempo considerado: 40 anos. . . . . . . . . . . . . . . 89

Quadro 1 - Especificações da busca pelas características socioeconômicas e ambientais ........................ 46

Quadro 2 - Variáveis filtradas e agrupadas ............... 65 



\section{Sumário}

Sumário . . . . . . . . . . . . . . . . . . . 17

1 INTRODUÇÃO E JUSTIFICATIVA . . . . . . . . . . 19

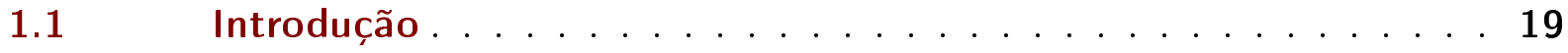

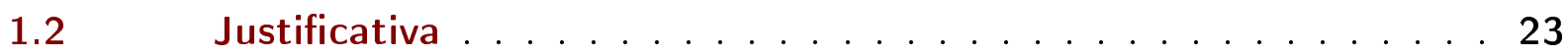

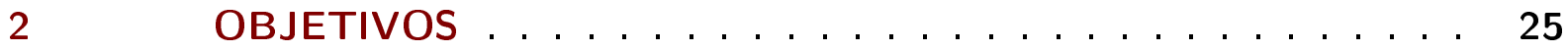

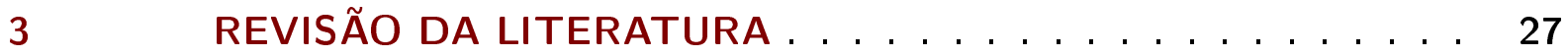

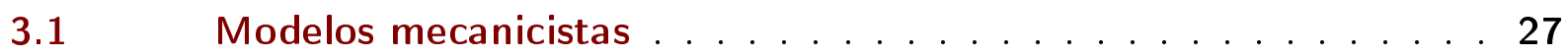

$3.2 \quad$ Modelos empíricos . . . . . . . . . . . . . . . . 29

$4 \quad$ METODOLOGIA $\ldots \ldots \ldots \ldots \ldots \ldots \ldots$

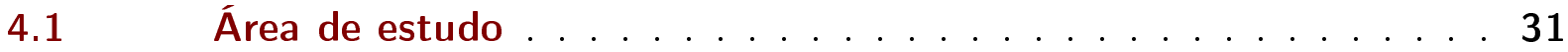

$4.2 \quad$ Materiais e métodos . . . . . . . . . . . . . . 34

$4.2 .1 \quad$ Coleta de dados . . . . . . . . . . . . . . . . . . 34

4.2 .2 Verificação do viés da amostra . . . . . . . . . . . . . 42

4.2.3 Variáveis socioeconômicas e ambientais . . . . . . . . . . . 46

4.2.4 Tratamento dos dados espaciais . . . . . . . . . . . . 47

$4.2 .5 \quad$ Modelo estatístico . . . . . . . . . . . . . . . . 47

$4.2 .6 \quad$ Validação e Predição . . . . . . . . . . . . . . . . . 55

4.2 .7 Problemas e limitações . . . . . . . . . . . . . . . . . . . . 56

$4.2 .8 \quad$ Softwares utilizados . . . . . . . . . . . . . . . . 57

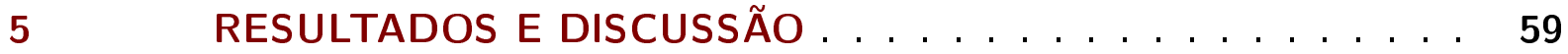

$5.1 \quad$ Aplicação do questionário . . . . . . . . . . . . 59

5.2 Características socioeconômicas e ambientais . . . . . . . . . 64

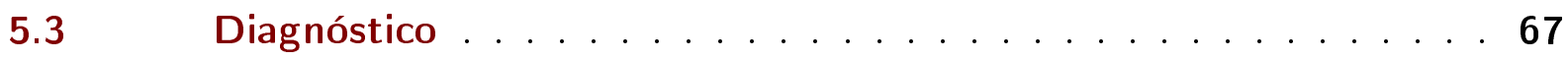

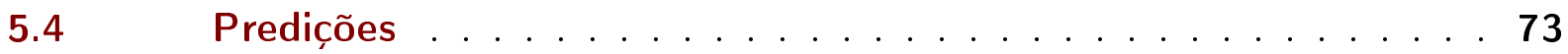

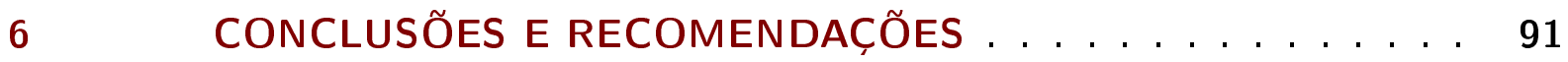

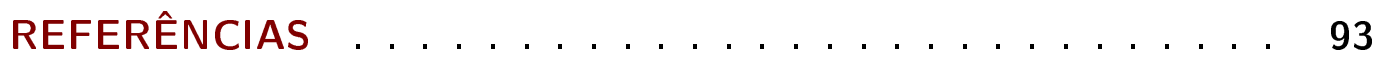

APÊNDICE A - VARIÁVEIS DE ARTIGOS SEMELHANTES . . 105

APÊNDICE B - VARIÁVEIS CANDIDATAS . . . . . . . 113

APÊNDICE C - LISTA DOS PRINCIPAIS ARQUIVOS . . . . . 119 



\section{InTRODUÇÃO E JUSTIFICATIVA}

\subsection{Introdução}

As alterações provocadas pelo ser humano no meio ambiente têm se mostrado crescentes, podendo suas magnitudes serem comparadas à de grandes eventos naturais. Estima-se que a atual taxa de perda de diversidade genética seja semelhante à de eventos de extinção em massa conhecidos no planeta, tendo ultrapassado a zona de incerteza científica em direção a uma zona de alto risco (ROCKSTRÖM et al., 2009; STEFFEN et al., 2015). A presença humana tem pressionado o planeta com muito mais intensidade do que as forças que caracterizaram o fim da era glacial, com o agravante de não haver uma situação de declínio esperada em breve. No entanto, se as últimas mudanças foram drásticas quanto à distribuição das espécies no planeta, o curto tempo da intensificação da ação humana não parece ser longo o suficiente para que sejam compensadas as extinções que possivelmente ocorrerão (BARNOSKY et al., 2011). Ao mesmo tempo em que as práticas humanas têm se mostrado potencialmente degradadoras, o ser humano tem se tornado cada vez mais dependente dos recursos naturais e dos serviços por eles gerados. Atualmente, cerca de um terço à metade da produção global de ecossistemas é utilizada em atividades antrópicas (FOLEY et al., 2005).

Os benefícios provenientes dos ecossistemas para os humanos são denominados serviços ecossistêmicos $(\mathrm{SE})^{1}$ e são frequentemente associados ao bem-estar do ser humano. A provisão de alimento, o sequestro de carbono e amenização do clima, a regulação de vazões e os benefícios espirituais são exemplos de benefícios que se enquadram dentro das quatro categorias de SE: serviços de provisão, de suporte, de regulação e culturais (MEA, 2005).

A correlação positiva entre os SEs e o bem-estar humano parece natural. No entanto, dados mostram que mesmo com o crescimento dos impactos sobre os SEs, o bem-estar humano não apresenta o decréscimo esperado nos últimos anos, em escala global. Este é o "paradoxo do ambientalista", que revela a não correspondência da realidade com a expectativa de que "a degradação e simplificação ecológica será seguida de um declínio na provisão dos serviços ecossistêmicos, levando a um declínio no bem-estar humano"2(RAUDSEPPHEARNE et al., 2010). A existência do paradoxo, no entanto não é consenso na literatura. Além de não se encontrar uma explicação conclusiva sobre a razão de sua existência, é possível que ele tenha aparecido devido à incoerência da análise da relação entre os SEs

1 A tipologia do termo "serviços ecossistêmicos" é questão de debate desde a década de 1970, com o estudo "Man's Impact on the Global Environment", que utilizava a denominação "serviços ambientais". No entanto, a definição de (MEA, 2005) é suficiente para a compreensão do tema na presente pesquisa. 
e o bem-estar humano em escala global (DURAIAPPAH, 2011).

Frente à situação de incerteza científica sobre a relação entre a degradação dos SEs e sua interferência no bem-estar humano (DURAIAPPAH, 2011), mesmo as abordagens utilitaristas da natureza (cf. Chan et al. (2016)) devem levar a ações de conservação dos SEs. Nesse sentido, em adição aos tradicionais instrumentos de comando e controle, os instrumentos econômicos têm tido crescente importância para o objetivo de aliar a conservação dos SEs com a internalização financeira das externalidades negativas impostas pelas atividades humanas ao meio ambiente. Dentre esses instrumentos, tem sido notável o destaque dos Pagamentos por Serviços Ambientais (PSA).

Na América Latina, as primeiras aplicações do PSA datam de meados da década de 1990, na Colômbia, mas a real disseminação de seu interesse parte do caso da aplicação na Costa Rica, em 1997. No Brasil, o número de projetos tem aumentado desde 2006, bem como o interesse na regulamentação do PSA. Neste curto período de tempo, diversos programas foram desenvolvidos e atualmente é possível encontrar aplicações do PSA em diferentes escalas, contextos e utilizando uma variedade de aproximações. Um levantamento de 2015 detectou a existência de mais de 2000 iniciativas de PSA no Brasil (FOREST TRENDS, 2015). As iniciativas brasileiras, contudo, ainda protegem uma parcela muito pequena em área: pouco menos de 50,000 ha (PAGIOLA; GLEHN; TAFFARELLO, 2013).

A contagem do número de ações de PSA é estritamente ligado com a definição adotada para o instrumento. O PSA tem sido definido de diversas maneiras, por vezes muito restritivas, mas por vezes tão amplas a ponto de incluírem quaisquer instrumentos para conservação baseados em criação de mercado (ENGEL; PAGIOLA; WUNDER, 2008). Uma definição frequente é a de Wunder (2005)), que se mostra adequada a uma ampla gama de situações:

1. uma transação voluntária onde

2. é comprado por (no mínimo) um comprador

3. um serviço ambiental bem definido (ou um uso do solo que assegure tal serviço)

4. de (no mínimo) um provedor

5. se, e somente se, o provedor assegurar a provisão do serviço (condicionalidade)

(WUNDER, 2005, p.3, grifos do autor)

No entanto, alguns autores criticam esta definição. As principais manifestações contrárias residem na crítica à abordagem, que seria demasiadamente estreita e Coaseana ${ }^{2}$ (WUNDER, 2015). Em resposta, o autor levanta as definições de PSA feitas após a sua, em 2005, e suas respectivas críticas endereçadas a elas. Uma crítica particularmente im-

2 Original: "Ecological degradation and simplification will be followed by a decline in the provision of ecosystem services, leading to a decline in human well-being." 
portante é sobre a questão da adição da adicionalidade ${ }^{3}$ como critério fundamental para definição do um sistema de PSA:

\begin{abstract}
A inclusão da adicionalidade é desejável? Ela pode ser problemática, já que depende de uma avaliação ex post dos impactos do PSA. Por exemplo, uma referência pioneira ao PSA em países em desenvolvimento tem sido o programa nacional de PSA da Costa Rica, implantado em 1996. Várias avaliações de impactos recentes tem revelado que o programa pode ter tido pouca adicionalidade. Então nós devemos após quase duas décadas de implementação declarar para o mundo: "isso não é, de fato, um PSA, já que agora sabemos que ele é largamente não-adicional"? A adicionalidade como critério também pode reduzir a robustez. Por exemplo, a Costa Rica recentemente introduziu práticas de que podem subitamente ter aumentado a adicionalidade. Isso significaria que do ano $\mathrm{X}$ ao $\mathrm{Y}$, isso não era um PSA, mas depois da mudança, ele teria se tornado um - uma sensibilidade na definição que não é útil. (...) Em conclusão, melhor não misturarmos avaliações de impacto com conceitos e definições

(WUNDER, 2015, p.3, tradução nossa).
\end{abstract}

Considerando que os resultados do presente projeto visam subsidiar a intervenção governamental na aplicação do instrumento, a definição a ser utilizada no presente projeto é a de Wunder (2015):

1. transações voluntárias

2. entre usuários do serviço

3. e provedores do serviço

4. sujeitas à regras de gestão dos recursos naturais acordados

5. para geração de serviços offsite ${ }^{4}$

(WUNDER, 2015, p.8, tradução e grifos nossos)

As mudanças dessa definição são sutis. No entanto, destacam-se a construção dos sistemas no entorno da "gestão dos recursos naturais" e não mais do "serviço ambiental", que nem sempre pode ser bem definido; a mudança do termo de demanda "comprador" para "usuários do serviço", que reduz a noção de mercado associada ao primeiro termo e se desvia do ideal Coaseano ao passo que amplia a noção do termo para organizações coletivas; e a consideração do serviço prestado como "geração de serviços offsite", o que reforça a relação entre o usuário e as externalidade ambientais que são endereçadas pelas regras acordadas (WUNDER, 2015).

Assim, pode-se estabelecer a lógica que um esquema de PSA deveria seguir (ENGEL; PAGIOLA; WUNDER, 2008). No exemplo do PSA em que os serviços são gerados a

2 A teoria Coaseana critica a universalidade da aplicação do princípio do poluidor pagador. Segundo seu autor, Coase, externalidades ambientais negativas seriam preferencialmente resolvidas por negociação particulares entre as partes envolvidas, que tornariam a intervenção governamental redundante. Esta definição parte do princípio de se obter baixos custos de transação e da definição clara dos direitos de propriedade (MURADIAN et al., 2010; WUNDER, 2015).

3 A adicionalidade seria o impacto positivo causado pela provisão do serviço ambiental, que não existiria se não fosse estabelecimento de um sistema de PSA no local.

4 Locais espacialmente externos ao local físico onde o serviço ambiental é gerado (WUNDER, 2015, tradução nossa). 
partir da conversão do uso do solo, os proprietários geralmente obtém poucos benefícios financeiros provenientes do uso da terra para conservação da natureza. Estes benefícios são frequentemente menores do que seriam caso a terra fosse utilizada, por exemplo, para plantação de monocultura ou pastagem. Contudo, ainda que pareça uma boa opção financeira para o gestor da terra, estes usos podem impor custos aos proprietários próximos, pois a conversão das terras poderia implicar na interrupção da provisão dos serviços, por exemplo, de filtração da água e de proteção das margens dos rios. Além destes proprietários, toda a comunidade seria afetada, pois poderia haver perda de biodiversidade e diminuição local no sequestro de carbono. O pagamento de uma quantia dos beneficiários do serviço para o gestor da terra pode ajudar a tornar a conservação uma opção mais atrativa, de tal modo que as externalidades ambientais negativas são, então, internalizadas financeiramente.

É necessário que seja reforçado o caráter estrito da aplicação do PSA. O instrumento não deve ser considerado para todos os problemas de uso de terra, apenas aos que realmente cumprirem as exigências e cuja aplicação do PSA possua referenciais teóricos seguros quanto a relação da ação de conservação, seja em ambiente terrestre ou aquático, com a provisão do SE. De fato, muitos projetos de PSA não se baseiam em resultados científicos e a eficácia da aplicação é raramente avaliada com o rigor necessário para que se permitam a expansão das aproximações e a compreensão da importância do PSA como instrumento de política para a conservação (NAEEM et al., 2015).

Além da dificuldade teórico-conceitual de se definir um esquema de PSA, este instrumento também frequentemente se depara com uma dificuldade prática: a não integração do conhecimento científico na sua execução. O sucesso das iniciativas de PSA reside no conhecimento científico dos ecossistemas de interesse, que embasam o estabelecimento da relação das práticas dos recursos naturais com a geração dos serviços, as iniciativas necessárias para a provisão dos serviços, as escalas a serem adotadas e outros fatores, como mensurabilidade dos resultados (KINZIG et al., 2011).

Devido ao caráter voluntário do PSA, um fator que merece destaque é a compreensão da disposição à participação dos proprietários, pois estudá-la permite melhor planejamento dos programas, com a avaliação alternativas e a criação de programas de melhor performance (LAYTON; SIIKAMÄKI, 2009). Encontra-se na literatura muitos estudos com este propósito, desde o desenvolvimento do modelo conceitual da participação até a aplicação de modelos para o maior conhecimento da disposição à participação dos proprietários rurais em diferentes programas de pagamentos. A maioria destes trabalhos, no entanto, foram feitos em países desenvolvidos - Estados Unidos, Finlândia, Austrália, entre outros -, sendo somente um dos estudo encontrados relativo a um país em desenvolvimento, o Quênia. As características desses trabalhos serão mais bem exploradas na revisão da literatura deste projeto. 


\subsection{Justificativa}

Quando devidamente planejados, os esquemas de PSA apresentam potencialidades em relação a outros instrumentos de política. Como exemplo, cita-se a conservação de espécies ameaçadas por meio de instrumentos regulatórios: a atribuição de responsabilidades sem retornos financeiros aos proprietários rurais cria um tipo de desincentivo para a proteção das espécies, que pode se refletir na adoção de práticas propositadamente negativas para a degradação das características de interesse para a conservação (LUECK; MICHAEL, 2003). O desincentivo gerado pelos instrumentos regulatórios possivelmente não ocorreria caso fosse adotado um programa de incentivos, como o PSA. No entanto, é necessário considerar os custos econômicos dos programas, pois enquanto o mal planejamento pode acarretar em perda de recursos financeiros, o bom planejamento pode influenciar na localização das áreas alvo da conservação e induzir à maior proteção e de melhor qualidade (BALMFORD et al., 2000; MURDOCH et al., 2007; ATKINSON; MOURATO, 2015).

Ademais, muitos programas existem hoje em grande escala. É o caso do Conservation Reserve Program nos Estados Unidos, PRONAFOR no México, PINPEP na Guatemala, Programa de Pago de Servicios Ambientales da Costa Rica e outros (cf. Campanhão (2016)). De fato, a maioria dos casos de PSA relatados na literatura corresponde a programas de pagamentos governamentais e em larga escala (SCHOMERS; MATZDORF, 2013), o que representa uma tendência mundial de ampliação da escala de aplicação do instrumento.

Nesse contexto de aumento da escala dos programas e da necessidade de um correto planejamento dos instrumentos, é conhecido que nos casos brasileiros da Mata Atlântica do estado de São Paulo, a relação custo-benefício não foi considerada em nenhum dos programas atualmente em curso (BERNARDO, 2016). Portanto, frente à escassez de recursos existente, considerar uma possível ampliação desses programas deve ser feito de forma planejada e com detalhes a respeito da relação entre os custos envolvidos nos programas e os respectivos benefícios almejados.

Uma análise de custo-benefício pode ser muito dispendiosa, pois envolveria atribuir valores financeiros aos resultados obtidos para a conservação. Uma estratégia similar é a análise de custo-eficácia, que consiste em "uma técnica que relaciona os custos de um programa a seus resultados chave ou benefícios" (CELLINI; KEE, 2015, tradução nossa). Embora essa técnica seja diferente da análise de custo-benefício, ambas possuem um grande potencial para auxiliar os tomadores de decisão (CELLINI; KEE, 2015) e sua execução possui a potencialidade de não demandar pressupostos econômicos envolvidos na valoração dos resultados obtidos. Assim, a presente pesquisa pretende analisar a custoeficácia do PSA como instrumento para restauração de vegetação nativa no estado de São Paulo. O estado de São Paulo foi escolhido como área de estudo pelo baixo percentual de conservação de seus principais biomas: Cerrado e Mata Atlântica, dois hotspots de 
biodiversidade (MYERS et al., 2000), e por sua relevância socioeconômica para o Brasil, sendo o Estado com maior número de habitantes e maior participação no Produto Interno Bruto nacional.

Esta pesquisa pretende contribuir para a compreensão da importância e da adequabilidade do PSA para a restauração de vegetação nativa em países em desenvolvimento, cuja baixa disponibilidade de recursos financeiros é uma limitação à aplicação do instrumento. Além do viés teórico da pesquisa, os resultados possuirão utilidade prática para subsidiar a tomada de decisão quanto ao investimento financeiro em iniciativas públicas e privadas para o PSA no estado de São Paulo. Desta forma, pretende-se contribuir para o aumento da eficiência da alocação de recursos no processo de restauração de vegetação por meio de instrumentos econômicos. 


\section{OBjetivos}

Este trabalho tem como objetivo geral

- Avaliar a custo-eficácia do PSA como instrumento para restauração de vegetação nativa em paisagens fragmentadas

Os objetivos específicos são:

- Obter a curva de área de vegetação restaurada por investimento aplicado para o estado de São Paulo

- Comparar o orçamento ambiental no estado de São Paulo com o orçamento calculado a partir do modelo estatístico 



\section{REVISÃO DA LITERATURA}

A seguinte revisão da literatura foca no levantamento de diferentes modelos com propósitos semelhantes ao da presente pesquisa.

A utilização de modelos que tentem representar os problemas a partir de equações ou de princípios conhecidos é recorrente em diferentes vertentes da ciência. Uma introdução a essas estruturas de representação é dada por Fiani (2006):

Um modelo nada mais é do que uma representação simplificada de um objeto de estudo (...), em que propositadamente alguns elementos são destacados, enquanto outros são omitidos. A seleção dos elementos a serem destacados ou omitidos não é arbitrária: omitimos os fatos que consideramos pouco importantes, ou até mesmo irrelevantes para a compreensão do que está sendo estudado, ao mesmo tempo em que destacamos aquilo que consideramos essencial e decisivo para o entendimento do nosso objeto de estudo.

Fazemos isso porque a realidade sempre envolve um elevado grau de complexidade, de tal forma que dificilmente conseguiríamos entender os fatos se tentássemos dar conta de todos os detalhes. É claro que isso envolve um risco: temos de ser criteriosos no momento de distinguir quais elementos devem ser destacados por sua importância e quais devem ser omitidos por serem pouco relevantes. Se, por algum equívoco, forem destacados elementos que não são muito importantes para o entendimento da situação e sua posterior análise e/ou, forem omitidos elementos importantes, corre-se o risco de chegar a conclusões totalmente equivocadas (FIANI, 2006, p.4)

Os modelos levantados foram classificados a partir da distinção encontrada em Bolker (2008) entre modelo mecanicista (mechanistic) e modelo empírico (empirical). De acordo com o autor, o modelo mecanicista é definido como "um modelo matemático baseado em suposições sobre os princípios científicos que regem o fenômeno a ser modelado". Por outro lado, o modelo empírico é definido como: "um modelo matemático baseado na verificação de dados numéricos". Modelos que eventualmente misturaram as duas aproximações foram incluídos na seção de modelos empíricos.

\subsection{Modelos mecanicistas}

A grande maioria dos modelos mecanicistas que abordam a questão da participação dos proprietários rurais em programas de pagamentos de incentivos provém da Teoria dos Jogos. Um exemplo de situação modelável é aquela em que um participante possui informações privilegiadas sobre elementos importantes de um jogo ${ }^{5}$, em relação aos demais participantes. Essa é uma situação de informação assimétrica, que acontece com frequência nas relações econômicas. A analogia do estabelecimento de um programa de PSA com 
a elaboração de jogo apresenta resultados prósperos para o planejamento do instrumento.

De acordo com Ferraro (2008), no caso da criação PSA, o agente elaborador do jogo geralmente lida com dois tipos importantes de informações assimétricas: informações omitidas e ações omitidas. No caso das informações omitidas, os provedores do serviço (na presente pesquisa, os proprietários rurais) possuem e escondem as suas características relevantes para o programa. Assim, podem informar os seus custos ao agente como sendo são maiores do que realmente são, criando a possibilidade de receberem pagamentos maiores do que o necessário para participarem. Cria-se, portanto, uma situação denominada seleção adversa (adverse selection), em que a omissão das informações pode induzir o agente a uma decisão incorreta. Esta situação é um empecilho anterior à elaboração dos contratos. Nas ações omitidas, o empecilho surge após o firmamento do contrato. Frente aos custos e à conhecida dificuldade de monitoramento dos resultados pelos agentes, os provedores se recusam a cumprir as ações acordadas. Esta possibilidade dos provedores não seguirem os termos acordados é denominada risco moral (moral hazard).

Desta forma, as informações assimétricas podem impossibilitar ao agente elaborador do jogo a imposição direta de resultados desejados. No entanto, a literatura dispõe de sólidas contribuições teóricas que contribuem para a formulação de programas de pagamentos de incentivos sob esta condição. Por meio da Teoria de Desenho de Mecanismo, um agente é capaz de elaborar estruturas de jogos de tal modo que, variando as características dos participantes, os resultados lhe sejam sempre favoráveis. Assim, mesmo que os participantes escolham suas ações com base na lógica de maximizar seus benefícios próprios, um mecanismo corretamente desenhado deverá trazer benefícios ao agente (FIANI, 2006; OSBORNE; RUBINSTEIN, 1994).

No caso de pagamentos de incentivos, o interesse do agente elaborador do jogo é o de assegurar a provisão do serviço por parte dos provedores. Como exemplo, é possível citar os programas públicos de pagamentos, em que o Estado elabora as condições para participação e paga os provedores, enquanto a sociedade faz o papel do beneficiário. Uma vez que é indesejado o pagamento pelos serviços sem o devido retorno, a abordagem da criação de programas de pagamentos por meio da Teoria de Desenho de Mecanismo se mostra adequada e pertinente.

A modelagem dos programas com foco nas informações omitidas foi desenvolvida por diversos autores (MOXEY; WHITE; OZANNE, 1999; POLASKY; DOREMUS, 1998; SMITH, 1995; SMITH; SHOGREN, 2002; WU; BABCOCK, 1995; WU; BABCOCK, 1996). O desenvolvimento do modelo depende da definição de quais informações são relevantes para o contrato. A partir dessas informações, o equacionamento e a resolução do "problema do governo", ou seja, do objetivo do governo com o programa de PSA,

\footnotetext{
5 Adota-se a seguinte definição de jogo: "Um jogo é uma descrição das interações estratégicas que inclui as restrições nas possíveis ações dos jogadores e seus interesses, mas não especifica as ações que os jogadores tomam" (OSBORNE; RUBINSTEIN, 1994, tradução nossa)
} 
permite maiores esclarecimentos sobre as variáveis de um programa antes de sua criação.

Os resultados de Smith (1995) servem de exemplo para ilustrar como a aplicação da Teoria de Desenho de Mecanismo ao PSA pode ser útil para a análise de sua custoeficácia. O autor propôs as equações ótimas para o estabelecimento do valor de contrato e para a área de participação dos produtores rurais nos Estados Unidos. Aplicando as equações desenvolvidas no Conservation Reserve Program, o autor concluiu que o governo estadunidense poderia estar gastando, por ano, US\$ 600 mi. além do necessário para a conservação das áreas. Até a época do estudo, o valor acumulado do gasto desnecessário era de US\$ 6.8 bi. a US\$ 8.7 bi.

Modelos semelhantes, porém com foco nas ações omitidas, foram criados por Ozanne, Hogan e Colman (2001) e Ozanne e White (2008). A modelagem a partir dos dois tipos de informações assimétricas seria a situação mais próxima da realidade. No entanto, é mais complexa do que as demais. Nesse sentido, destacam-se os trabalhos de Peterson e Boisvert (2004), Ozanne e White (2007) e Gao (2015).

Em contraste aos modelos descritos acima, o presente projeto priorizará a abordagem empírica, ou estatística, apresentada a seguir.

\subsection{Modelos empíricos}

Diferente da abordagem mecanicista, os modelos empíricos de programas de PSA se baseiam na abordagem estatística dos dados de participação dos proprietários. Em todos os trabalhos encontrados na literatura, a coleta de dados se deu a partir da aplicação de questionário para diversos proprietários, que passaram a constituir a amostra das análises. Os trabalhos, no entanto, se diferenciam pelo tipo de questionário aplicado e por cada modelo estatístico utilizado. Embora muitos estudos tenham sido encontrados, abaixo foram apresentados apenas alguns artigos, que caracterizam um breve histórico da evolução da modelagem da participação por meio de ferramentas estatísticas.

Lohr e Park (1994) e Lohr, Park et al. (1995) estudaram a disposição à participação de agricultores em um programa de plantação de cobertura permanente ao redor dos corpos d'água. Os autores adotaram que o problema da participação consistia em um processo de três etapas: detecção da erosão, decisão pela adoção de práticas de conservação do solo e, por fim, decisão do nível de esforço a ser adotado. A partir dessa sequência, nota-se que o problema de modelos discretos ou de apenas uma equação é que ignoram a sequência e tratam a participação e a intensidade de participação como uma única etapa, o que seria prejudicial aos resultados obtidos:

Ao considerar somente aqueles que participaram do programa, não é possivel determinar as razões para a não participação. Ignorar os não participantes reduz as informações sobre o intervalo de possíveis instrumentos de política para encorajar a participação

(LOHR; PARK, 1994, p.2, tradução nossa) ${ }^{6}$ 
Em seguida, os autores desenvolveram um modelo discreto-contínuo. A escolha discreta é a participação, cujo resultado é binário: ou o proprietário participa, ou não participa. A escolha contínua é a intensidade de participação, ou seja, o percentual de terras convertidas para cobertura permanente.

Após as contribuições de Lohr e Park (1994) e Lohr, Park et al. (1995), é possível encontrar estudos que adotaram algum modelo de escolha discreta para representar a participação dos proprietários. Esses modelos focam especificamente na questão de se os proprietários participarão do programa proposto ou não. Exemplos destas aplicações na conservação ou na conversão do uso do solo são os trabalhos de Cooper e Keim (1996), Cooper e Osborn (1998), Claassen e Tegene (1999), Lynch e Lovell (2003), Cooper (2003), Langpap (2004).

Layton e Siikamäki (2009) também criticam o estudo da participação de maneira discreta. De acordo com os autores, é indispensável, além de saber se o proprietário participará ou não, entender como se dará a participação de cada proprietário nos programas propostos. Assim, os autores estudaram a preservação de habitats ameaçados entre proprietários de florestas não industriais na Finlândia e propuseram duas alternativas ao modelo discreto-contínuo: o modelo beta-binomial e o de regressão multivariada para variáveis censuradas.

Como será melhor detalhado na seção metodológica, ambos os modelos propostos por Layton e Siikamäki (2009) possuem problemas conceituais e limitações. Por este motivo, neste trabalho propomos a utilização de outra categoria de modelos.

6 Original: "By considering only those who participated in the program, it is not possible to determine reasons for nonparticipation. Ignoring nonparticipants reduces information about the range of possible policy instruments for encouraging enrollment." 


\section{Metodologia}

\section{1 Área de estudo}

O estado de São Paulo possui área total de aproximadamente $248.222 \mathrm{~km}^{2}$ e se localiza na região Sudeste do Brasil. Possui uma população total, estimada em 2015, de 44.396.484 habitantes, distribuída em 645 municípios. O estado de São Paulo é o mais populoso e o que mais contribui para o Produto Interno Bruto do Brasil (IBGE, 2015b).

O estado se localiza em uma região de transição de dois importantes biomas: o Cerrado e a Mata Atlântica, de área total igual a $2.040 .000 \mathrm{~km}^{2}$ e $1.300 .000 \mathrm{~km}^{2}$, respectivamente. O problema da fragmentação nesses biomas é conhecido e descrito na literatura em conjunto com seus principais causadores:

O desenvolvimento econômico explosivo no estado de São Paulo (SP), Brasil, causado pela agricultura, indústria, urbanização e outras interferências antrópicas tem reduzido os biomas em áreas ricas e diversas, como o Cerrado e a Mata Atlântica, para pequenos remanescentes florestais, afetando as vidas e a existência da maioria das espécies e resultando em áreas que estão sob extrema pressão para o uso em diversas aplicações econômicas.

(CARDOSO; SILVA; VENDRAME, 2016, p.1, tradução nossa) ${ }^{7}$

Tanto o Cerrado quanto a Mata Atlântica são reconhecidamente relevantes, constando na lista dos 25 hotspots globais para a biodiversidade (MYERS et al., 2000). No entanto, seus percentuais de vegetação nativa remanescentes são muito baixos, como decorrência do processo de fragmentação que ocorre na região. Dos $170.713 \mathrm{~km}^{2}$ originais de cobertura de Mata Atlântica no estado de São Paulo, restavam apenas $26.622 \mathrm{~km}^{2}$ (15,59\%) em 2012 (SOSMA/INPE, 2014). Em relação ao Cerrado, dos 81.137 km² originais no estado, apenas $16,9 \%$ da área original do bioma era remanescente em 2013 (MINISTÉRIO DO MEIO AMBIENTE, 2015).

O aumento populacional em áreas urbanas é notado nos dados de SEADE (2016), por meio do grande decréscimo na população rural do Estado de São Paulo desde a década de 1980 (Figura 1). Enquanto a população rural em 1980 era de 2.834 .398 habitantes (11,36\% da população total de 24.953.238 habitantes), em 2016 passou a 1.594.959 habitantes (3,68\% da população total de 43.359.005 habitantes).

Os dados de SEADE (2016) mostram que, em relação à dinâmica econômica do estado de São Paulo, foram registrados 321.171 empregos formais da agricultura, pecuária, produção florestal, pesca e aquicultura em 2014, o equivalente a 2,28\% do total de empregos

7 Original: "Explosive economic development in the State of São Paulo (SP), Brazil caused by agriculture, industry, urbanization and other anthropogenic interferences has reduced the biomes in rich and diverse areas, such as Cerrado and Mata Atlântica to small forest remnants, affecting the lives and existence of most species and resulting in areas that are under extreme pressure for use in diverse economic applications" 


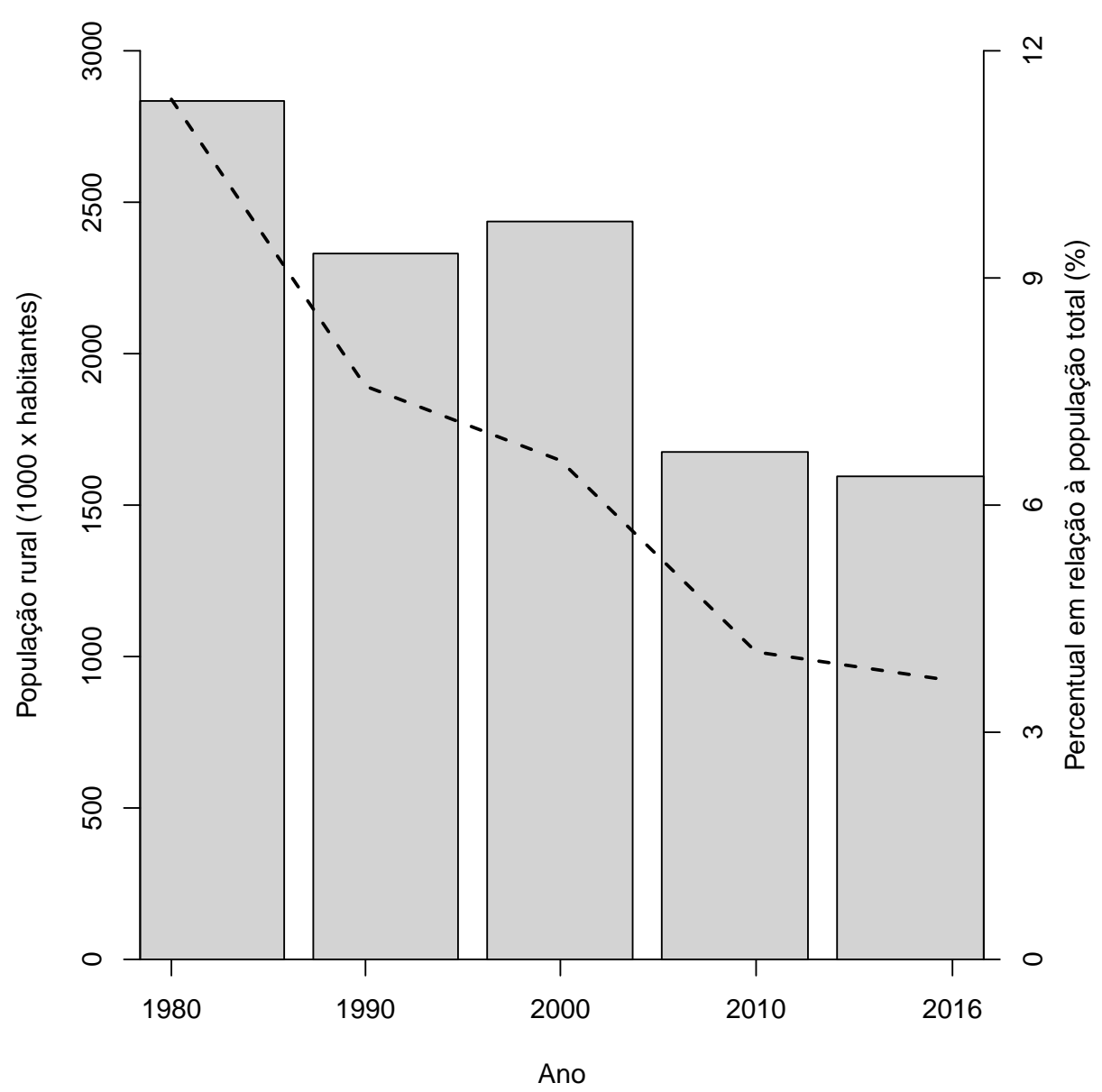

Figura 1 - Evolução da população rural do Estado de São Paulo

Fonte: Adaptado de (SEADE, 2016)

formais do ano. Em 2011, $\mathrm{R} \$ 14.068 .337 .793,00$ e $\mathrm{R} \$ 3.537 .565 .777,00$ (valores em $\mathrm{R} \$$ de 2015) foram destinados à agricultura e pecuária, respectivamente, na forma de crédito rural. As principais culturas agrícolas são a cana de-açúcar, o milho, a soja, a laranja e o café. As áreas colhidas discriminadas por cultura são mostradas na Tabela 1:

Tabela 1 - Área colhida das principais culturas agrícolas do estado de São Paulo

\begin{tabular}{lrr}
\hline Cultura agrícola & Área colhida $(2012$, em ha) & Percentual do total da área colhida no estado \\
\hline \hline Cana-de-açucar & 5.150 .461 & $65,53 \%$ \\
Milho (Em Grão) & 837.660 & $10,66 \%$ \\
Soja (Em Grão) & 562.647 & $7,16 \%$ \\
Laranja & 470.082 & $5,98 \%$ \\
Café (Em Grão) & 197.540 & $2,51 \%$ \\
\hline Soma: & 7.218 .390 & $91,84 \%$ \\
\hline
\end{tabular}

Fonte - (SEADE, 2016)

8 Total calculado a partir da soma das áreas colhidas pelas culturas: cana-de-açúcar, milho, soja, la- 
No estado de São Paulo, os Pagamentos por Serviços Ambientais constam na Lei Estadual nº 13.798/2009, a Política Estadual de Mudanças Climáticas. Na seção relativa aos instrumentos econômicos da Política, tem-se:

Art. 23 - O Poder Executivo instituirá, mediante decreto, o Programa de Remanescentes Florestais, sob coordenação da Secretaria do Meio Ambiente, com o objetivo de fomentar a delimitação, demarcação e recuperação de matas ciliares e outros tipos de fragmentos florestais, podendo prever, para consecução de suas finalidades, o pagamento por serviços ambientais aos proprietários rurais conservacionistas, bem como incentivos econômicos a políticas voluntárias de redução de desmatamento e proteção ambiental (SÃO PAULO, 2009).

Atualmente, existem, no estado de São Paulo, três programas de PSA de abrangência estadual coordenados pelo poder público. Em ordem cronológica, são: O Projeto Mina D’água, criado pela Resolução SMA nº 123/2010, o Projeto de Pagamentos por Serviços Ambientais para as Reservas Particulares do Patrimônio Natural, criado pela Resolução SMA no 89/2013, e o Pagamento por Serviços Ambientais Mata Ciliar, criado pela Resolução SMA no 19/2015 e alterado pela Resolução SMA nº 60/2016. Desses projetos, apenas o Pagamento por Serviços Ambientais Mata Ciliar ainda não se encontra em fase de execução.

Para serem beneficiários de esquemas de PSA no estado de São Paulo, os proprietários rurais devem possuir um cadastro eletrônico denominado Cadastro Ambiental Rural (CAR) previsto pelo Art. 29 da Lei Federal no $12.651 / 2012$.

Art. 29. É criado o Cadastro Ambiental Rural - CAR, no âmbito do Sistema Nacional de Informação sobre Meio Ambiente - SINIMA, registro público eletrônico de âmbito nacional, obrigatório para todos os imóveis rurais, com a finalidade de integrar as informações ambientais das propriedades e posses rurais, compondo base de dados para controle, monitoramento, planejamento ambiental e econômico e combate ao desmatamento

(BRASIL, 2012).

O cadastro dos imóveis rurais no CAR é condicionado ao georreferenciamento dos limites das propriedades e de suas parcelas para vegetação natural, agricultura, entre outros usos. Em agosto de 2016, quatro meses após do prazo final para cadastro de todas as propriedades do país, o estado de São Paulo havia cadastrado um valor estimado em mais de 100\%, em área, do total estimado de propriedades rurais (SFB, 2016). Ressalta-se que o estado de São Paulo é pioneiro na disponibilização dos dados do CAR, por meio do sistema DataGEO - Sistema Ambiental Paulista (SÃO PAULO, 2016).

ranja, café, feijão, amendoim, mandioca, banana, borracha, trigo, limão, batata-inglesa, arroz, sorgo, algodão, tomate, manga, tangerina, uva, triticale, melancia, cebola, abacate, goiaba, palmito, caqui, abacaxi, batata-doce, coco-da-Bahia, urucum, aveia, maracujá, pêssego, chá-da-Índia, noz, figo, mamão, girassol, fumo, maçã, mamona, pera, alho e melão. Esta ordem de apresentação corresponde à ordem decrescente das áreas colhidas no estado de São Paulo. 


\subsection{Materiais e métodos}

O método utilizado se divide em etapas sucessivas, cada uma cuja descrição consta a seguir. A Figura 2 foi feita facilitar a compreensão do processo e deve ser consultada sempre que haja dúvida em relação a como os dados utilizados se relacionam. O caminho tracejado se refere ao ajuste e diagnóstico do modelo, enquanto o caminho com traços largos e pontos mostra como as predições foram realizadas. As setas que saem de traços que ligam duas extremidades representam processos que foram feitos utilizando as informações das extremidades. Uma vez que a unidade amostral da pesquisa é a propriedade rural, podem ser tomados como exemplos para interpretação da imagem: a 'Base de predição', formada a partir da utilização dos dados do 'CAR' com as 'Variáveis da literatura', e a 'Base de ajuste', formada pela interseção dos dados da 'Base de predição' com as 'Respostas válidas'.

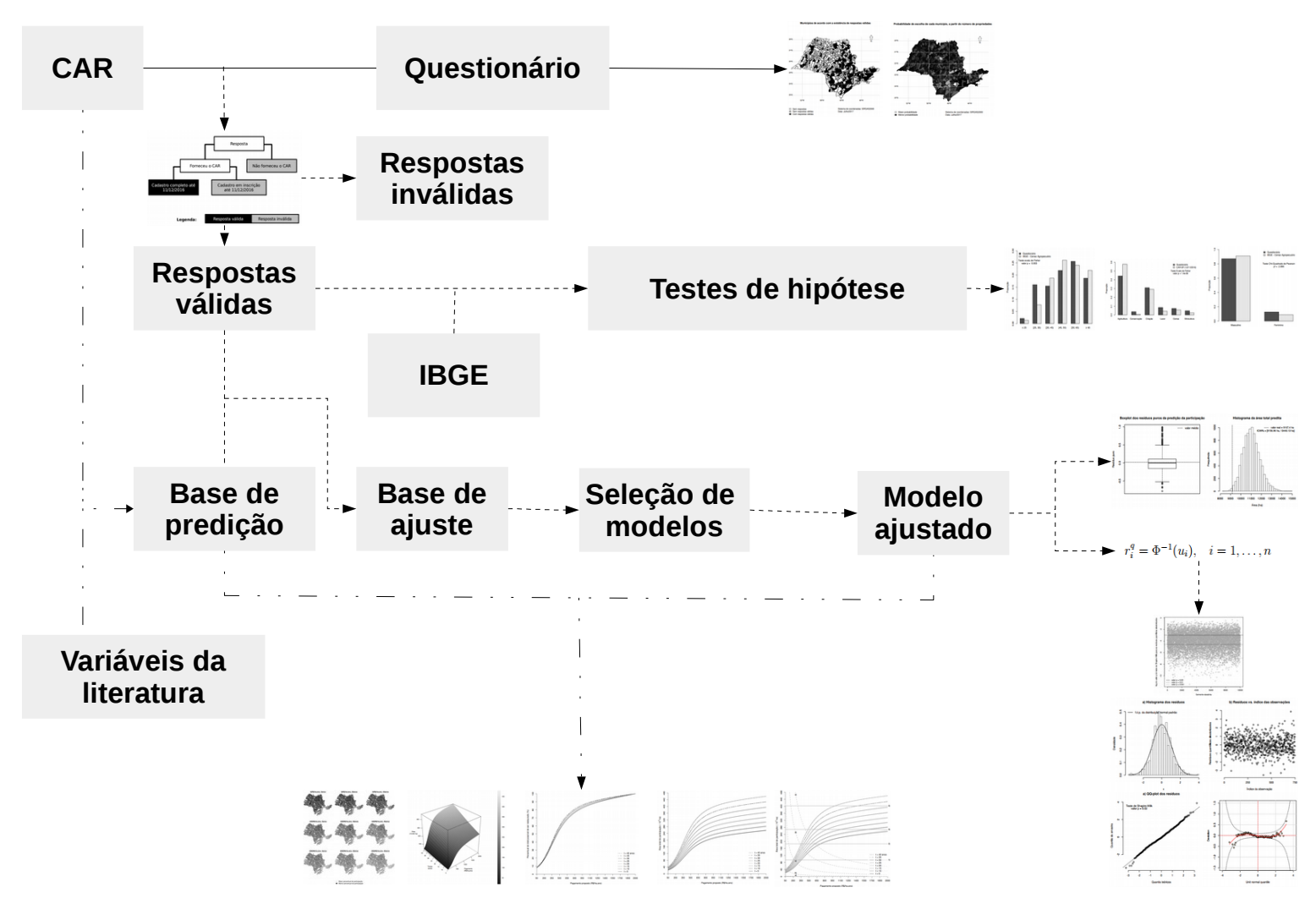

Figura 2 - Índice dos procedimentos realizados.

Fonte: Elaboração própria

\subsubsection{Coleta de dados}

O objetivo da coleta de dados da pesquisa foi obter a variável resposta do modelo estatístico: a participação de um proprietário rural em um programa hipotético de PSA para 
restauração de vegetação nativa. Para este fim, foi elaborado um questionário para os produtores rurais a partir da técnica de preferências declaradas, que usa as respostas das preferências dos indivíduos em relação a cenários criados (KROES; SHELDON, 1988). A preferência desta técnica em detrimento de uma técnica de preferências reveladas, onde são analisadas as reais ações dos entrevistados frente às opções já existentes, se deu principalmente por inexistir um programa estadual de PSA que abranja todos os proprietários e que oferte diferentes combinações de tempo e valor de contrato. Assim, as ações adotadas não refletem as escolhas dos usuários perante uma gama de opções e, portanto, é inviável a adoção de alguma técnica de preferências reveladas dentro dos propósitos da presente pesquisa.

O primeiro passo foi definir um programa como sendo composto por uma combinação entre o tempo de contrato ofertado e o pagamento proposto. Dessa forma, de maneira semelhante à Lohr e Park (1994), Lohr, Park et al. (1995) e Layton e Siikamäki (2009), os proprietários foram abordados com programas hipotéticos de PSA e cabia a eles responder a pergunta: "Quantos hectares de vegetação nativa você restauraria se recebesse $N R \$ /$ ha.ano por $M$ anos?". As variáveis 'tempo de contrato' (anos) e 'pagamento proposto' ( $\mathrm{R} \$$ /ha.ano) foram chamadas de controláveis, uma vez que foram planejadas para sua inserção no questionário.

Para a definição do intervalo das variáveis controláveis, o fator tempo de contrato foi definido para variar dentro de um intervalo total de cinco até 40 anos, em intervalos de cinco anos, de maneira semelhante à Layton e Siikamäki (2009). A variação do fator pagamento proposto foi escolhida com base nos programas de PSA atualmente em curso na região Sudeste, e nos valores pagos por hectare para compensação na Bolsa de Valores Ambientais (BVRio) (Tabela 2). Assim, os valores a serem pagos foram definidos em torno dos valores encontrados: entre $50 \mathrm{R} \$ /$ ha.ano e $2.000 \mathrm{R} \$ /$ ha.ano, com variação de $50 \mathrm{R} \$ /$ ha.ano entre as opções.

Assim, foram propostos oito possíveis valores para o fator tempo de contrato e 40 possíveis valores para o fator pagamento proposto. Como um programa representa uma combinação de tempo de contrato e pagamento proposto, a quantidade total de programas é igual ao produto dos dois números mencionados: 320 combinações. Seria inviável que cada proprietário respondesse a sua participação em um número tão grande de programas, por isso optou-se por solicitar a resposta de apenas quatro programas diferentes. Para evitar repetições, de aqui em diante um conjunto de quatro programas diferentes é denominado 'grupo'.

Visando facilitar a resposta do questionário por parte dos proprietários rurais, optou-se por oferecer apenas grupos contendo programas com valores simultaneamente crescentes para pagamento proposto e tempo de contrato. Para este fim, cada grupo foi definido de modo que a diferença entre os tempos de um programa para o próximo nunca fosse superior a 20 anos e, simultaneamente, a diferença entre os pagamentos não superasse 
Tabela 2 - Valores de pagamentos por hectare ano para os proprietários em programas de PSA e na aquisição de Cotas de Reserva Ambiental.

\begin{tabular}{ccll}
\hline $\begin{array}{c}\text { Mínimo } \\
(\mathrm{R} \$ \text { ha.ano })\end{array}$ & $\begin{array}{c}\text { Máximo } \\
(\mathrm{R} \$ / \text { ha.ano })\end{array}$ & Local ou Projeto & Fonte \\
\hline \hline 228,70 & 508,20 & Cotas de Reserva Ambiental (CRAs) - Estado de SP & BVRio (SP)* \\
399,20 & 585,40 & CRAs - Estado do RJ & BVRio (RJ)* \\
220,00 & 428,40 & CRAs - Estado de MG & BVRio (MG)* \\
375,00 & 550,00 & Estado do ES & BVRio (ES)* \\
- & 141,00 & Projeto Conservador de Águas & \\
- & 110,10 & Projeto Ecocréditos Montes Claros & \\
75,00 & 370,00 & Projeto Oásis São Paulo e Apucarana & (PAGIOLA; \\
30,00 & 50,00 & Produtores de Água e Floresta - Guandu & GLEHN; TAF- \\
25,00 & 125,00 & Produtor de Água na Bacia Hidrográfica PCJ & FARELLO, \\
76,00 & 228,00 & Produtor de Âgua do Rio Camburiú & 2013) \\
- & 256,00 & Programa Carbono Seguro & \\
- & 423,00 & Projeto ProdutorES de Água & \\
- & 200,00 & Bolsa Verde & \\
- & $1.745,00$ & Projeto Mina d'Água & \\
\hline
\end{tabular}

* Valores consultados em 14/07/2016.

Nota - Os valores não incluem custos de transação.

$450 \mathrm{R} \$$ /ha.ano. Um número finito de grupos foi elaborado e a cada abertura do questionário os proprietários rurais se deparavam com um grupo diferente, geralmente um dentre os menos respondidos até o momento do recebimento do questionário pelo respondente. O número escolhido de grupos foi 35, o mesmo utilizado no trabalho realizado anteriormente na Finlândia (LAYTON; SIIKAMÄKI, 2009). Como a quantidade de grupos satisfazendo as restrições impostas é muito grande, foi necessário utilizar o algoritmo point exchange (AGUIAR et al., 1995) considerando um modelo de regressão linear entre a variável resposta e os preditores tempo de contrato e pagamento proposto. O algoritmo foi ligeramente modificado para a necessidade da pesquisa de trocar 'grupos' em vez de 'observações'. Embora o modelo de regressão linear não tenha sido utilizado posteriormente, foi suficiente para suprir a necessidade de escolha dos grupos a essa altura da pesquisa. Os grupos obtidos e fornecidos aos proprietários constam na Tabela 3.

Caso o proprietário não demonstrasse interesse em participar dos programas propostos, foi sugerido que respondesse com valor zero. Embaixo de cada pergunta, foi adicionada a frase "Não considere a área de Reserva Legal e APP na resposta, mesmo que sua propriedade ainda não esteja adequada". Este estudo optou por considerar apenas as áreas não protegidas legalmente para assegurar que o programa de PSA proposto levasse em consideração a adicionalidade da restauração em relação ao cumprimento da lei. Os proprietários respondentes não foram informados se deveriam arcar com os custos da restauração ou se esses custos seriam subsidiados pelo proponente dos programas. Por fim, os questionários foram distribuídos eletronicamente aos proprietários rurais do estado de São Paulo por um período de testes, de 23/07/2016 à 23/08/2016. Neste período, alguns 
Tabela 3 - Grupos ofertados aos proprietários por meio do questionário.

\begin{tabular}{|c|c|c|c|c|c|c|c|c|}
\hline \multirow{2}{*}{ \# grupo } & \multicolumn{2}{|c|}{ Programa A } & \multicolumn{2}{|c|}{ Programa B } & \multicolumn{2}{|c|}{ Programa $\mathrm{C}$} & \multicolumn{2}{|c|}{ Programa D } \\
\hline & Pagamento 1 (P1) & Tempo 1 (T1) & $\mathrm{P} 2$ & $\mathrm{~T} 2$ & P3 & T3 & $\mathrm{P} 4$ & $\mathrm{~T} 4$ \\
\hline Grupo 1 & $5 \mathrm{R} \$ /$ ha.ano & 50 anos & 10 & 200 & 15 & 350 & 20 & 650 \\
\hline Grupo 2 & 5 & 50 & 10 & 200 & 20 & 350 & 25 & 650 \\
\hline Grupo 3 & 5 & 50 & 15 & 200 & 25 & 350 & 30 & 650 \\
\hline Grupo 4 & 5 & 50 & 15 & 200 & 25 & 500 & 30 & 650 \\
\hline Grupo 5 & 5 & 50 & 20 & 200 & 25 & 350 & 30 & 650 \\
\hline Grupo 6 & 5 & 50 & 20 & 200 & 25 & 500 & 30 & 650 \\
\hline Grupo 7 & 5 & 50 & 20 & 200 & 30 & 350 & 35 & 500 \\
\hline Grupo 8 & 5 & 50 & 20 & 200 & 30 & 350 & 35 & 650 \\
\hline Grupo 9 & 5 & 50 & 20 & 200 & 30 & 500 & 35 & 650 \\
\hline Grupo 10 & 5 & 50 & 20 & 500 & 25 & 650 & 35 & 950 \\
\hline Grupo 11 & 5 & 1100 & 10 & 1550 & 15 & 1850 & 25 & 2000 \\
\hline Grupo 12 & 5 & 1250 & 10 & 1550 & 15 & 1850 & 20 & 2000 \\
\hline Grupo 13 & 5 & 1250 & 10 & 1700 & 20 & 1850 & 25 & 2000 \\
\hline Grupo 14 & 5 & 1250 & 20 & 1550 & 30 & 1700 & 35 & 1850 \\
\hline Grupo 15 & 5 & 1250 & 20 & 1550 & 30 & 1850 & 35 & 2000 \\
\hline Grupo 16 & 5 & 1400 & 10 & 1550 & 15 & 1700 & 25 & 1850 \\
\hline Grupo 17 & 5 & 1400 & 10 & 1550 & 15 & 1700 & 25 & 2000 \\
\hline Grupo 18 & 5 & 1400 & 10 & 1550 & 15 & 1850 & 20 & 2000 \\
\hline Grupo 19 & 5 & 1400 & 10 & 1550 & 15 & 1850 & 25 & 2000 \\
\hline Grupo 20 & 5 & 1400 & 10 & 1700 & 15 & 1850 & 20 & 2000 \\
\hline Grupo 21 & 5 & 1400 & 10 & 1700 & 20 & 1850 & 25 & 2000 \\
\hline Grupo 22 & 5 & 1400 & 15 & 1700 & 25 & 1850 & 30 & 2000 \\
\hline Grupo 23 & 5 & 1400 & 20 & 1550 & 30 & 1700 & 35 & 2000 \\
\hline Grupo 24 & 5 & 1400 & 20 & 1550 & 30 & 1850 & 35 & 2000 \\
\hline Grupo 25 & 5 & 1400 & 20 & 1700 & 30 & 1850 & 35 & 2000 \\
\hline Grupo 26 & 5 & 1550 & 20 & 1700 & 30 & 1850 & 35 & 2000 \\
\hline Grupo 27 & 10 & 50 & 25 & 200 & 30 & 350 & 40 & 500 \\
\hline Grupo 28 & 10 & 50 & 25 & 200 & 30 & 500 & 40 & 650 \\
\hline Grupo 29 & 15 & 50 & 25 & 200 & 30 & 350 & 40 & 650 \\
\hline Grupo 30 & 15 & 50 & 25 & 200 & 35 & 350 & 40 & 650 \\
\hline Grupo 31 & 15 & 50 & 30 & 200 & 35 & 500 & 40 & 650 \\
\hline Grupo 32 & 20 & 50 & 25 & 200 & 30 & 500 & 40 & 650 \\
\hline Grupo 33 & 20 & 50 & 30 & 350 & 35 & 500 & 40 & 800 \\
\hline Grupo 34 & 25 & 50 & 30 & 350 & 35 & 500 & 40 & 650 \\
\hline Grupo 35 & 25 & 50 & 30 & 350 & 35 & 650 & 40 & 800 \\
\hline
\end{tabular}

usuários reportaram erros, que foram corrigidos até o início da distribuição mais ampla do questionário, que se deu a partir de 24/08/2016.

Para o envio dos questionários aos proprietários, foram consideradas a divulgação via correspondência física (cartas), eletrônica (e-mails) e a divulgação por meio de visitas a campo. A divulgação via correspondência física foi descartada, pois o serviço de entregas do local possui restrição em relação a áreas rurais em diversos municípios. A divulgação por meio de visitas a campo foi descartada como principal modo de divulgação devido à grande extensão da área de estudo e o grande número de respostas necessário para a estimação dos parâmetros do modelo estatístico. Assim, a divulgação via correspondência eletrônica foi adotada como a principal maneira de veiculação do questionário da pesquisa. Para que fosse viabilizado o envio de e-mails a proprietários, foi criada uma 
base de e-mails a partir, principalmente, dos usuários do Sistema Integrado de Gestão Ambiental (SIGAM). O SIGAM é uma plataforma que abrange o Sistema de Cadastro Ambiental Rural (SiCAR), onde obrigatoriamente todos os proprietários rurais devem cadastrar suas propriedades. Uma vez que o SIGAM abrange outros sistemas além do SiCAR, uma conhecida limitação da base de e-mails é a de ser pouco especializada em relação ao público alvo. É importante ressaltar que foram removidos da base os e-mails pertencentes a funcionários de órgãos públicos que acessam o SIGAM, como a Secretaria do Meio Ambiente e a Polícia Militar. Assim, a base de e-mails criada corresponde a um subconjunto do conjunto total de e-mails dos proprietários rurais paulistas. Os e-mails foram enviados para essa base e o conjunto dos proprietários respondentes compõem a amostra da nossa pesquisa. Um exemplo do e-mail enviado é mostrado na Figura 3. 


\section{Olá, Proprietário Rural ou Consultor!}

Faço parte de um grupo de pesquisadores da Universidade de São Paulo (USP) que está realizando um estudo sobre Pagamento por Serviços Ambientais (PSA)

- O que é PSA? O PSA consiste no pagamento para proprietários rurais. Em troca de tais pagamentos, os proprietários deixam de usar uma parte de sua terra para restaurar a vegetação nativa no local

O objetivo do nosso estudo é avaliar a viabilidade de um programa de PSA no Estado de São Paulo. Para isso, precisamos de respostas dos proprietários rurais paulistas a um pequeno questionário, cujas perguntas dizem respeito ao interesse dos proprietários na participação de programas de PSA

Assim, gostaria de saber se você poderia nos ajudar, respondendo o questionário ou encaminhando para proprietários rurais conhecidos. O endereço é:

http://questionariorural.link

Independente das características suas ou de sua propriedade, sua participação é muito importante para nossa pesquisa!

Caso queira mais informações, esta pesquisa faz parte de um Mestrado, desenvolvido no Programa de Pós-Graduação em Ciências da Engenharia Ambiental (PPG-SEA), da Escola de Engenharia de São Carlos (EESC/USP).

No caso de dúvidas, fique à vontade para me contactar por e-mail: arthur.fendrich@usp.br

Caso você já tenha respondido ao questionário, gostaríamos de agradecer por sua contribuição!

Agradeço pela atenção!

Atenciosamente,

Arthur Nicolaus Fendrich

Figura 3 - E-mail enviado aos proprietários rurais e consultores

Fonte: Elaboração própria 
O questionário foi disponibilizado por meio do endereço: <http://questionariorural. link $>$. Um conjunto de regras foi programado no site para não aceitar respostas incompletas, de forma que os respondentes precisaram preencher todos os campos antes de submeter a resposta para a base de dados. A Figura 4 ilustra o questionário enviado. O endereço permanecerá no ar até 30/04/2018, mas poderá ser visualizado após essa data por meio da ferramenta WAYBACK MACHINE (2017): 


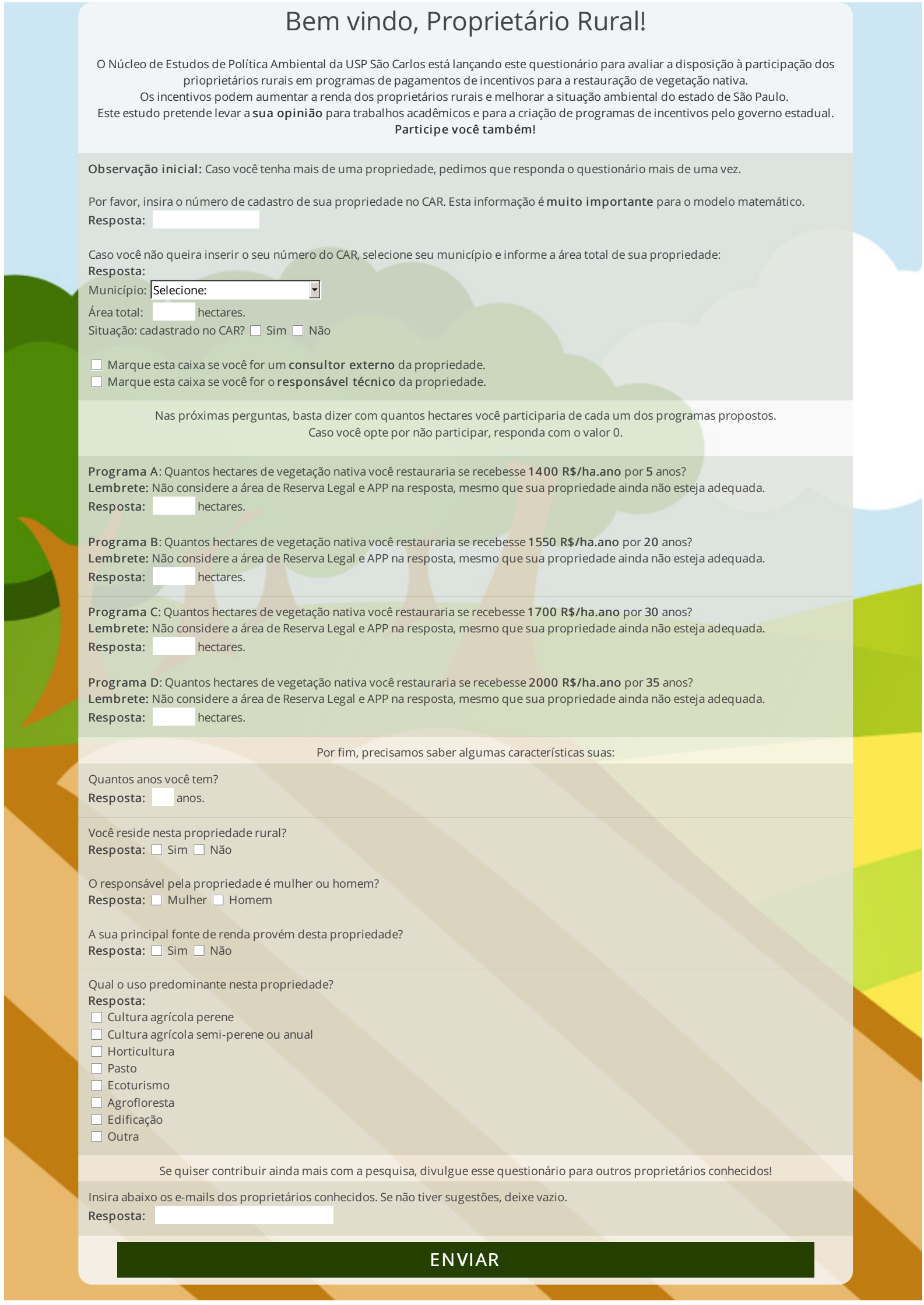

Figura 4 - Questionário aplicado. Os valores dos programas A, B, C e D variam a cada atualização da página.

Fonte: Elaboração própria 
Além das perguntas relativas aos programas hipotéticos, foram solicitados dados que possibilitassem a localização espacial das respostas e que dissessem respeito a suas características demográficas. A principal forma de localização é o número de cadastro no CAR, código único para cada propriedade rural e vinculado a uma base de dados disponível publicamente, que contém a delimitação da propriedade e suas características ambientais. Essas características não foram utilizadas como variáveis para o modelo estatístico, porém foram úteis na análise do viés da amostra, descrita na subseção 4.2.2.

O número de cadastro da propriedade no CAR foi o único campo do qual não foi tornado obrigatório o fornecimento no questionário, pois a necessidade de identificação poderia ser um fator de desestímulo da participação. Para contornar este problema, o respondente pôde escolher entre duas opções: 1) fornecer o número do CAR; ou 2) fornecer o município em que a propriedade se localiza, a área total da propriedade e a situação da propriedade em relação ao cadastro no CAR (propriedade cadastrada ou não cadastrada no CAR). A regra, neste caso, era de que o respondente deveria obrigatoriamente escolher pelo menos uma das duas opções. As respostas dos que escolheram a segunda opção foram consideradas inválidas.

A Figura 5 sintetiza o procedimento de validação das respostas coletadas:

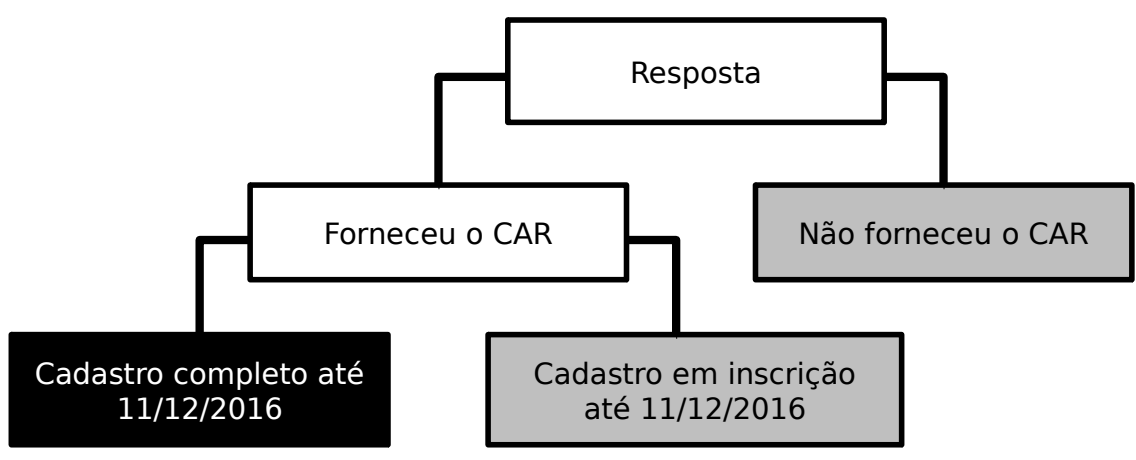

Legenda:

Resposta válida

Resposta inválida

Figura 5 - Sequência de procedimentos para validação das respostas obtidas.

Fonte: Elaboração própria

\subsubsection{Verificação do viés da amostra}

É preciso maior cautela com um específico componente dos erros da aplicação de um questionário quando a internet é adotada como principal meio de veiculação. Esse componente, denominado erro de cobertura, ocorre quando alguns membros de uma população 
possuem probabilidade zero de serem selecionados na amostra. Sua ocorrência se divide em três principais formas:

A forma mais comum do erro de cobertura é a subcobertura [undercove-
rage], isso é, nem todas as unidades da população alvo são incluídas na
base de amostragem. Um exemplo claro de subcobertura são as pessoas
sem telefone listado, quando a base de amostragem é a lista telefônica.
Outra forma de erro de cobertura é a sobrecobertura [overcoverage];
Aqui, uma unidade da população alvo aparece mais de uma vez na base
de amostragem. Duplicações como essa podem ocorrer quando uma base
de amostragem resulta da combinação de várias listas. Por exemplo, em
uma lista uma mulher é listada com seu nome de solteira, e na segunda
lista, com seu nome de casada. Se essas listas são combinadas, a mesma
pessoa é listada em duas diferentes entradas. Outro exemplo são questi-
onários que usam telefones celulares; esses sobrecobrem as pessoas com
mais de um telefone. Um terceiro tipo de erro de cobertura é causado
por inclusões errôneas na base. Por exemplo, um número empresarial
é incluído em uma lista com números de telefones de proprietários de
residências (LEEUW; DILLMAN, 2008, p.8, tradução nossa)

Se confirmado, o erro de cobertura pode interferir na estimativa dos parâmetros do modelo estatístico e, consequentemente, na posterior inferência para a população. Por esse motivo, alguns autores que consideram o erro de cobertura como a principal ameaça à representatividade de questionários conduzidos via internet (LEEUW; DILLMAN, 2008).

O método utilizado para a elaboração da base de amostragem na presente pesquisa utilizou dados de apenas uma base de dados. Assim, é plausível supor que a sobrecobertura não seja a forma pela qual o erro de cobertura possa ocorrer. No entanto, não é igualmente fácil descartar a subcobertura e as inclusões errôneas, sendo a Figura 6 uma representação esperada da situação:

A subcobertura deve ser analisada, pois como o questionário foi aplicado por meio da Internet, os respondentes necessariamente precisam dispor de acesso à rede e de um conhecimento tecnológico mínimo, o que pode excluir parte da população da amostragem. Igualmente, a inclusão errônea deve ser analisada, pois o SIGAM - base de dados utilizada para definição da base de amostragem - abrange muitos outros serviços além daquele destinado a proprietários rurais.

Como o CAR é, por Lei, obrigatório aos proprietários rurais e cerca de $100 \%$ das propriedades do estado de São Paulo estão cadastradas (SFB, 2016), não é possível estimar o efeito do erro de cobertura sem a utilização de dados externos à pesquisa. Um dos métodos utilizados para verificar esse erro a partir de dados externos é a comparação das informações demográficas dos respondentes com valores conhecidos para a população (LEEUW; DILLMAN, 2008).

Esta comparação não é decisiva, pois a amostra pode conter informações demográficas semelhantes à população, mas com outras propriedades - por exemplo, crenças ou valores diferentes. No entanto, dado que é desconhecido um mapeamento de tais informações para os proprietários rurais paulistas, bem como a influência de tais informações na disposição à 


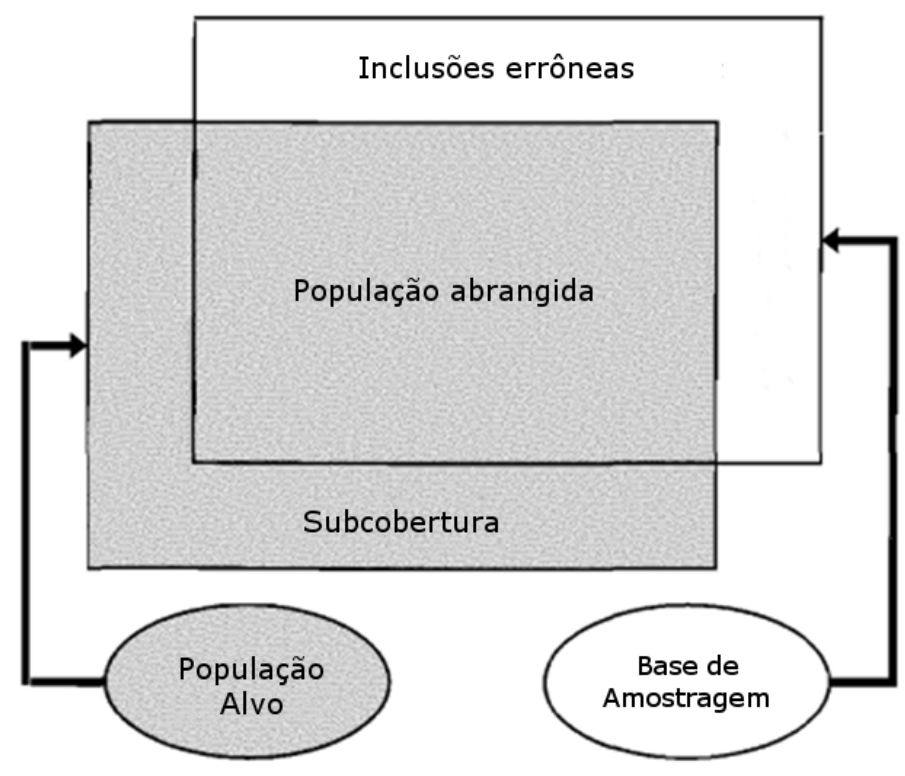

Figura 6 - Formas do erro de cobertura.

Fonte: (GROVES, 2004, tradução nossa)

participação de programas de PSA, foi adotada a comparação de informações demográficas como método para verificação do viés da amostra.

Assim, as informações do respondente solicitadas no questionário foram:

1. Quantos anos você tem?

2. Você reside nessa propriedade rural?

3. O responsável pela propriedade é mulher ou homem?

4. A sua principal fonte de renda provém desta propriedade?

5. Qual o uso predominante nesta propriedade?

Os itens 1. e 3. apresentaram dados análogos no Censo Agropecuário de 2006 do IBGE e puderam ser comparados com a população. Para o uso predominante da propriedade (item 5), a resposta dos proprietários foi descartada e optou-se por utilizar o dado oficial declarado ao CAR e requisitado à Secretaria do Meio Ambiente por meio de solicitação de informação (SMA, 2017a). As informações dos itens 2. e 4. não foram comparadas entre a amostra e a população, pois, no primeiro caso, a correspondência com o dado do IBGE não é precisa e, no segundo caso, não há dado correspondente nas estatísticas oficiais para servir de comparação.

Para a verificação do viés da amostra foi utilizado o teste $\chi^{2}$ (chi-quadrado) de Pearson, que testa a hipótese de homogeneidade em uma tabela de contingência bidimensional (TAEGER; KUHNT, 2014). O objetivo da aplicação do teste é avaliar a hipótese de que a proporção das respostas do questionário é idêntica à proporção informada por fontes 
oficiais. Formalmente, a definição de uma tabela de contingência bidimensional é mostrada no Tabela 4:

Tabela 4 - Elementos de uma tabela de contingência

\begin{tabular}{ccccc}
\hline$X_{1} / X_{2}$ & 1 & $\ldots$ & $\mathrm{J}$ & $\sum$ \\
\hline \hline 1 & $n_{11}$ & $\ldots$ & $n_{1 J}$ & $n_{1+}$ \\
$\vdots$ & $\vdots$ & $\vdots$ & $\vdots$ & $\vdots$ \\
1 & $n_{I 1}$ & $\ldots$ & $n_{I J}$ & $n_{I+}$ \\
$\sum$ & $n_{+1}$ & $\ldots$ & $n_{+J}$ & $n$ \\
\hline \multicolumn{7}{l}{ Fonte - (TAEGER; KUHNT, 2014$)$}
\end{tabular}

Nota-se que para cada $n_{i j}$ da tabela de contingência ${ }^{9}$, tem-se atribuída uma proporção $p_{i j}$, dada por $p_{i j}=\frac{n_{i j}}{n}$ e que respeita $\sum_{i=1}^{I} \sum_{j=1}^{J} p_{i j}=1$. A partir desta definição, o teste chiquadrado para a homogeneidade visa avaliar a hipótese de que duas amostras possuem proporções idênticas de determinadas informações. Em outras palavras, tem-se o seguinte teste (TAEGER; KUHNT, 2014):

$$
\begin{array}{ll}
\text { Hipótese } H_{0} \text { (nula) } & p_{i j}=p_{i+} \cdot p_{+j}, \forall i, j \\
\text { Hipótese } H_{1} \text { (alternativa) } & \exists i^{\prime}, j^{\prime}: p_{i^{\prime} j^{\prime}} \neq p_{i+} \cdot p_{+j} \\
& \chi^{2}=\sum_{i=1}^{I} \sum_{j=1}^{J} \frac{\left(n_{i j}-E_{i j}\right)^{2}}{E_{i j}} \\
\text { Estatística de teste: } & \text { Em que } E_{i j} \text { é a proporção esperada, } E_{i j}=\frac{n_{i+} \cdot n_{+j}}{n}
\end{array}
$$

Decisão:

$$
\text { Rejeita } H_{0} \text { se } \chi^{2}>\chi_{\alpha,(I-1)(J-1)}^{2}
$$

Esse procedimento permite verificar a semelhança das respostas obtidas na aplicação do questionário com os dados, por exemplo, do Censo Agropecuário (IBGE, 2015a) ${ }^{10}$ e das informações disponíveis no CAR. Conforme descrito acima, o resultado do teste de hipótese aponta duas situações: rejeita ou não rejeita a hipótese $H_{0}$ para um determinado nível de significância. A rejeição de $H_{0}$ permite afirmar que as proporções são diferentes dentro do nível de significância adotado. A não rejeição dessa hipótese, embora não permita afirmar que as proporções são idênticas, significa que os dados não contêm evidência suficiente de que as proporções são diferentes.

Por fim, o teste $\chi^{2}$ demanda que a aproximação da distribuição chi-quadrado seja satisfatória. Um critério comumente adotado é o de que as frequências esperadas calculadas possuam valor maior ou igual a cinco (TAEGER; KUHNT, 2014). Durante a análise, notou-se que esse critério permitiu que apenas a informação 'sexo' fosse avaliada por meio do teste $\chi^{2}$, assim as informações 'idade' e 'uso do solo' foram avaliadas pelo Teste Exato de Fisher, que fornece os valores $p$ necessários para a análise(cf. Taeger e Kuhnt (2014)).

9 Especialmente nesta seção do texto, os índices $i$ e $j$ representam o índice para linha e coluna, respectivamente. Estes índices serão usados com outro significado na seção relativa ao modelo estatístico.

10 Embora o Censo Agropecuário seja consideravelmente antigo, é o mais recente levantamento demográfico que abrange o setor rural em todo o Estado de São Paulo. 


\subsubsection{Variáveis socioeconômicas e ambientais}

Características socioeconômicas e ambientais foram extraídas para cada propriedade rural do estado de São Paulo, a fim de serem utilizadas como variáveis candidatas para explicar a variável resposta. Antes da extração, foi necessário elencar quais principais características poderiam ser relevantes por meio de uma análise de modelos utilizados em estudos semelhantes. Assim, foi realizada uma revisão da literatura de trabalhos existentes e com abordagens parecidas, segundo as especificações do Quadro 1:

Quadro 1 - Especificações da busca pelas características socioeconômicas e ambientais

\begin{tabular}{|c|c|}
\hline \multicolumn{2}{|r|}{ Especificações da busca ${ }^{11}$} \\
\hline \multirow[t]{2}{*}{ Plataforma utilizada: } & SCOPUS \\
\hline & Title \\
\hline \multirow[t]{2}{*}{ Local de busca: } & Abstract \\
\hline & Keywords \\
\hline Termos utilizados & $\begin{array}{l}\left.\text { (payment }^{*} \text { OR } \text { incentive }^{*}\right) A N D \\
\text { (ecosystem }^{*} \text { OR environment } \\
\text { (model }) \text { AND } \\
\text { (marticipat }^{*}\end{array}$ \\
\hline Data: & From 1989 to 2016 \\
\hline Idiomas: & Portuguese and English \\
\hline \multirow{2}{*}{ Tipos de documento: } & Article \\
\hline & Environmental Science \\
\hline \multirow{2}{*}{ Áreas } & Agricultural and Biological Sciences \\
\hline & $\begin{array}{l}\text { Economics, Econometrics and Finance Engineering } \\
\text { Earth and Planetary Sciences }\end{array}$ \\
\hline Data da busca: & 09 de fevereiro de 2017 \\
\hline
\end{tabular}

Após a obtenção dos artigos, foi feita uma primeira filtragem a partir da seguinte pergunta:

- O artigo contém um modelo da participação em programas de conversão do uso do solo ou semelhantes?

Foi feita uma leitura dos resumos e dos resultados de cada artigo encontrado pela busca. As variáveis dos artigos que responderam positivamente à pergunta foram extraídas a partir da leitura de sua seção metodológica. Buscou-se responder à seguinte pergunta:

- Quais variáveis foram consideradas no(s) modelo(s) para explicar a participação dos proprietários

11 Chave da busca para reprodução: TITLE-ABS-KEY ((payment ${ }^{*} O R$ incentive*) AND (ecosystem * OR environment $\left.{ }^{*}\right)$ AND (model* OR statistic* ${ }^{*}$ OR econometric*) AND participat ${ }^{*}$ ) AND DOCTYPE (ar) AND PUBYEAR > 1988 AND PUBYEAR <2017 AND (LIMIT-TO (LANGUAGE , "English") OR LIMIT-TO (LANGUAGE , "Portuguese")) AND (LIMIT-TO (SUBJAREA , "ENVI") OR LIMIT-TO (SUBJAREA, "AGRI") OR LIMIT-TO (SUBJAREA , "ECON") OR LIMIT-TO (SUBJAREA , "ENGI") OR LIMIT-TO (SUBJAREA, "EART")) 
Por fim, foi aplicado um último filtro após a extração das variáveis de cada artigo, a fim de levantar as variáveis candidatas para a aplicação no modelo da presente pesquisa:

- Quais variáveis explicativas são adequadas e estão disponíveis para o contexto do estado de São Paulo?

\subsubsection{Tratamento dos dados espaciais}

Os arquivos espaciais contendo os limites e as informações ambientais das propriedades rurais paulistas foram obtidas por meio do Sistema DataGEO (SÃO PAULO, 2016), no dia 12 de novembro de 2016. Nesta data, a base de dados continha 303.038 propriedades. A primeira etapa de tratamento dos dados foi reparar as geometrias inválidas em todos os arquivos. Em seguida, propriedades com geometria duplicada foram removidas, tendo sido mantidos nestes casos os cadastros mais recentes.

Como o questionário perguntava a participação dos proprietários além da obrigação legal, foi necessário obter a área disponível para a participação dos programas propostos. Para obtê-la, do limite de cada propriedade foram subtraídas espacialmente as feições das APPs hídricas, da RL, da vegetação nativa e das outras APPs (topo de morro, declividade etc.). A subtração foi feita para cada propriedade separadamente. Se feito de outra forma, o cálculo seria incorreto, uma vez que as sobreposições entre-propriedades são frequentes em todas as camadas mencionadas.

Algumas variáveis candidatas foram extraídas a partir dos arquivos de Reserva Legal, APPs hídricas, outras APPs e vegetação nativa. Nesses casos, a etapa final de cálculos consistiu no recorte das feições dentro dos limites da propriedade. Embora o Manual de Orientações para o Cadastro no SiCAR-SP (SMA, 2016) ateste que esse procedimento é feito automaticamente pelo sistema, foram encontrados diversos casos em que a área da propriedade era inferior às demais.

Por fim, a extração das demais variáveis candidatas para o modelo estatístico foi feita também individualmente para cada propriedade rural a partir de dados espaciais públicos. Esses dados utilizados foram selecionados a partir do resultado da busca de artigos já descrita e outras novas informações disponíveis foram também incorporadas para serem candidatas.

Todos os cálculos realizados são computacionalmente custosos e demandaram a utilização de processamento paralelo no Cluster Euler do Instituto de Ciências Matemáticas e Computação (ICMC/USP).

\subsubsection{Modelo estatístico}

Para obter a resposta dos proprietários sobre os programas propostos a partir de suas informações é necessário estabelecer um modelo que relacione matematicamente as variáveis explanatórias - no caso da presente pesquisa, as variáveis da busca bibliográfica 
da subseção 4.2.3 posteriormente extraídas com os procedimentos da subseção 4.2.4, e a variável resposta - conforme apresentado na subseção 4.2.1, a participação de um proprietário rural em um programa hipotético de PSA para restauração de vegetação nativa -. Considerando os objetivos da presente pesquisa, duas características importantes dessa relação matemática proposta devem ser: a capacidade de representar a relação funcional - não necessariamente causal - entre as variáveis, e a capacidade de possibilitar predições para grupos de diferentes características. A técnica estatística mais adequada para o estabelecimento de modelos com essas características é a análise de regressão, que possui uma ampla gama de aplicações.

O estudo semelhante mais recente é o de Layton e Siikamäki (2009). Os autores atribuíram uma distribuição beta-binomial ao percentual de participação fornecido pelos respondentes. Este modelo merece destaque em três pontos. Em primeiro lugar, a distribuição beta é contínua e utilizada para modelar variáveis no intervalo $(0,1)$. Isso significa que os autores, após transformar a variável resposta para este intervalo, trataram a decisão de não participar (a resposta nula) de maneira idêntica à decisão de participar. Na prática, no entanto, parece fazer mais sentido assumir que o proprietário faz duas decisões ao deparar com o contrato proposto: 1) de participar ou não participar; 2) caso participar, com qual intensidade ${ }^{12}$. O segundo ponto de destaque é a atribuição da distribuição binomial para a probabilidade de um proprietário participar de um programa com $x$ do total de $n$ hectares. Esta decisão é questionável, pois a distribuição binomial deve ser utilizada para modelar o número de sucessos de $n$ independentes ensaios de Bernoulli (FORBES et al., 2011) com probabilidade de sucesso constante. No caso, nem são feitos ensaios independentes de Bernoulli com os hectares da propriedade e nem seria realístico assumir que todos os hectares possuem probabilidade igual de participação ${ }^{13}$. Essa mesma atribuição demanda que os valores utilizados sejam arredondados, pois a distribuição binomial é utilizada com números inteiros apenas. Isso deve influenciar o resultado, principalmente em pequenas propriedades. Por fim, o terceiro ponto de destaque é que o modelo proposto pelos autores assumiu a independência entre as respostas de um mesmo proprietário. Além de bem pouco provável, este ponto é crítico, pois influencia no método adotado para estimação dos parâmetros, isto é, na construção da função de verossimilhança.

A forma encontrada pelos autores para justificar a definição de independência entre as observações foi mostrar que o modelo com este pressuposto forneceu resultados melhores do que um modelo que considera a correlação entre as respostas, a regressão multivariada para variáveis censuradas. No entanto, essa regressão multivariada também possui um problema: a variável-resposta não é censurada e, portanto, não é adequado trata-la como

\footnotetext{
$\overline{12}$ Essa abordagem é adotada por outros autores, por exemplo Lohr e Park (1994), Lohr, Park et al. (1995)

13 Como exemplo, a existência de viés na proteção de áreas naturais já foi comprovada em outro instrumento para conservação, as áreas protegidas (JOPPA; PFAFF, 2009).
} 
tal. O seguinte parágrafo de Smithson e Merkle (2013) ajuda a verificar esta diferença:

Os critérios para determinar se uma variável aleatória contínua é limitada, em oposição a ser censurada, foram apresentados no Capítulo 1. Primeiro, os limites são considerados "reais" no sentido de que nenhum valor significante pode ser atribuído fora desses limites (e.g., um percentual não vale menos de 0 ou excede 100). Segundo, os valores do limite são considerados valores verdadeiros e não observações censuradas.

(SMITHSON; MERKLE, 2013, p.153, tradução nossa)

A experiência de Layton e Siikamäki (2009) reforça que a definição do modelo de regressão adequado não é uma tarefa simples, pois envolve questões conceituais a respeito do problema em questão e da forma como os dados são coletados. A forma do problema posto possui algumas características particulares que impedem que modelos mais simples sejam utilizados. Uma dessas característica (1) que precisa ser corretamente modelada é o fato de a variável resposta ser limitada no intervalo fechado entre zero, pois não é possível participar com um valor de área negativo, e a área disponível da propriedade em questão, pois também não é possível participar com mais de $100 \%$ da área disponível de uma propriedade. Outra característica (2) particular do problema é a existência de dependência entre as observações de um mesmo proprietário. Por exemplo: a coleta de dados consistiu em obter a participação de diversos proprietários rurais sobre quatro diferentes programas de PSA. Uma vez que a área de estudo é todo o estado de São Paulo e os proprietários respondentes estão a uma distância suficientemente grande entre si, é plausível pressupor que as respostas entre-proprietários são independentes (ou seja, que as respostas dadas por um proprietário não são influenciadas pelas respostas dadas por outros proprietários). No entanto, não é igualmente plausível pressupor que, para um mesmo proprietário, a resposta para uma combinação de tempo e valor proposta é independente da resposta para outra combinação de tempo e valor proposta. Por fim, outra característica (3) que merece atenção é a necessidade de se modelar também a decisão dos respondentes em não participar dos programas.

Por conta das dificuldades impostas pelo problema, os modelos mais comuns de regressão, como a Regressão Linear ou os Modelos Lineares Generalizados, não são suficientes. Assim, foi considerada a classe mais geral de Modelos Aditivos Generalizados para Posição, Escala e Forma (GAMLSS, no idioma original: Generalized Additive Models for Location, Shape and Scale), descrito por Rigby e Stasinopoulos (2005a). Os modelos GAMLSS são semi-paramétricos, pois por mais que demandem a definição de uma distribuição para a variável resposta, podem incluir funções de suavização não-paramétricas em sua formulação. Logo, possuem uma grande flexibilidade e abrangem uma ampla classe de modelos como casos particulares (cf. Stasinopoulos, Rigby et al. (2007)).

Os modelos GAMLSS permitem "qualquer distribuição para a variável resposta" (STASINOPOULOS et al., 2017) e "todos os parâmetros da distribuição podem ser modelados como funções das variáveis explanatórias" (STASINOPOULOS et al., 2017) ${ }^{14}$. Como será 
apresentado mais adiante, essas propriedades sozinhas já são capazes de resolver os problemas relacionados às características (1) e (3) descritas. No entanto, as vantagens dos modelos GAMLSS para a presente pesquisa vão além, pois sua definição pode ser feita de forma a suportar a adição de efeitos aleatórios em cada um dos parâmetros da distribuição resposta (cf. Stasinopoulos et al. (2017)). Em outras palavras, isso significa que os modelos GAMLSS são também capazes de lidar com o problema atrelado à caracteristica (2) mencionada anteriormente.

Assim, a definição genérica dos modelos GAMLSS evidencia sua capacidade de lidar com o principal entrave para o estabelecimento do modelo da pesquisa: a dependência existente entre as quatro respostas provenientes de um mesmo proprietário. Por esse motivo, maior detalhamento é dado abaixo, onde também consta uma explicação sobre o termo 'efeito aleatório' utilizado. A questão da distribuição da variável resposta será tratado em sequência, completando a explicação da adequabilidade dos modelos GAMLSS para resolver os problemas atrelados as características (1), (2) e (3) descritas.

Um modelo multinível é capaz de lidar com a dependência existente entre as respostas de um mesmo grupo ${ }^{15}$. Uma definição bastante compreensível é dada por Gelman e Hill (2007):

\begin{abstract}
De maneira mais geral, consideramos um modelo multinível como sendo uma regressão (uma Regressão Linear ou um Modelo Linear Generalizado) em que aos parâmetros - os coeficientes da regressão - é atribuído um modelo de probabilidade. Esse modelo de segundo nível tem seus próprios parâmetros - os hiperparâmetros do modelo - que também são estimados a partir dos dados.

As duas partes centrais de um modelo multinível são os coeficientes variáveis e o modelo para esses coeficientes variáveis (que pode incluir preditores ao nível de grupo). (...) A característica que distingue os modelos multinível da regressão clássica é a modelagem da variação entre-grupos. (GELMAN; HILL, 2007, p.1, tradução nossa)
\end{abstract}

Um modelo misto é capaz lida com dados agrupados (PINHEIRO; BATES, 2000), sendo capaz de resolver o mencionado problema da dependência. Alguns exemplos de aplicação desses modelos ressaltam a semelhança com o problema da presente pesquisa: análise do desempenho escolar de alunos de diferentes classes (GELMAN; HILL, 2007), em que os desempenhos de alunos de mesma classe são correlacionados por estudarem sob condições parecidas (mesmo material de ensino, mesmos professores etc.); de faturas de cartão de crédito (ZERBETO, 2014), cujos valores são também correlacionados de maneira única para cada pessoa; do efeito de políticas municipais sobre o pagamento de pensões (GELMAN; HILL, 2007), em que as alterações são feitas no âmbito municipal

14 Original: "It allows any distribution for the response variable. All the parameters of the distribution can be modelled as functions of explanatory variables"

15 Em relação à terminologia, os nomes: modelo multinível, modelo hierárquico, modelo de efeito misto, modelo de efeito aleatório, e modelo de componente de variância são utilizados algumas vezes de forma indistinta (RAUDENBUSH; BRYK, 2002) 
e acarretam correlação entre as medidas no âmbito individual; análise da qualidade da água em diferentes reservatórios (BONAT; RIBEIRO-JR; ZEVIANI, 2015), em que há correlação entre as medidas de cada reservatório; entre outros (GELMAN; HILL, 2007; PINHEIRO; BATES, 2000).

Seguindo estes conceitos, Gelman e Hill (2007) dizem que "os coeficientes variáveis em um modelo multinível são chamados algumas vezes de efeitos aleatórios, um termo que se refere à aleatoriedade no modelo de probabilidade para os coeficientes no nível de grupo" ${ }^{16}$. Assim, um efeito aleatório é capaz de lidar com a interdependência dos dados e os modelos GAMLSS são capazes de considerá-los tanto de forma não-paramétrica quanto paramétrica (STASINOPOULOS et al., 2017). Embora a literatura possa ser confusa na definição dos parâmetros não-aleatórios do modelo, eles são aqui denominados efeitos fixos (cf. Gelman e Hill (2007) para uma compilação de definições do termo 'fixed effect').

Uma definição geral dos modelos GAMLSS para uma varíavel resposta univariada $\mathbf{Y}$ é dada abaixo:

$$
\begin{aligned}
& \mathbf{Y} \mid \boldsymbol{\gamma} \stackrel{i n d}{\sim} \mathcal{D}(\boldsymbol{\mu}, \boldsymbol{\sigma}, \boldsymbol{\nu}, \boldsymbol{\tau}) \\
& \boldsymbol{\eta}_{k}=g_{k}\left(\boldsymbol{\theta}_{k}\right)=\mathbf{X}_{k} \boldsymbol{\beta}_{k}+\sum_{j=1}^{J_{k}} \mathbf{Z}_{k j} \boldsymbol{\gamma}_{k j}
\end{aligned}
$$

em que $n$ é o número de dados para ajuste do modelo, $\boldsymbol{\theta}_{k}(n \times 1)$ é o vetor relativo ao $k$-ésimo parâmetro da distribuição $\mathcal{D}$ atribuída à variável resposta (i.e. $\boldsymbol{\theta}_{1}=\boldsymbol{\mu}, \boldsymbol{\theta}_{2}=\boldsymbol{\sigma}$, $\left.\boldsymbol{\theta}_{3}=\boldsymbol{\nu}, \boldsymbol{\theta}_{4}=\boldsymbol{\tau}\right)$ e $\boldsymbol{\eta}_{k}(n \times 1)$ é denominado preditor de $\boldsymbol{\theta}_{k}$. O modelo é composto também pela função de ligação $g_{k}(\cdot)$, pelas matrizes de planejamento $\mathbf{X}_{k}\left(n \times J_{k}^{\prime}\right)$ e $\mathbf{Z}_{k j}\left(n \times q_{k j}\right)$, pelo vetor $\boldsymbol{\beta}_{k}$ de tamanho $J_{k}^{\prime} \times 1$, dos parâmetros de efeito fixo, e pelo vetor $\gamma_{k j}$ de tamanho $q_{k j} \times 1$, dos parâmetros correspondentes aos efeitos aleatórios. É necessário ressaltar que a distribuição $\mathcal{D}$ não precisa possuir, necessariamente, todos os quatro parâmetros $(\mu, \sigma, \nu, \tau)$ descritos.

Uma vez que muitas funções de suavização podem ser representadas na forma $\mathbf{Z} \gamma$, a definição geral dos modelos GAMLSS abrange diversos sub-modelos, como o paramétrico aditivo, o paramétrico linear, o não-linear semiparamétrico aditivo, entre outros (cf. Stasinopoulos et al. (2017)). Na presente pesquisa não serão utilizadas as funções de suavização, portanto daqui em diante será tratada apenas a questão dos efeitos aleatórios. Por assumir a independência condicional da variável resposta em relação ao vetor $\boldsymbol{\gamma}=\left(\boldsymbol{\gamma}_{11}^{\top}, \ldots, \boldsymbol{\gamma}_{1 J_{1}}^{\top}, \boldsymbol{\gamma}_{21}^{\top}, \ldots, \boldsymbol{\gamma}_{4 J_{4}}^{\top}\right)^{\top}$ dos parâmetros dos efeitos aleatórios, o modelo (4.1) se mostra adequado para tratar de observações correlacionadas e, portanto, resolver o problema associado à característica (2).

Na prática, é possível tratar os efeitos aleatórios como provenientes de uma distribuição não paramétrica. No entanto, atribuir uma distribuição normal aos vetores $\gamma_{k j}$ ${ }_{16}$ Original: "The varying coefficients $\left(\alpha_{j}\right.$ 's or $\beta_{j}$ 's) in a multilevel model are sometimes calles random effects, a term that refers to the randomness in the probability model for the group-level coefficients(...)" 
é conveniente para a estimação dos parâmetros do modelo. O procedimento adequado consta em Stasinopoulos, Rigby et al. (2007) e Stasinopoulos et al. (2017) e trata de assumir que os vetores $\gamma_{k j}$ dos efeitos aleatórios são independentes e seguem a distribuição normal multivariada com matriz de variância-covariância igual à $\left[\boldsymbol{G}_{k j}\left(\boldsymbol{\lambda}_{k j}\right)\right]^{-1}$. Isto é, assumir: $\boldsymbol{\gamma}_{k j} \sim \mathcal{N}\left(\mathbf{0},\left[\boldsymbol{G}_{k j}\left(\boldsymbol{\lambda}_{k j}\right)\right]^{-1}\right)$, em que $\left[\boldsymbol{G}_{k j}\left(\boldsymbol{\lambda}_{k j}\right)\right]^{-1}$ é a inversa (generalizada) de uma matriz $\boldsymbol{G}_{k j}\left(\boldsymbol{\lambda}_{k j}\right)$ simétrica de ordem $q_{k j} \times q_{k j}$, função do vetor de hiperparâmetros $\boldsymbol{\lambda}_{k j}$. Caso $\boldsymbol{G}_{k j}\left(\lambda_{k j}\right)$ não possua inversa, então à $\boldsymbol{\lambda}_{k j}$ é atribuída uma função densidade imprópria proporcional à $\left(-\frac{1}{2} \boldsymbol{\gamma}_{k j}^{\top} \boldsymbol{G}_{k j}\left(\boldsymbol{\lambda}_{k j}\right) \boldsymbol{\gamma}_{k j}\right)$.

A estimação dos parâmetros do modelo descrito acima é feito, para valores fixos de $\boldsymbol{\lambda}_{k j}$, por meio da maximização da função de log-verossimilhança penalizada ( $\ell_{p}$, vide abaixo). Dois algoritmos são utilizados para a maximização desta função: o algoritmo CG, de Cole e Green, e o algoritmo RS, desenvolvido por Rigby e Stasinopoulos. Nesta pesquisa optou-se pela utilização do algoritmo RS. Mais informações sobre esses algoritmos e sobre a obtenção dos hiperparâmetros $\boldsymbol{\lambda}_{k j}$ pode ser encontrada em Stasinopoulos et al. (2017).

$$
\ell_{p}=\sum_{i=1}^{n} \log f\left(y_{i} \mid \mu_{i}, \sigma_{i}, \nu_{i}, \tau_{i}\right)-\frac{1}{2} \sum_{k=1}^{4} \sum_{j=1}^{J_{k}} \boldsymbol{\gamma}_{k j}^{\top} \boldsymbol{G}_{k j}\left(\boldsymbol{\lambda}_{k j}\right) \boldsymbol{\gamma}_{k j}
$$

em que $y_{i}$ denota os valores observados da variável resposta e $f\left(y_{i} \mid \mu_{i}, \sigma_{i}, \nu_{i}, \tau_{i}\right)$ é a função massa de probabilidade, no caso da variável resposta ser discreta, ou a função densidade de probabilidade, no caso de ser contínua.

Como mencionado na análise do modelo de Layton e Siikamäki (2009), a distribuição beta adotada para a variável resposta se restringe ao intervalo aberto $(0,1)$ e isso possui implicações para a análise. A distribuição da variável resposta deve ser então escolhida de forma a tratar das características (1) e (3) descritas. A proposta mais adequada para a presente pesquisa foi encontrada em Ospina e Ferrari (2010), em que autores propõe uma distribuição discreta-contínua capaz de modelar os intervalos $(0,1]$ (distribuição beta inflacionada de um - BEINF1), [0,1) (distribuição beta inflacionada de zero - BEINF0) ou $[0,1]$ (distribuição beta inflacionada de zero e um - BEINF). Essas distribuições se mostram mais adequadas, uma vez que podem abranger os casos em que os respondentes optam por não participar do programa, por participar com toda sua área disponível, ou ambos simultaneamente.

A distribuição mais adequada seria a BEINF, que abrange o intervalo fechado [0,1]. No entanto, como será mostrado nos resultados, a proporção de respondentes que optaram por participar com toda a área disponível da propriedade não é tão grande. Além disso, considerar a massa de probabilidade em um significa adotar uma distribuição com todos os quatro parâmetros $(\boldsymbol{\mu}, \boldsymbol{\sigma}, \boldsymbol{\nu}, \boldsymbol{\tau})$ descritos no modelo 4.1, enquanto desconsiderala reduz a complexidade do modelo por considerar apenas três desses parâmetros. Além dessa distribuição, os modelos GAMLSS permitem o ajuste de distribuições truncadas. 
Diversos modelos foram ajustados considerando essas distribuições ${ }^{17}$, mas verificou-se que os melhores resultados foram encontrados com a distribuição BEINF0.

A melhor solução encontrada foi considerar a participação completa $(y=100 \%)$ como uma participação alta $(y=99 \%)$ e tratá-la em conjunto com a parte contínua da distribuição BEINF0. Esta proposta resolve os problemas das características (1) e (3), mencionados anteriormente e não acarreta perda para a interpretabilidade do fenômeno. Essa distribuição é descrita abaixo a partir de Ospina e Ferrari (2010), mas com a nomenclatura de seus parâmetros alterada para a mesma do modelo descrito em 4.1.

$$
f(y \mid \mu, \sigma, \nu)= \begin{cases}p_{0}, & \text { se } y=0 \\ \left(1-p_{0}\right) f(y \mid \mu, \sigma) & \text { se } 0<y<1\end{cases}
$$

em que $p_{0}, 0<p_{0}<1$, é a probabilidade de $y=0$ e $f(y \mid \mu, \sigma)=\frac{\Gamma(\alpha+\beta)}{\Gamma(\alpha) \Gamma(\beta)} y^{\alpha-1}(1-y)^{\beta-1}$ é a função densidade de probabilidade da distribuição beta. Muitas relações se verificam para essa distribuição, dentre as quais se destacam as seguintes: $\alpha>0, \beta>0, \alpha=\frac{\mu\left(1-\sigma^{2}\right)}{\sigma^{2}}$, $\beta=\frac{(1-\mu)\left(1-\sigma^{2}\right)}{\sigma^{2}}$. Os parâmetros são então definidos: $0<\mu<1,0<\sigma<1$. O valor esperado da distribuição BEINF é $E(y)=\left(1-p_{0}\right) \mu=\frac{\mu}{1+\nu}$ e $p_{0}=\frac{\nu}{1+\nu}$. Logo, $\nu>0$. A interpretação do termo $p_{0}$ para a presente pesquisa é a probabilidade de um proprietário se negar a participar de um determinado programa, um valor de grande interesse para o planejamento de políticas de PSA, uma vez que o modelo deve ser capaz de considerar a existência de proprietários que rejeitam os programas (LAYTON; SIIKAMÄKI, 2009).

Um modelo GAMLSS pode ser representado como $\mathcal{M}=\{\mathcal{D}, \mathcal{G}, \mathcal{T}, \mathcal{L}\}$, em que $\mathcal{D}$ especifica a distribuição da variável resposta e, consequentemente, o número de parâmetros desta distribuição, $\mathcal{G}$ especifica o conjunto das funções de ligação para os parâmetros da distribuição, $\mathcal{T}$ especifica os termos nos preditores para os parâmetros da distribuição, e $\mathcal{L}$ especifica o conjunto dos hiperparâmetros do modelo (STASINOPOULOS et al., 2017). A correta seleção de modelos deve passar por todos seus componentes. Acima, foi justificada a escolha da distribuição da variável resposta (componente $\mathcal{D}$ do modelo) a partir de considerações conceituais a respeito do problema. Neste projeto, também teve maior atenção as componentes $\mathcal{T}$ e $\mathcal{G}$, cujo procedimento é descrito abaixo.

A seleção das variáveis preditoras (componente $\mathcal{T}$ ) para os parâmetros da distribuição foi feita após a definição da distribuição para a variável resposta. Para evitar uma busca arbitrária de preditores, tendo em vista que é quase infinita a possibilidade de obtenção de informações por meio dos limites das propriedades rurais, restringimos a busca apenas entre as variáveis obtidas pela busca da seção 4.2 .3 e suas interações com as variáveis de tempo e pagamento propostos em contrato. A comparação dos modelos foi feita por meio da minimização do Akaike Information Criterion (AIC), que possui um termo de penalização para evitar que o modelo se torne demasiadamente complexo (cf. Stasinopoulos

$\overline{17}$ Esses modelos não serão apresentados na dissertação, pois seus resultados são extensos e não influenciam no resultado do procedimento adotado de fato. 
et al. (2017)). Todas as variáveis candidatas foram normalizadas no intervalo $[0,1]$. A variável de uso do solo não foi considerada dentre as candidatas, pois continha classes sem observação (por exemplo, extrativismo).

Em seguida, foi feita a seleção das funções de ligação (componente $\mathcal{G}$ ). Como visto em (4.2), os parâmetros $\mu$ e $\sigma$ são definidos no intervalo $(0,1)$ e $\nu$, em $(0, \infty)$. Para $\nu$ foi definida a função exponencial como função de ligação, isso é, $g_{3}^{-1}(x)=e^{x}$, em que $e$ é o número de Euler. Essa função é adequada, pois garante que $g_{3}^{-1}(x)>0$. Para $\mu$ e $\sigma$, mais funções candidatas foram consideradas: logit, probit e cloglog. Todas as nove combinações possíveis dessas candidatas entre os parâmetros $\mu$ e $\sigma$ foram testadas e avaliadas segundo o critério AIC.

Por fim, para o diagnóstico do modelo foi seguida a proposta de Ospina e Ferrari (2012) de utilizar os resíduos quantílicos aleatorizados (DUNN; SMYTH, 1996), que são capazes de lidar ao mesmo tempo com a parte discreta e parte contínua do modelo. São dados por:

$$
r_{i}^{q}=\Phi^{-1}\left(u_{i}\right), \quad i=1, \ldots, n
$$

em que $\Phi(\cdot)$ é a função distribuição acumulada da distribuição normal padrão. No caso da distribuição BEINF0, $u_{i}$ é uma variável aleatória distribuída uniformemente em $\left(0, \hat{p_{0}}\right]$, se $y_{i}=0$, ou, caso contrário, assume o valor de $u_{i}=F\left(y_{i} \mid \hat{\mu}_{i}, \hat{\sigma}_{i}, \hat{\nu}_{i}\right)$, em que $F$ é a função distribuição acumulada da distribuição BEINF0 e o símbolo chapéu ( ${ }^{`}$ ) representa os parâmetros estimados no ajuste do modelo. Após os cálculos, a distribuição de $r_{i}$ deve ser a normal padrão se o modelo estiver adequado. Na prática, a distribuição de $r_{i}$ deve variar a partir da semente aleatória utilizada. Por este motivo, os resíduos foram gerados e avaliados quantitativamente para 10.000 sementes aleatórias diferentes.

A comparação da distribuição de $r_{i}$ com a normal padrão foi feita de diversas formas. A primeira delas foi a comparação quantitativa, por meio do teste de Shapiro-Wilk (SHAPIRO; WILK, 1965) para a normalidade da distribuição de $r_{i}$. Esse teste foi feito para cada uma das 10.000 vezes em que os resíduos quantílicos aleatorizados foram gerados. A outra maneira de avaliação foi a comparação visual, com o histograma de $r_{i}$ contra a função de densidade da distribuição normal padrão teórica. A comparação visual também contou com o qq-plot, que compara os quantis da distribuição de $r_{i}$ com os quantis da distribuição normal padrão teórica, e o worm-plot, que é capaz de identificar problemas no ajuste do modelo. Esses resultados serão apresentados somente para uma das 10.000 repetições realizadas que apresentou um valor intermediário de valor $p$. Cabe ressaltar que em todos os casos a estimativa dos parâmetros foi idêntica, pois a semente aleatória influencia apenas no cálculo dos resíduos quantílicos aleatorizados. Maiores informações sobre os gráficos mencionados serão dadas no momento de sua apresentação e mais detalhes podem ser encontrados em Stasinopoulos et al. (2017). Por conta do termo 'resíduo 
quantílico aleatorizado' ser extenso, ele será mencionado apenas como 'resíduo'. Assim, os 'resíduos puros' serão tratados separadamente sob esta nomenclatura.

\subsubsection{Validação e Predição}

Após o ajuste do modelo, foi feita uma validação cruzada por meio da técnica leave-oneout. Essa técnica consiste em repetir para todos os respondentes o seguinte procedimento: ajustar o modelo com as respostas de todos os respondentes, exceto o $n$-ésimo, e predizer os valores para o $n$-ésimo respondente, que não faz parte da base de ajuste na ocasião. $\mathrm{O}$ principal obstáculo para a predição em modelos mistos é escolher o valor adequado para o efeito aleatório, uma vez que só são conhecidos são aqueles valores referentes aos dados utilizados para o ajuste do modelo. Na presente pesquisa, a proposta foi utilizar para todas as predições o valor esperado da distribuição atribuída aos efeitos aleatórios (isso é, o valor zero). Essa abordagem pode ser encontrada na literatura sob o nome de predição de 'média zero' (MANCO, 2013), 'ao nível de população' (PINHEIRO; BATES, 2000) ou 'marginal' (GILMOUR et al., 2004). Caso o modelo esteja adequado, os resultados da validação cruzada devem possuir propriedades que garantam que as predições são úteis para o problema em análise.

Após a validação cruzada, foi feito mais um corte na base de dados mencionada no item 4.2.4. Considerando todas as variáveis preditoras selecionadas, foram excluídos do processo de predição aqueles proprietários que possuíam valores maiores ou menores que os utilizados para o ajuste do modelo. Por exemplo: caso todos os respondentes tenham uma temperatura média anual de 15 a $20^{\circ} \mathrm{C}$ na propriedade e essa variável tenha sido escolhida como preditora, então foram removidas as propriedades que tenham como temperatura média anual valores abaixo de $15^{\circ} \mathrm{C}$ ou acima de $20^{\circ} \mathrm{C}$. Esse procedimento teve como objetivo evitar o que é conhecido como extrapolação do modelo:

\footnotetext{
Extrapolação, i.e. predição (da distribuição da variável resposta) fora do intervalo de valores das variáveis explanatórias dos dados originais, é perigoso para qualquer modelo estatístico (porque a relação entre a variável resposta e as variáveis explanatórias pode não se estender para fora da base de dados original). Extrapolação deve ser evitada ou tratada com grande precaução

(STASINOPOULOS et al., 2017, p.135, tradução nossa).
}

A redução decorrente do corte não foi muito extensa, tendo sobrado na base de predição 275.566 propriedades rurais. Em seguida, foi feita a predição da participação para os demais proprietários rurais do estado de São Paulo. Para um programa $i$ com pagamento $p$ e tempo $t$ propostos, a relação entre a área total de participação, $A_{T_{i}}$, os valores preditos pelo modelo e a área disponível para participação em cada propriedade, $a_{d}$, é dada por:

$$
A_{T_{i}}=\sum_{j=1}^{n^{*}} Y_{i j} \cdot a_{d_{j}}
$$


em que $n^{*}$ é o número total de propriedades rurais do estado e $Y_{i j} \sim B E I N F 0\left(\mu_{i j}, \sigma_{i j}, \nu_{i j}\right)$ é a variável aleatória do percentual de participação do determinado programa, com os coeficientes da distribuição preditos pelo modelo.

Por conta das propriedades do valor esperado (ROSS, 2007), uma maneira de obter o valor esperado da área total de participação de um dado programa seria somar, para todas as propriedades, o produto entre o valor esperado do percentual de participação pela respectiva área disponível. No entanto, optamos por também construir intervalos de confiança para este valor, de forma a avaliar parte da variabilidade inerente ao problema. O intervalo de confiança do valor esperado de uma distribuição pode ser calculado a partir dos quantis, cuja função é a inversa da função distribuição acumulada. A função quantil deve ser calculada em determinados pontos de tal forma que seus limites contemplem o nível de confiança desejado. Por exemplo: para se obter um intervalo de confiança de $99 \%$, é preciso calcular os quantis de $0,5 \%$ e $99,5 \%$, para o intervalo de $95 \%$, calcular em $2,5 \%$ e $97,5 \%$ e assim em diante. A distribuição da área total de participação foi obtida em quatro passos: 1) definir uma combinação de tempo e valor de interesse; 2) a partir do modelo ajustado, predizer os parâmetros da distribuição resposta para cada uma das propriedades considerando a combinação escolhida; 3) amostrar aleatoriamente 10.000 valores da distribuição resposta de cada uma das propriedades da base de predição; 4) somar todos esses vetores, resultando no vetor de distribuição da área total predita para o determinado programa.

Assim, foram construídas as curvas de retorno em função do investimento aplicado com os respectivos intervalos de confiança. Os resultados foram comparados com os orçamentos da Secretaria do Meio Ambiente, obtidos por meio de solicitação de informação (SMA, 2017b). A Secretaria não informou se os valores fornecidos já estão corrigidos pela inflação do período, portanto optou-se por não corrigi-los.

\subsubsection{Problemas e limitações}

Dada a descrição do modelo estatístico e das bases de dados utilizadas, cabe ressaltar as limitações encontradas e os problemas decorridos durante a pesquisa. Os principais pontos foram:

1. A qualidade da base de dados do CAR. Foi verificada uma quantidade bastante elevada de erros nos cadastros e uma grande área de sobreposição entre os imóveis. Na base de dados utilizada para as predições, a sobreposição das propriedades chegou a cerca de 900.000 ha e isso pode resultar em uma superestimativa da área total de participação nos resultados finais desta pesquisa.

2. A qualidade dos dados incorporados ao modelo, pois alguns arquivos públicos utilizados não possuem resolução suficiente para fornecerem preditores de alta qualidade para pequenas propriedades. 
3. A desconsideração de uma possível dependência espacial dos dados. Considerando o problema em questão, os modelos GAMLSS são capazes de incorporar uma possível dependência existente entre uma propriedade e seus vizinhos. As estruturas disponíveis nesses modelos são conceitualmente mais adequadas do que as utilizadas, por exemplo, nos trabalhos de Figueroa et al. (2016), Torabi et al. (2016). Por motivos computacionais, uma vez que o número de propriedades rurais considerado na pesquisa é muito grande, essa questão não foi incorporada e pode ser considerada como uma limitação do modelo.

4. Problemas conhecidos no questionário. Uma reconhecida falha da pesquisa foi não informar aos proprietários se deveriam responder ao questionário considerando que os custos da restauração seriam cobertos com recursos próprios ou recursos do proponente dos programas. Isso pode ter influenciado no percentual de participação fornecido em alguns casos. Além disso, nada foi mencionado a respeito do reajuste dos valores de contrato pelos índices de inflação. Por fim, o último problema desta categoria foi o fato de que a Lei no 8.666/93 (BRASIL, 1993) prevê duração máxima de 60 meses ( 5 anos) para os contratos de prestação de serviço. Portanto, os proprietários deveriam ter sido informados que os contratos de duração maior a cinco anos necessitariam de atualização periódica e isso poderia, eventualmente, influenciar na resposta fornecida.

5. A desconsideração de mudanças que podem ocorrer ao longo da execução dos programas hipotéticos (por exemplo: problemas de mudanças climáticas eventualmente podem aumentar o orçamento destinado à restauração de vegetação nativa na área de estudo).

Essas limitações podem implicar em resultados de área de restauração inflada em relação às que de fato ocorreriam caso os programas propostos fossem executados. Por outro lado, os valores apresentados serão bastante inferiores aos reais, pois o modelo considera apenas o valor pago aos proprietários. Em um programa real, outros custos devem ser considerados, como o custo de transação, que pode ser bastante elevado aumentar substancialmente o custo total do programa (MURADIAN et al., 2010).

\subsubsection{Softwares utilizados}

Todos os procedimentos utilizados foram feitos no R ( $\mathrm{R}$ Core Team, 2016), em conjunto com seus pacotes para manipulação de dados espaciais rgdal (BIVAND; KEITT; ROWLINGSON, 2016), raster (HIJMANS, 2016) e rgeos (BIVAND; RUNDEL, 2017), e o pacote gamlss (RIGBY; STASINOPOULOS, 2005b) para o ajuste do modelo estatístico.

A dissertação foi escrita com o sistema tipográfico ${ }^{A} T_{\mathrm{E}} \mathrm{X}$, com a classe abntex2. A adoção de software livre foi intencional e teve como intuito permitir a reprodução dos 
procedimentos por qualquer interessado, uma vez que sua aquisição não demanda qualquer custo e sua utilização é compatível com uma ampla gama de sistemas operacionais. 


\section{Resultados e discussão}

\subsection{Aplicação do questionário}

Foram registradas um total de 403 respostas ao questionário, das quais 209 forneceram o CAR e 193, não forneceram. Desse total de 209 respostas, 22 foram desconsideradas por serem relativas a propriedades cujo CAR foi feito após $12 / 11 / 2016$, de quando foi obtida a base de dados do CAR estadual utilizada nesta pesquisa, ou por estarem localizadas em regiões que as bases de dados utilizadas não possuíam dados completos. Assim, 187 respostas foram utilizadas para as análises e para o estabelecimento do modelo estatístico. A localização dos municípios que responderam o questionário é dada na Figura 7.

\section{Municípios de acordo com a existência de respostas válidas}

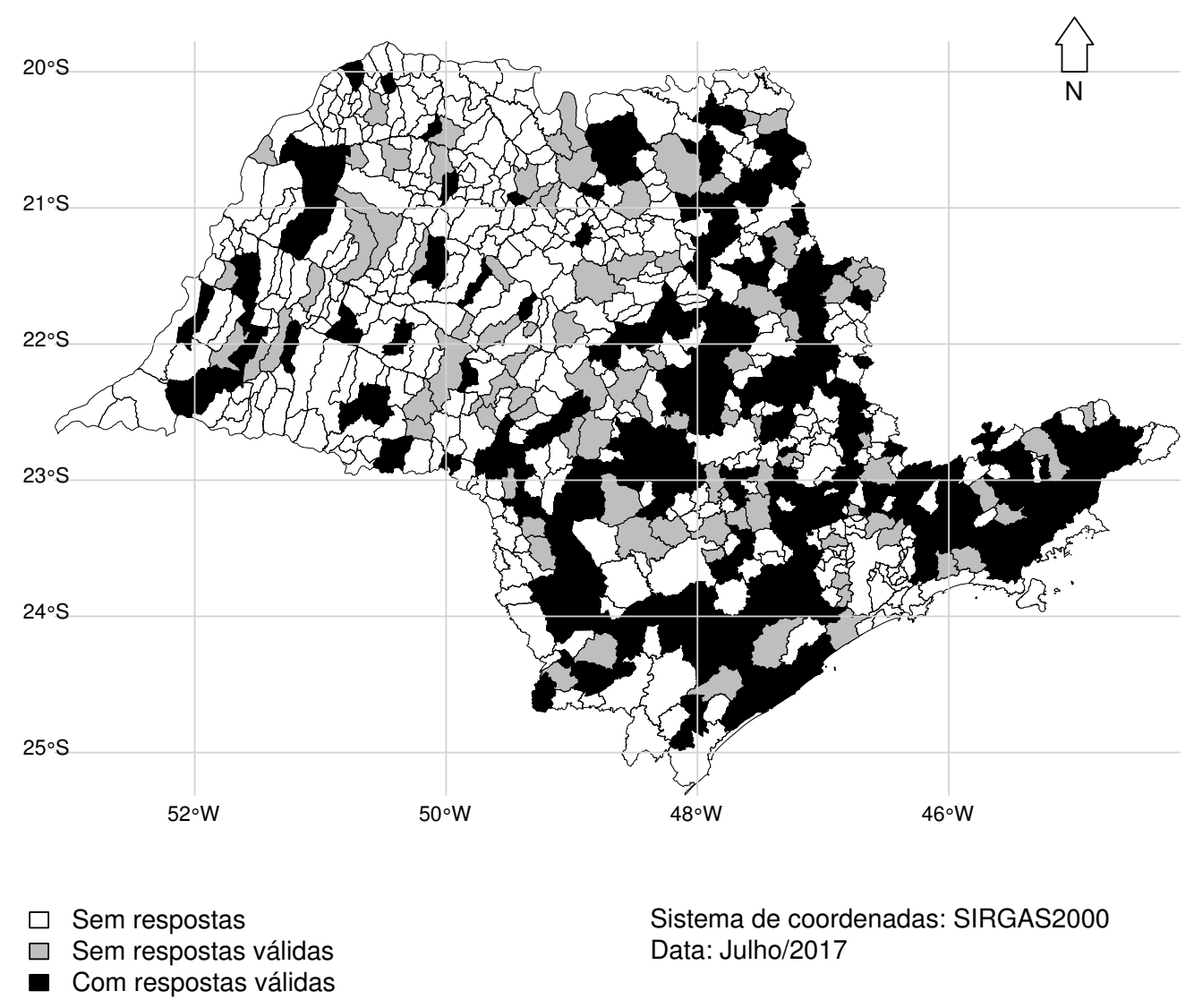

Figura 7 - Mapa contendo os municípios com e sem respostas válidas Fonte: Elaboração própria 
Percebe-se uma grande concentração das propriedades respondentes na região sudeste do estado. Isso pode ser explicado pela própria distribuição dos proprietários rurais paulistas. A Figura 8 mostra que a probabilidade de escolha de um proprietário aleatório do estado, calculada a partir da divisão do número de proprietários de um dado município pelo número total de proprietários no estado, diminui a medida em que se caminha para a região noroeste do mapa. As cores mais escuras nessa região mostram que a maior concentração de propriedades na região sudeste existe de fato e a amostra apenas reproduziu este padrão.

\section{Probabilidade de escolha de cada município, a partir do número de propriedades}

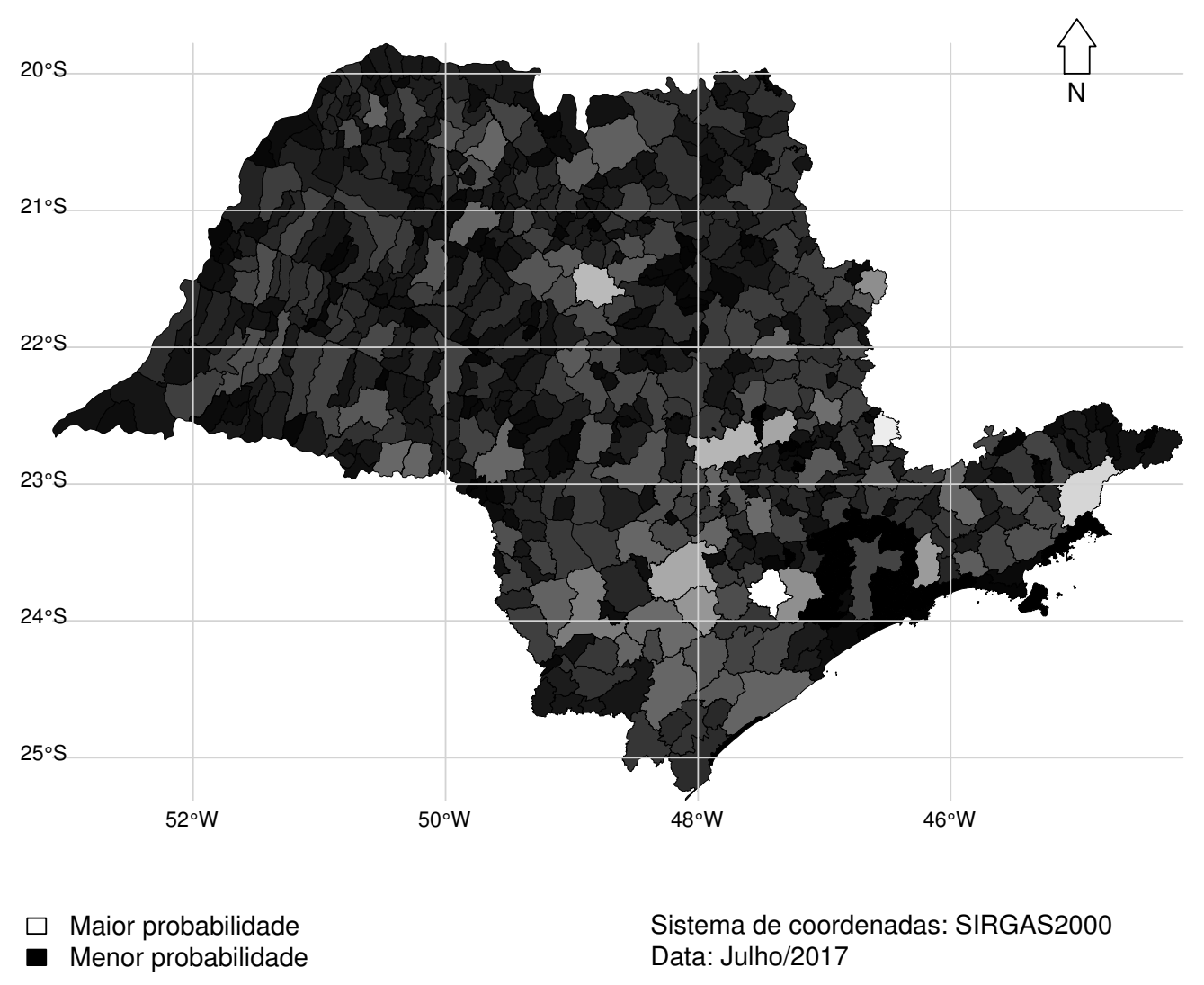

Figura 8 - Probabilidade espacializada de escolha de uma propriedade aleatória no estado Fonte: Elaboração própria

Como descrito na seção metodológica, a análise do viés da amostra em relação à população foi feita a partir das respostas consideradas válidas. A comparação foi feita para o sexo dos respondentes (Figura 9), a idade (Figura 10) e o uso do solo (Figura 11). Em seguida, o Tabela 5 apresenta os valores necessários para a rejeição da hipótese nula, considerando os valores $p$ de 0,05, 0,01 e 0,001. 


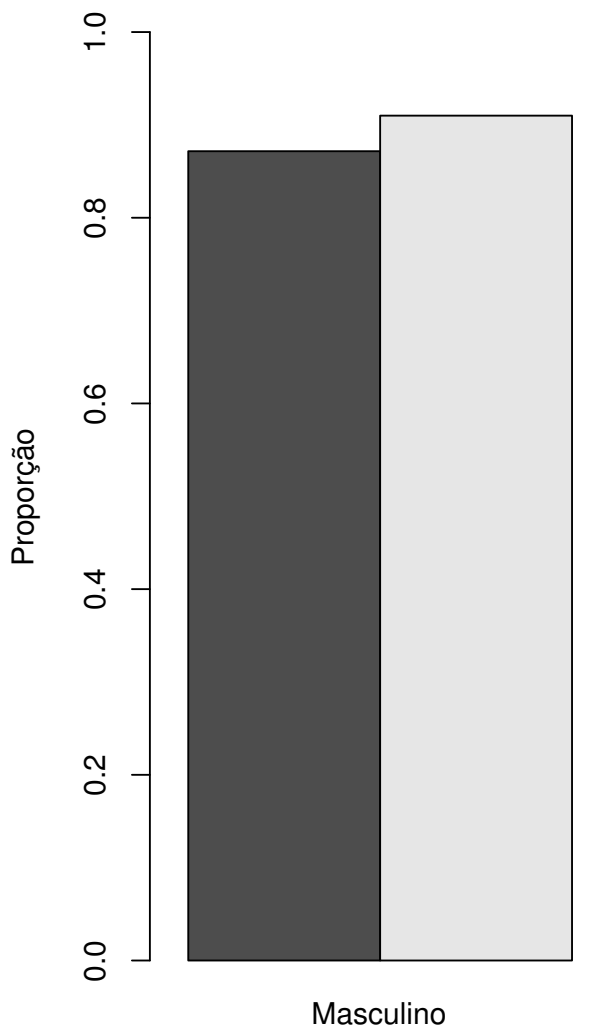

Masculino
Questionário
$\square \quad$ IBGE - Censo Agropecuário

Teste Chi-Quadrado de Pearson $X^{2}=2.896$

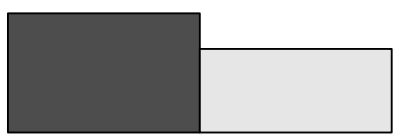

Feminino

Figura 9 - Comparação do sexo dos respondentes entre a amostra e a população. Teste realizado: $\chi^{2}$ de Pearson

Fonte: Elaboração própria

Tabela 5 - Valores utilizados para rejeição das hipóteses nulas

\begin{tabular}{|c|c|c|c|c|}
\hline \multirow{2}{*}{ Característica } & \multirow{2}{*}{ Estatística de teste } & \multicolumn{3}{|c|}{ Valores críticos para a rejeição de $H_{0}$} \\
\hline & & $95 \%$ & $99 \%$ & $99,9 \%$ \\
\hline Sexo & $\begin{array}{l}\chi_{1}^{2}=2.896 \\
\left(\text { Teste } \chi^{2}\right)\end{array}$ & $\begin{array}{r}\chi_{1}^{2}>3,841 \\
\text { (não rejeita) }\end{array}$ & $\begin{array}{r}\chi_{1}^{2}>6,635 \\
\text { (não rejeita) }\end{array}$ & $\begin{array}{l}\chi_{1}^{2}>10.827 \\
\text { (não rejeita) }\end{array}$ \\
\hline Idade & $\begin{array}{r}\text { valor } p=0,003 \\
\text { (Teste Exato de Fisher) }\end{array}$ & $\begin{array}{r}\text { valor } p<0,05 \\
(\text { rejeita) }\end{array}$ & $\begin{array}{r}\text { valor } p<0,01 \\
(\text { rejeita) }\end{array}$ & $\begin{array}{r}\text { valor } p<0,001 \\
\text { (não rejeita) }\end{array}$ \\
\hline Uso do solo & $\begin{array}{l}\text { valor } p=1.4 \cdot 10^{-6} \\
\text { (Teste Exato de Fisher) }\end{array}$ & $\begin{array}{r}\text { valor } p<0,05 \\
(\text { rejeita })\end{array}$ & $\begin{array}{r}\text { valor } p<0,01 \\
\text { (rejeita) }\end{array}$ & $\begin{array}{r}\text { valor } p<0,001 \\
(\text { rejeita) }\end{array}$ \\
\hline
\end{tabular}

Os resultados indicam que não é possível rejeitar a hipótese de que as proporções são idênticas no caso do sexo dos respondentes, no nível de confiança de 95\%, e das classes de idade dos respondentes, no nível de confiança de 99,9\%. O teste indicou também que, para o uso do solo, a amostra difere significativamente da população representada pelo CAR.

Um fator que pode influenciar no resultado do uso do solo é a má representação do cenário rural pelos dados. Tanto o CAR, quanto o IBGE e a presente pesquisa reduziram 


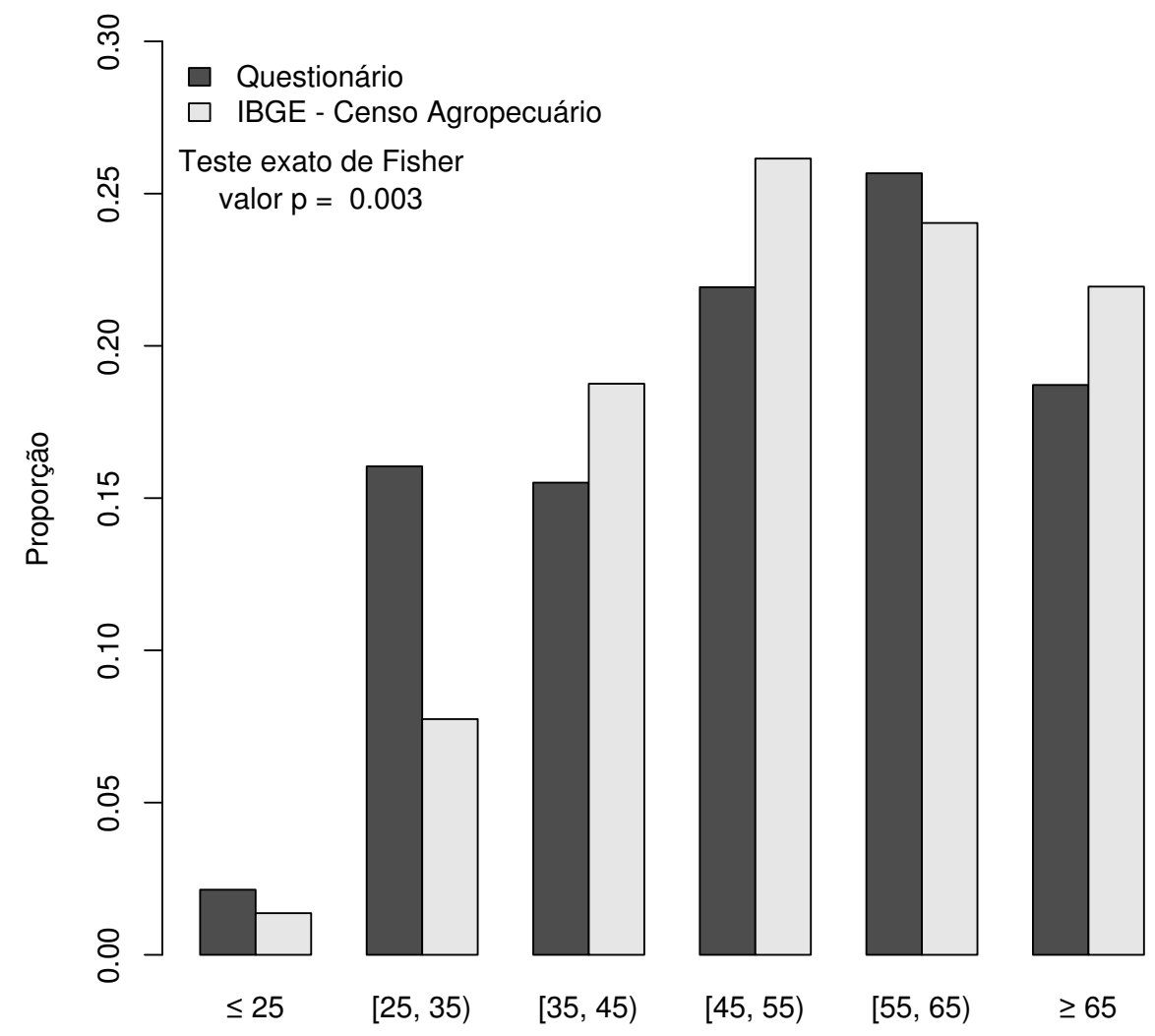

Figura 10 - Comparação da idade dos respondentes entre a amostra e a população. Teste realizado: Teste exato de Fisher

Fonte: Elaboração própria

o uso do solo da propriedade a uma única atividade, quando na prática, uma propriedade pode não só possuir mais de um uso do solo predominante, como pode alternar de forma intermitente entre os usos na propriedade. Como o CAR é preenchido de forma declaratória e individual, não é certo que os proprietários utilizaram todos o mesmo critério para selecionar o uso do solo predominante durante o cadastro e, portanto, também não é certo que os dados de uso do solo representem fielmente a realidade. Um exemplo claro são os sistemas agroflorestais que poderiam preencher simultaneamente os campos de agricultura e conservação. Essa limitação foi percebida por alguns proprietários e relatada via e-mail:

(...) no campo sobre o uso predominante só ter uma opção, no meu ver, é muito pouco e pobre. Eu sei que existem propriedades "especialistas" em produção de cana, mas eu conheço muitas que tem outras atividades além da cana para se manter. Deste modo quem sabe, estas propriedades, não estariam mais propensas ao programa de PSA?

(R., respondente do questionário)

Cabe ressaltar também que a hipótese nula do teste de hipóteses realizado é a de que todas as proporções são idênticas. Por conta da grandes discrepâncias relativas nos per- 


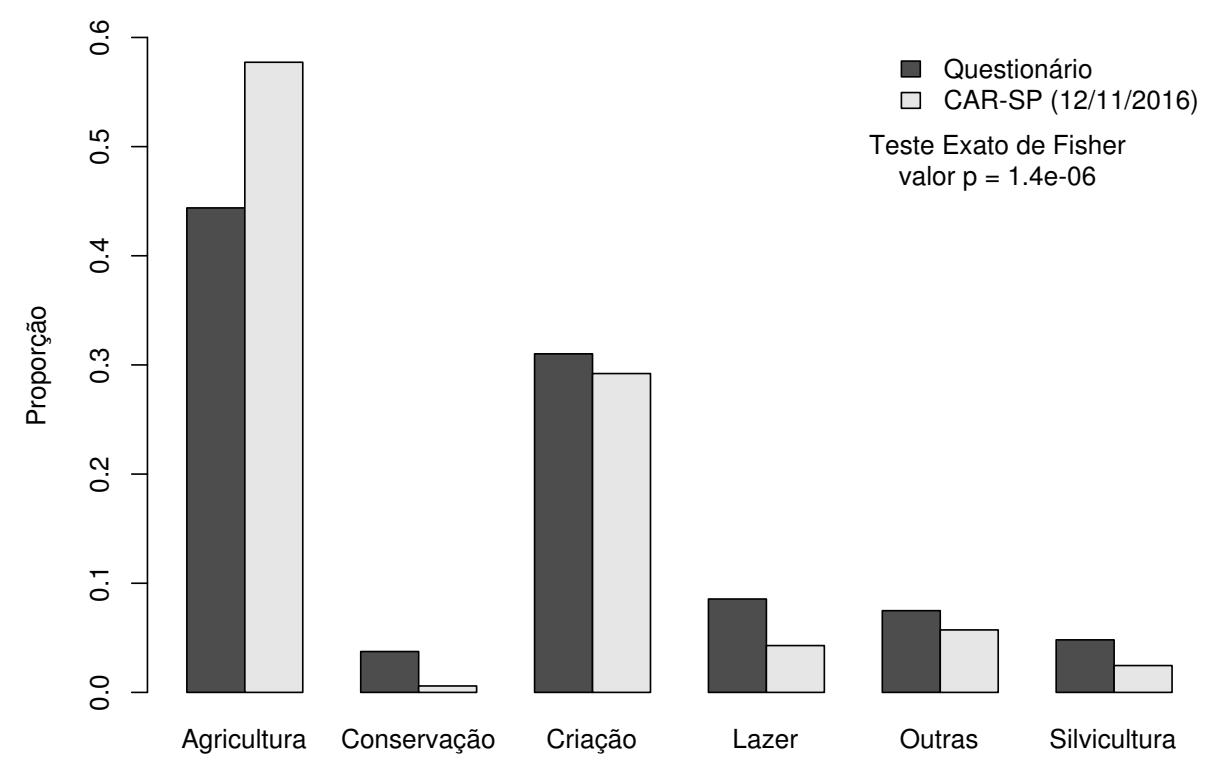

Figura 11 - Comparação da uso do solo entre a amostra e a população. Teste realizado: Teste exato de Fisher

Fonte: Elaboração própria

centuais de conservação, turismo, lazer e silvicultura, essas categorias o podem a rejeição desta hipótese nula. No entanto, o percentual de agricultura e criação somados ultrapassam $70 \%$, de forma que em termos absolutos as categorias com diferenças nos percentuais contribuem muito menos para o ajuste do modelo. Logo, os dados de uso do solo são suficientes somente para dar uma noção geral das proporções dos usos e, nesse sentido, a comparação visual das distribuições da amostra coletada e da população são convincentes para afirmar que se tratam da mesma população, ainda que a rejeição da hipótese tenha sido estatisticamente significante. Essa comparação fica ainda mais evidente quando o grupo 'Outras' da Figura 11 é desmembrado em seus grupos originais (Figura 12).

A insuficiência do dado para a representação do cenário também ocorre nos casos em que a hipótese nula não é rejeitada. A variável sexo do proprietário, por exemplo, considera que há apenas uma pessoa responsável legalmente pela propriedade. Na prática, isso frequentemente não é verdade. Prova disso é o próprio sistema do CAR estadual (SMA, 2017c), que permite que múltiplas pessoas sejam listadas como donas dos imóveis. A mesma preocupação vale para a idade da pessoa responsável pela propriedade. Durante a coleta de dados, esse questionamento foi levantado algumas vezes pelos próprios respondentes por meio do e-mail fornecido para contato. A justificativa fornecida como resposta foi a necessidade de compatibilização da base de coleta com a base do IBGE. 


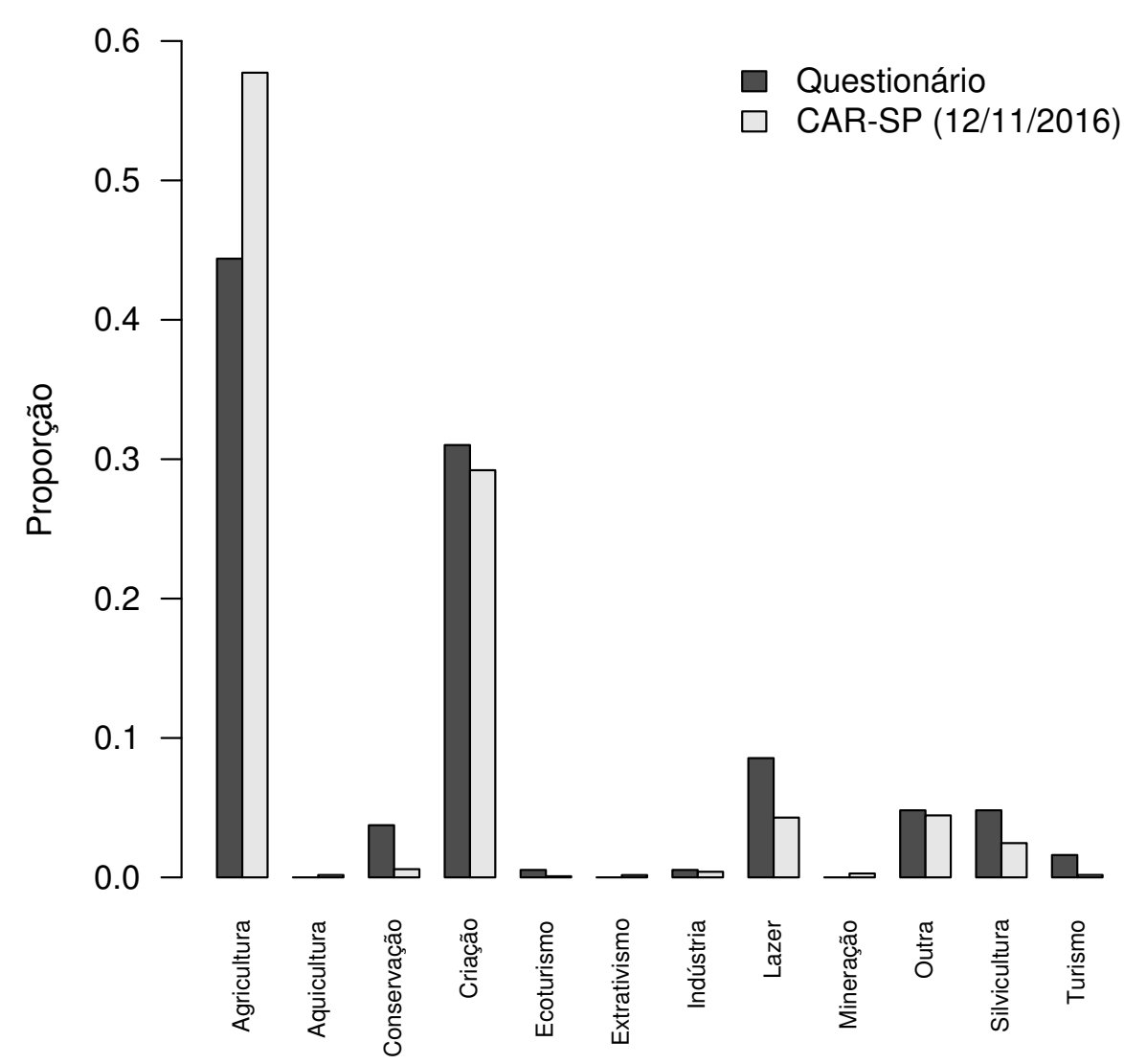

Figura 12 - Comparação do uso do solo dos respondentes com o uso do solo dos respondentes do CAR

Fonte: Elaboração própria

\subsection{Características socioeconômicas e ambientais}

A busca bibliográfica retornou 261 artigos no total. O primeiro filtro descrito na seção 4.2.3 selecionou aqueles que tratam de situações semelhantes, deixando apenas 23 artigos para a análise dos respectivos modelos (GREINER, 2016; KACZAN; SWALLOW et al., 2013; MA et al., 2012; LIU, 2011; LAYTON; SIIKAMÄKI, 2009; MATTA; ALAVALAPATI; MERCER, 2009; YANG et al., 2014; GREINER, 2015; TORABI et al., 2016; FIGUEROA et al., 2016; THACHER; LEE; SCHELHAS, 1996; LUZAR; DIAGNE, 1999; DUKE, 2004; ZBINDEN; LEE, 2005; DEFRANCESCO et al., 2008; ARRIAGADA et al., 2009; RUTO; GARROD, 2009; GAUVIN et al., 2010; BROCH; VEDEL, 2012; BEHARRY-BORG et al., 2013; GUO et al., 2014; JIANG; KOO, 2014; MURPHY et al., 2014). Em seguida, as variáveis foram extraídas. Um número bastante elevado de variáveis foi encontrado e é apresentado no Apêndice A.

Nota-se que muitas variáveis se relacionam com características informadas pelos proprietários. É o caso, por exemplo, das variáveis "Extrai madeira há mais de 30 anos?" e "Atitude em relação à provisão de serviços ecossistêmicos para seu próprio benefício". 
$\mathrm{Na}$ presente pesquisa, essas variáveis foram desconsideradas, pois são de conhecimento apenas dos respondentes do questionário e o modelo da presente pesquisa pretende ser preditivo. Faz-se necessário, portanto, que as variáveis utilizadas sejam conhecidas tanto para os respondentes quanto para os não respondentes. Assim, as variáveis encontradas foram filtradas e agrupadas de acordo com o procedimento descrito na metodologia. Os grupos de variáveis considerados adequados para a utilização na presente pesquisa são descritos no Quadro 2:

Quadro 2 - Variáveis filtradas e agrupadas

\begin{tabular}{lc}
\hline \multicolumn{1}{c}{ Variável encontrada $^{18}$} & Grupo atribuído \\
\hline - Área agricultável & \\
- Área da propriedade & \\
- Área agricultável da propriedade & Área agricultável \\
- Área total da propriedade & \\
- Área total & \\
- Área da propriedade & \\
- Tamanho da propriedade & Áreas especiais \\
\hline - Presença de fatores ambientais (wetlands, vegetação endêmica etc.) & Áreas protegidas \\
\hline - Grupo 5: Existência de áreas protegidas ou de especial interesse & Cumprimento da lei \\
\hline - Cumprimento da legislação local sobre áreas agricultáveis & Declividade \\
\hline - Percentual da fazenda com áreas íngremes de acordo com a percepção & \\
do proprietário & \\
- Percentual da fazenda alta declividade, de acordo com a percepção do & \\
proprietário & \\
- Declividade & \\
- Percentual das áreas agricultáveis da propriedade em áreas montanho- & \\
\hline sas &
\end{tabular}

- Distância da área agricultável para a administração pública local

- Distância da área agricultável para o escritório do proprietário

- Distância para a cidade mais próxima

- Distância de áreas urbanas

Distância

- Existência de central de esgoto próxima à propriedade

- Distância da propriedade à casa

- Pagamento proposto

- Pagamento adicional por hectare

- Pagamento

Pagamento proposto

- Valor do contrato

- Preço ofertado pela geração de carbono

- Produtividade da terra (média da produtividade dos 3 últimos anos, em cabeças de gado por $\mathrm{km}^{2}$ )

- Grupo 4: Capacidade biofísica do solo

Produtividade 
Continuação...

\begin{tabular}{lc}
\hline \multicolumn{1}{c}{ Variável encontrada $^{18}$} & Grupo atribuído \\
\hline - Percentual da fazenda com solo degradado de acordo com a percepção & \\
do proprietário & \\
- Adequabilidade do solo para a agricultura & \\
- Percentual da fazenda com solo de má qualidade, de acordo com a & \\
percepção do proprietário & Mata ciliar \\
- Produção por hectare & Solo \\
\hline - Protege mata ciliar com pelo menos 100 pés de largura? & \\
- Protege mata ciliar com pelo menos 200 pés de largura? & \\
\hline - Grupo 1: Tipo de solo & \\
- Nitrogênio orgânico
\end{tabular}

- Número de parcelas da área agricultável

- É uma grande propriedade?

- A propriedade possui mais de 200 hectares?

Tamanho da propriedade

- Grupo 2: Tamanho da propriedade

\begin{tabular}{lc}
\hline - Graus-dia acumulados da estação de crescimento, de 1971 a 2000 & Temperatura \\
\hline - Tempo de contrato & Tempo de contrato \\
- Duração/longevidade do programa & \\
\hline - Ocupação & \\
- Área predominantemente agrícola? & Uso do solo \\
- O respondente cultiva soja? & \\
- Grupo 6: Uso principal do solo & \\
- O agricultor planta na propriedade? & \\
\hline
\end{tabular}

Fonte: Elaboração própria

Uma variável que apareceu com certa frequência e que não consta acima foi a renda (LIU, 2011; LAYTON; SIIKAMÄKI, 2009; MATTA; ALAVALAPATI; MERCER, 2009; FIGUEROA et al., 2016; THACHER; LEE; SCHELHAS, 1996; LUZAR; DIAGNE, 1999; ZBINDEN; LEE, 2005; DEFRANCESCO et al., 2008; RUTO; GARROD, 2009; BROCH; VEDEL, 2012; GUO et al., 2014; JIANG; KOO, 2014; MURPHY et al., 2014). É bastante compreensível que essa variável influencie na participação de programas de PSA, no entanto, ela não é passível de ser obtida facilmente, pois o valor não é conhecido para os proprietários não-respondentes do questionário e, portanto, não é adequada para um modelo preditivo.

Assim, tendo em vista o objetivo de extrair variáveis especializadas que se encaixassem nos grupos do Quadro 2, a busca por dados abrangeu diversas bases: IBGE (2015a), que contém os principais levantamentos oficiais em âmbito nacional, Fundação SEADE (2016), com dados em âmbito estadual, SoilGrids (HENGL et al., 2017), que contém informações

\footnotetext{
18 As referências podem ser encontradas no Apêndice A, onde constam todas as variáveis encontradas
} 
pedológicas na resolução de 250m, Serviço Geológico dos Estados Unidos (USGS, 2017), que disponibiliza diversas informações espaciais em âmbito global, o DataGEO (SÃO PAULO, 2016), que centraliza a disponibilização de dados estaduais no estado de São Paulo, WorldClim (FICK; HIJMANS, 2017), com dados climáticos, o sistema i3geo do Ministério do Meio Ambiente (MMA, 2017), o INCRA (2017), com a base de dados dos módulos fiscais por município, o levantamento das erosões paulistas por DAEE/IPT (2012), a série Produção Agrícola Municipal (IBGE, 2015c) e Produto Interno Bruto dos Municípios (IBGE, 2012), ambas do IBGE, a base de rodovias do Departamento Nacional de Infraestrutura de Transportes (DNIT, 2017), além da própria base de dados do CAR.

As variáveis candidatas foram derivadas a partir dos dados encontrados nessas fontes. Alguns dados, mesmo não citados no Quadro 2, foram também adicionados como candidatos. Tal adição se justifica, em primeiro lugar, por nenhum dos modelos levantados ter utilizado ferramentas de geoprocessamento para a extração das variáveis, enquanto algumas variáveis só podem ser obtidas dessa forma. Ou seja, o fato de uma variável (por exemplo, a face para qual a propriedade está virada) não ter sido utilizada não necessariamente implica em ela ser irrelevante para o modelo. Além disso, a disponibilidade de dados na escala adequada é escassa e, considerando que houve um critério objetivo para a seleção das variáveis mais adequadas dentre todas candidatas, optou-se por não descartar os dados encontrados. No Apêndice B são apresentadas as variáveis obtidas e os respectivos grupos a que se adequam. Os grupos não levantados na literatura aparecem em itálico. A estrutura das pastas utilizadas na pesquisa é mostrada no Apêndice C. A pasta 'arquivos' contém todos os dados utilizados e a paste 'Modelo', uma parte dos arquivos escritos para o trabalho.

\subsection{Diagnóstico}

A execução dos procedimentos descritos na seção 4.2.5 selecionou a melhor opção dentre os modelos considerados. Sendo $y_{i j}$ a $i$-ésima observação $(i=1,2,3,4)$ do $j$-ésimo $(j=1,2, \ldots, J)$ respondente, o modelo descrito pelas expressões $5.1,5.2$ e 5.3, com os coeficientes da Tabela 6 foi selecionado. Nessa tabela o símbolo de dois pontos (:) representa uma interação. 


$$
\begin{aligned}
& Y_{i j} \mid \gamma_{1 j}, \gamma_{2 j} \stackrel{\text { ind }}{\sim} \operatorname{BEINF} 0\left(\mu_{i j}, \sigma_{i j}, \nu_{i j}\right) \\
& \operatorname{logit}\left(\mu_{i j}\right)=\beta_{1}+\text { pagamento }_{i j} \cdot\left(\beta_{2}+\text { percentual_app } p_{j} \cdot \beta_{3}+\text { percentual }_{-} R L_{j} \cdot \beta_{4}\right)+ \\
& \text { tempo }_{i j} \cdot\left(\beta_{5}+\text { percentual_veg } j \cdot \beta_{6}+\text { vadic_agrop_bruto } j \cdot \beta_{7}+\text { centroide_ }_{j} \cdot \beta_{8}+\right. \\
& \text { densidade_erosao } \left.j \cdot \beta_{9}\right)+\gamma_{1 j} \\
& \operatorname{logit}\left(\sigma_{i j}\right)=\beta_{10}+\text { bioma }_{j} \cdot \beta_{11}+\text { pagamento }_{i j} \cdot\left(\text { vadic_agrop_perc_total }_{j} \cdot \beta_{12}+\right. \\
& \text { renda_bruta_maior }{ }_{j} \cdot \beta_{13}+\text { precipitacao_media_mm } m_{j} \cdot \beta_{14}+ \\
& \text { percentual_disponivel } \left._{j} \cdot \beta_{15}+\text { bioma }_{j} \cdot \beta_{16}\right)+ \text { tempo }_{i j} \cdot\left(\text { percentual_RL_vegetada }_{j} \cdot \beta_{17}+\right.
\end{aligned}
$$

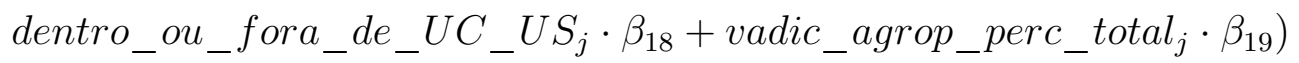

$$
\begin{aligned}
& \log \left(\nu_{i j}\right)=\beta_{20}+\text { percentual_argila_superficie }{ }_{j} \cdot \beta_{21}+\text { rend_emprego_agro }{ }_{j} \cdot \beta_{22}+ \\
& \text { pagamento }_{i j} \cdot\left(\beta_{23}+\text { grande_ou_pequena }_{j} \cdot \beta_{24}+\text { insolacao_janeiro_kWh.m } 2_{j} \cdot \beta_{25}+\right. \\
& \text { percentual_app_vegetad } a_{j} \cdot \beta_{26}+c r 2011 \_p e r c \_p e c_{j} \cdot \beta_{27}+p H \_ \text {superficie }_{j} \cdot \beta_{28}+ \\
& \text { temperatura_media_10.celsius } \left.{ }_{j} \cdot \beta_{29}\right)+\gamma_{2 j} \\
& \gamma_{1 j} \sim \mathcal{N}\left(0, \sigma_{s_{1}}^{2}\right) \\
& \gamma_{2 j} \sim \mathcal{N}\left(0, \sigma_{s_{2}}^{2}\right)
\end{aligned}
$$

em que a função logit, dada por $\operatorname{logit}(x)=\log \left(\frac{x}{1-x}\right)$, tem como inversa $\operatorname{logit}^{-1}(x)=$ $\frac{1}{1+\exp (-x)}$, e a função $\log$ tem como inversa a função exponencial.

Na nomenclatura adotada, as variáveis obtidas pelo IBGE contém o índice $j$, como se variassem por propriedade, o que não acontece na prática. Porém, como não foi considerado um efeito aleatório no nível de município (isso é, não foi modelada uma eventual dependência existente entre propriedades de um mesmo município), o modelo foi estabelecido com essa característica. Outra característica importante do modelo é a presença de interações. Pode-se interpretar que tanto o tempo como o valor possuem como coeficiente um preditor linear composto pelas demais variáveis mais um intercepto. A consideração das interações como preditoras torna o modelo mais realístico, pois permite que as variáveis levantadas sejam consideradas não somente na parte constante associada a cada resposta - isso é, a parte que não varia independente do contrato proposto -, mas também na parte variável - isso é, na variação da resposta em função da alteração do tempo ou pagamento proposto.

Nota-se na Tabela 6 que a maioria dos coeficientes selecionados são estatisticamente significantes. A interpretação dos coeficientes no modelo proposto não é intuitiva, pois é necessário considerar que cada um dos parâmetros possui uma função de ligação e que os valor esperado e a probabilidade de não participação também dependem dessas funções

19 É necessário tratar com cuidado os valores $p$ quando na presença de funções de suavização ou de efeitos aleatórios (STASINOPOULOS; RIGBY et al., 2007), mas eles foram aqui incluídos para darem apenas uma noção geral da significância dos parâmetros. 
Tabela 6 - Coeficientes do modelo estatístico escolhido

\begin{tabular}{|c|c|c|c|c|}
\hline & Estimativa & Erro-padrão & Estatística $t$ & valor $p^{19}$ \\
\hline \multicolumn{5}{|c|}{$\mu$} \\
\hline (Intercepto) & $-1,61622$ & 0,04449 & $-36,326$ & 0,0000 \\
\hline pagamento $(p)$ & 0,05508 & 0,04876 & 1,129 & 0,2590 \\
\hline$p: p e r c e n t u a l \_a p p$ & 3,97284 & 0,08877 & 12,313 & 0,0000 \\
\hline$p:$ percentual_RL & $-2,38970$ & 0,13675 & 21,591 & 0,0000 \\
\hline tempo $(t)$ & 1,09309 & 0,10156 & $-8,110$ & 0,0000 \\
\hline$t:$ percentual_veg & 2,95258 & 0,12307 & $-7,969$ & 0,0000 \\
\hline$t:$ vadic_agrop_bruto & $-0,82371$ & 0,14606 & 27,200 & 0,0000 \\
\hline$t:$ centroide_ $x$ & $-0,98083$ & 0,10026 & $-23,835$ & 0,0000 \\
\hline$t:$ densidade_erosao & 1,32616 & 0,12572 & 10,549 & 0,0000 \\
\hline$\sigma_{s 1}^{2}$ & 1,6191 & & & \\
\hline \multicolumn{5}{|c|}{$\sigma$} \\
\hline (Intercepto) & $-0,03555$ & 0,15977 & $-0,222$ & 0,8240 \\
\hline bioma & $-1,27328$ & 0,16758 & $-7,598$ & 0,0000 \\
\hline$p: v a d i c \_a g r o p \_p e r c \_t o t a l$ & 2,61690 & 0,29614 & 8,837 & 0,0000 \\
\hline$t:$ percentual_RL_vegetada & $-1,38276$ & 0,15498 & $-8,922$ & 0,0000 \\
\hline$t:$ dentro_ou_for $\bar{a} \_d e_{-} U C_{-} U S$ & 0,74842 & 0,17258 & 4,337 & 0,0000 \\
\hline$p:$ renda_bruta_maior & $-2,00935$ & 0,37815 & $-5,314$ & 0,0000 \\
\hline$t: v a d i c \_a g r o p \_p e r c \_t o t a l$ & $-2,43097$ & 0,32587 & $-7,460$ & 0,0000 \\
\hline$p:$ precipitacao_media_mm & $-1,36951$ & 0,27446 & $-4,990$ & 0,0000 \\
\hline$p:$ percentual_tisponivel & $-3,08102$ & 0,26437 & $-11,654$ & 0,0000 \\
\hline$p:$ bioma & 2,56484 & 0,24918 & 10,293 & 0,0000 \\
\hline \multicolumn{5}{|c|}{$\nu$} \\
\hline (Intercepto) & 2,6374 & 0,7266 & 3,630 & 0,0003 \\
\hline$p$ & $-9,5961$ & 1,1192 & $-8,574$ & 0,0000 \\
\hline percentual_argila_superficie & 10,2530 & 1,3553 & 7,565 & 0,0000 \\
\hline rend_emprego_agro & $-14,2453$ & 1,9461 & $-7,320$ & 0,0000 \\
\hline$p:$ grande_ou_pequena & $-13,6097$ & 0,8124 & $-16,751$ & 0,0000 \\
\hline$p:$ insolacao_janeiro_kWh.m 2 & 53,4746 & 2,2227 & 24,059 & 0,0000 \\
\hline$p:$ percentual_app_vegetada & $-17,2668$ & 1,2960 & $-13,324$ & 0,0000 \\
\hline$p: c r 2011 \_p e r c \_p e c$ & $-12,8195$ & 1,2622 & $-10,156$ & 0,0000 \\
\hline$p: p H_{\text {_ superficie }}$ & 30,4698 & 2,0443 & 14,905 & 0,0000 \\
\hline$p:$ temperatura_media_10.celsius & $-31,2217$ & 2,0347 & $-15,345$ & 0,0000 \\
\hline$\sigma_{s 2}^{2}$ & 10,00527 & & & \\
\hline
\end{tabular}

de ligação (vide 4.2). Um resultado relevante é que a seleção de variáveis não manteve o tempo e suas interações para o parâmetro $\nu$, do qual deriva a obtenção da probabilidade de não participação. Isso significa que o pagamento apresentou maior influência sobre a decisão dos proprietários em participarem ou não dos programas propostos. Considerando a interpretação das interações como mencionada no parágrafo anterior, a análise do parâmetro $\mu$ mostra que a relação entre o valor esperado do percentual de participação com o tempo se altera conforme variam no município o valor adicionado da agropecuária e na propriedade, o percentual de vegetação, a longitude e a densidade de erosão.

O modelo escolhido é complexo no sentido de possuir dois interceptos aleatórios e um número elevado de parâmetros. Isso demanda um diagnóstico detalhado de suas características para que seja verificada sua adequabilidade aos dados. Como mencionado 
na seção 4.2.5, o diagnóstico dos resíduos é dependente da semente aleatória adotada e a hipótese a ser testada é a de que eles seguem uma distribuição normal padrão. $\mathrm{O}$ gráfico do valor $p$ do teste de Shapiro-Wilk para a normalidade dos resíduos versus a semente aleatória utilizada (Figura 13) evidencia que não se pode rejeitar a hipótese nula de normalidade na maioria dos casos, pois os valores são superiores aos pré-determinados em muitas ocasiões. Em números, o valor $p$ do teste se mostrou superior a 0,001 em 95,67\% das 10000 sementes utilizadas, a 0,01 em $67,24 \%$ e a 0,05 , em $26,07 \%$ das vezes. Esta figura é o principal diagnóstico do modelo, pois mostra que para a grande maioria de sementes aleatórias adotadas o pressuposto de normalidade é plausível. Como descrito na seção de metodologia, foi feita a apresentação dos gráficos de diagnóstico considerando uma semente aleatória que retornou um valor intermediário (entre as linhas de valor $p$ igual a 0.05 e 0.01) dos resultados para fins de ilustração.

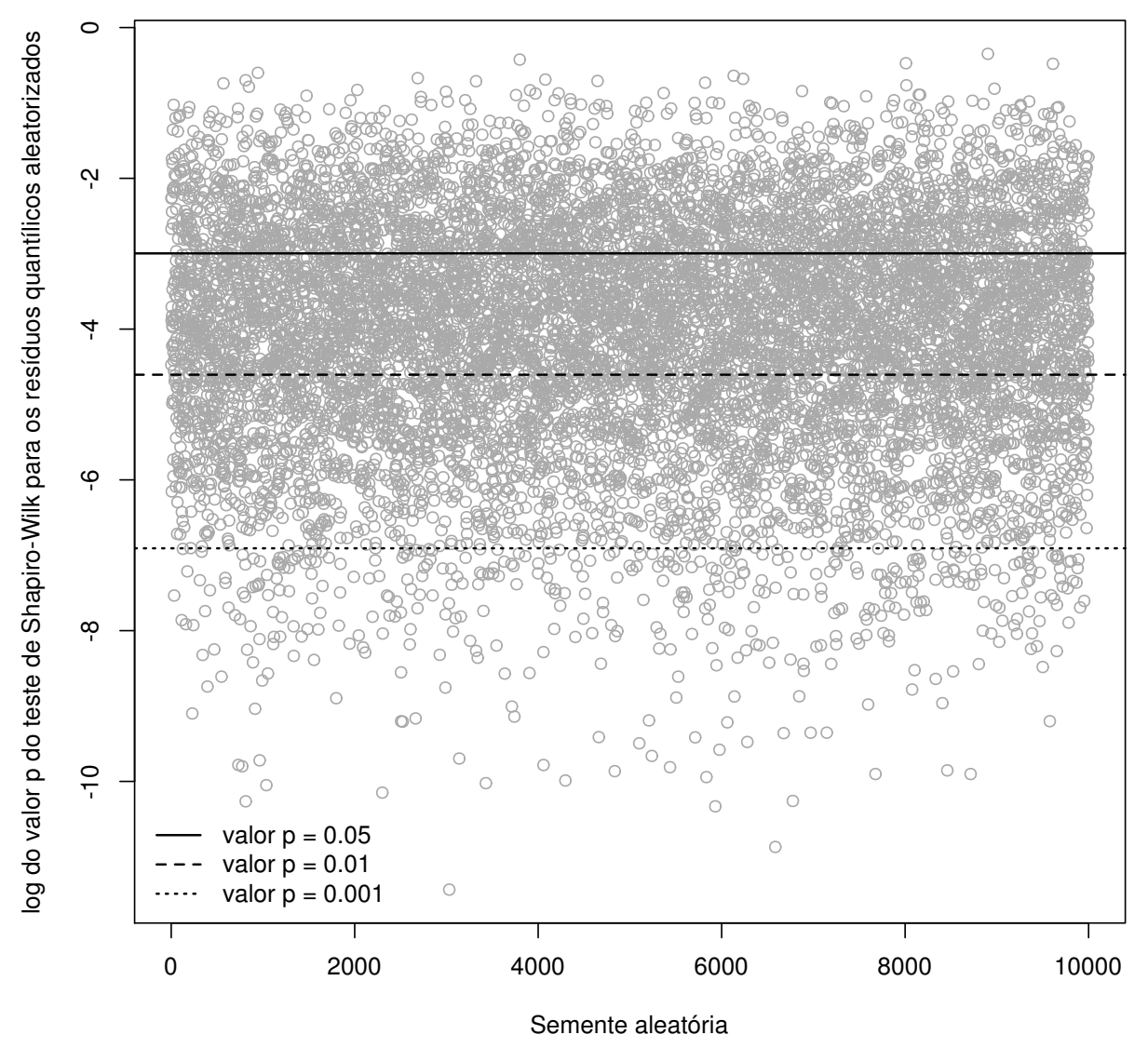

Figura 13 - Gráfico do valor $p$ do teste de Shapiro-Wilk para a normalidade dos resíduos versus a semente aleatória utilizada

Fonte: Elaboração própria

Como mostrado acima, a normalidade dos resíduos não ocorre apenas quando é escolhida uma semente aleatória adequada para tal. A sobreposição do histograma dos resíduos com a função densidade de probabilidade da normal padrão também indica que 
a aproximação é adequada (Figura 14) e o gráfico dos resíduos contra o índice das observações não mostra nenhum padrão, como também é esperado no caso de um modelo bem ajustado (cf. Ferrari e Cribari-Neto (2004)).

a) Histograma dos resíduos

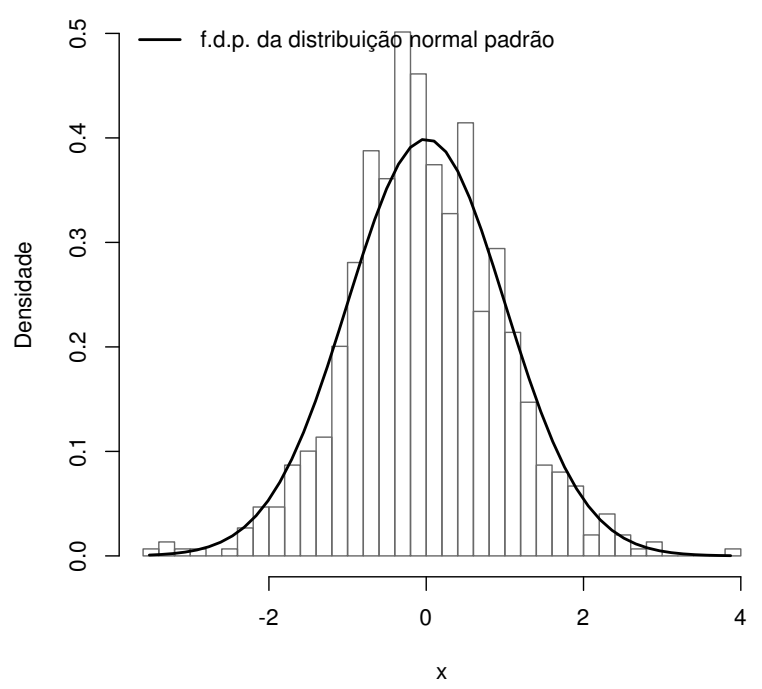

b) Resíduos vs. índice das observações

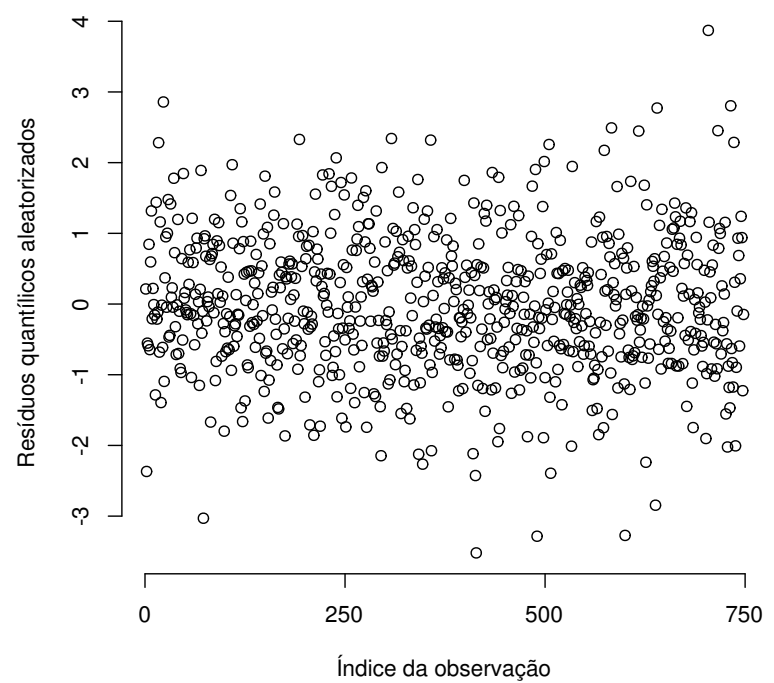

Figura 14 - Gráficos de diagnóstico do modelo: à esquerda (a), o histograma dos resíduos e à direita (b), os resíduos plotados versus o índice das observações

Fonte: Elaboração própria

A visualização dos resíduos pelo QQ-plot e o worm plot também indicam que a distribuição dos resíduos é bem aproximada por uma distribuição normal padrão. No worm plot, as semi-circunferências indicam os intervalos de confiança para o desvio do quantil empírico da distribuição dos resíduos em relação aos quantis teóricos da distribuição normal padrão. Como mostrado na Figura 15, a grande maioria dos pontos fica próxima da linha horizontal central. Este padrão nos dados indica que o modelo foi capaz de ajustar todas as características da distribuição da variável-resposta, como a média, a variância, a assimetria e a curtose (BUUREN; FREDRIKS, 2001).

Outro diagnóstico bastante relevante para a presente pesquisa, que possui o intuito de aplicar o modelo preditivo, é o worm plot dos resíduos para diferentes intervalos das variáveis preditoras. A Figura 16 mostra que, para diferentes intervalos das variáveis tempo e pagamento propostos, os resíduos ficam dentro dos intervalos de confiança da distribuição normal padrão. Isso significa que o modelo está corretamente ajustado para todo o intervalo dessas duas variáveis, que são as mais importantes para as predições realizadas. A única violação encontrada de maior magnitude parece ser para o caso de tempo proposto pequeno com valor proposto alto, indicando que essa combinação deve ser analisada com cautela.

Como explicado na seção metodológica, o modelo foi pensado de forma a contornar a maioria dos principais empecilhos não considerados por outros trabalhos encontrados 
a) QQ-plot dos resíduos

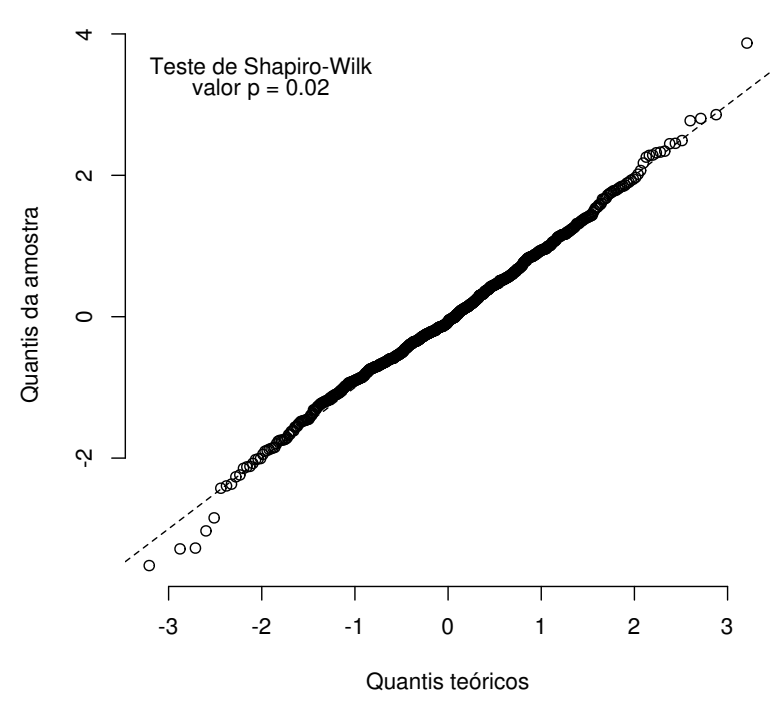

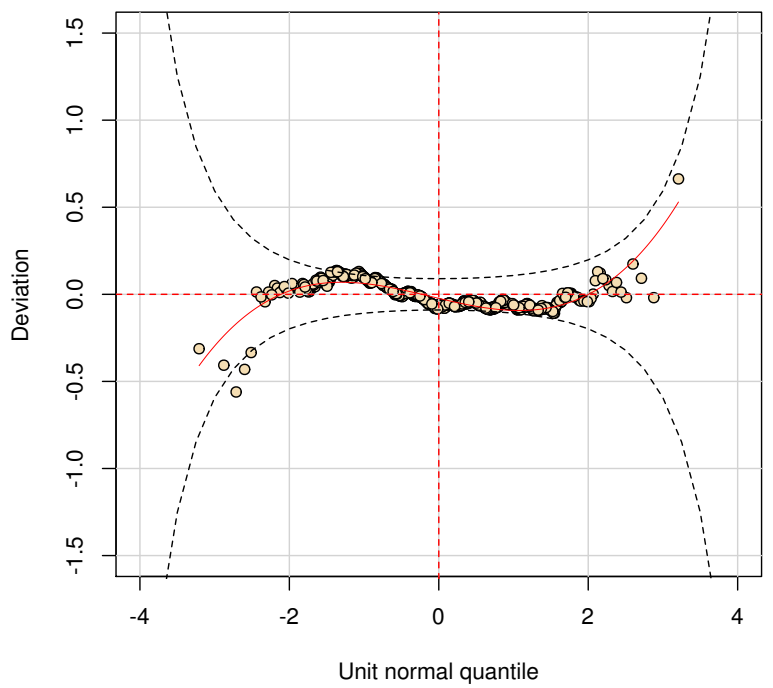

Figura 15 - Gráficos de diagnóstico do modelo: à esquerda (a), o QQ-plot dos resíduos e à direita, o worm-plot

Fonte: Elaboração própria

na literatura e a principal conclusão obtida a partir dos gráficos anteriores é a de que o modelo proposto apresenta um bom ajuste aos dados. Assim, a complexidade adicional imposta pela adição de efeitos aleatórios e pela utilização de outra distribuição para a variável-resposta parece ser, neste ponto, justificável.

Também realizou-se o diagnóstico da capacidade preditiva do modelo, que é de grande interesse para a pesquisa, uma vez que o objetivo final decorre da realização de predições. O boxplot dos resíduos puros das predições do modelo por meio da técnica leave-one-out são apresentados na Figura 17. Nota-se que valores bastante estreitos caracterizam os quantis de $25 \%$ e $75 \%$. Metade das predições possui um erro absoluto de até $13,81 \%$ em relação ao valor verdadeiro e $70 \%$ das predições possuem um erro absoluto de até $24,58 \%$. Considerando a complexidade do problema modelado, esses valores podem ser considerados bons para as análises.

Também merece destaque o resultado de que a média dos resíduos puros é bastante próxima de zero, indicando que as predições superestimadas compensam as subestimadas e vice-versa. Esta informação em conjunto com o fato de que a correlação entre os resíduos puros e a área disponível das propriedades é 0,06559 - bem próxima de zero -, significa que a somatória do produto entre as áreas disponíveis e os percentuais preditos deve ficar próxima do valor verdadeiro. Conforme mostrado na Figura 17, à direita, o valor real caiu dentro do intervalo de confiança de $99 \%$ do valor esperado predito. Em outras palavras, o modelo conseguiu oferecer uma boa estimativa do valor verdadeiro para os proprietários não observados em seu ajuste. Ainda assim, o valor observado ficou bastante próximo do limite inferior do intervalo de confiança e pode-se considerar que há 


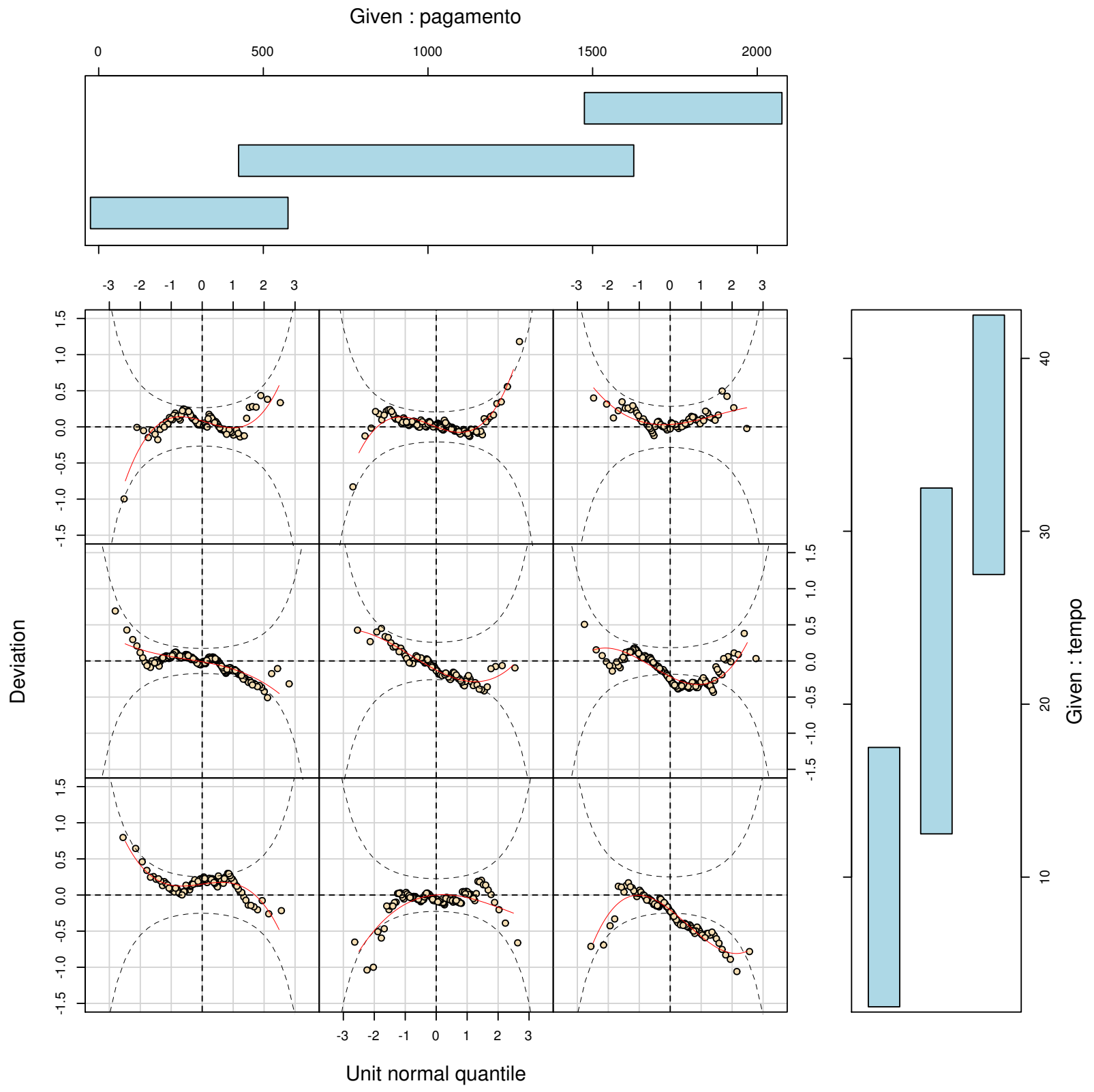

Figura 16 - Gráficos de diagnóstico do modelo: worm-plot para diferentes intervalos das variáveis preditoras tempo e pagamento propostos no questionário

Fonte: Elaboração própria

alguma superestimação na área predita. Considerando os demais resultados obtidos e que serão apresentados na seção 5.4, esse fator não foi visto como um problema. Portanto, a capacidade preditiva do modelo também foi considerada suficientemente adequada para a aplicação no âmbito da população de proprietários rurais paulistas.

\subsection{Predições}

As apresentações individualizadas são apresentadas na Figura 18. Essa visualização não possibilita a apresentação do intervalo de confiança dos valores preditos e percebe-se tam- 
Boxplot dos resíduos puros da predição da participação

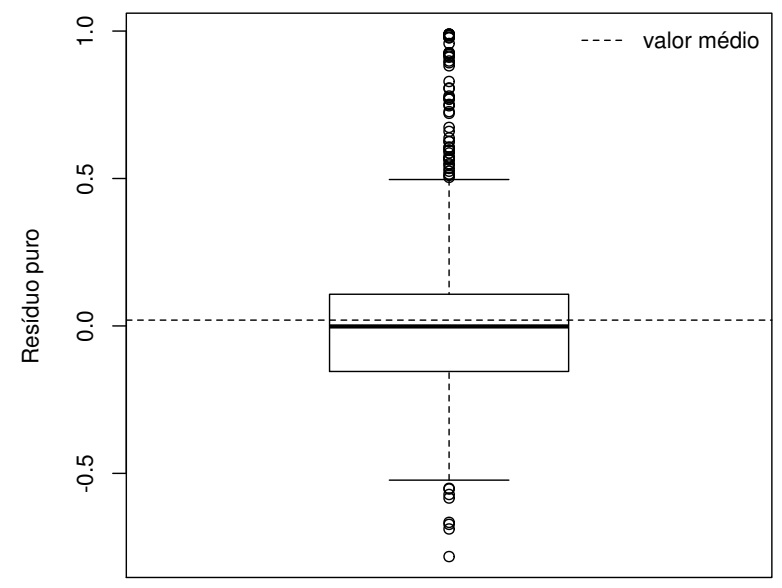

Histograma da área total predita

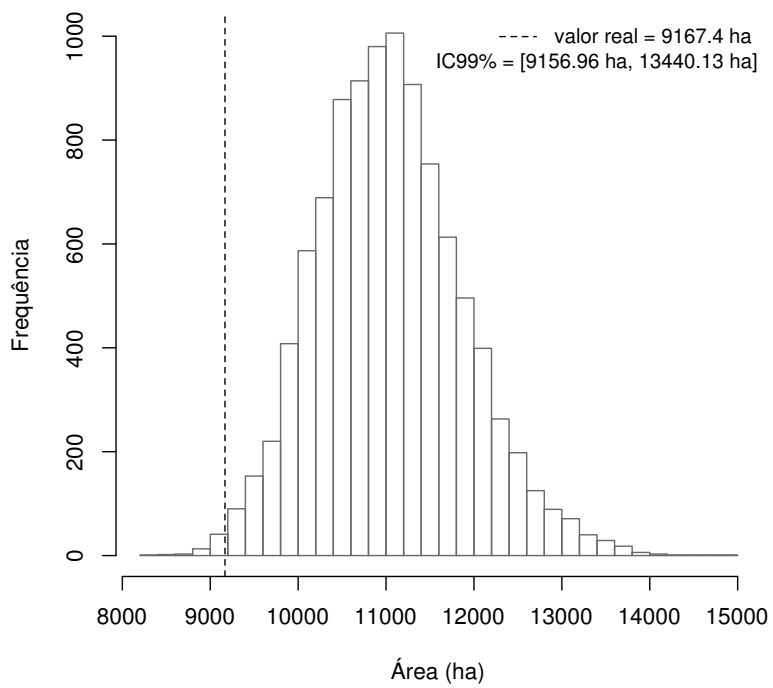

Figura 17 - Gráficos de diagnóstico da predição do modelo: à esquerda (a), boxplot dos resíduos puros preditos e à direita (b), a área total predita com o intervalo de confiança de $99 \%$

Fonte: Elaboração própria

bém que alguns municípios não aparecem na base de predição, o que decorre da inexistência de dados em nível municipal para esses locais e dos cortes na base feitos e descritos na seção metodológica. Essa figura logo evidencia dois resultados importantes: em primeiro, a visualização espacial das predições de participação no estado não permite a detecção de nenhum padrão muito claro, sendo a distribuição dos valores preditos bastante heterogênea. A única tentativa nesse sentido é a combinação de pagamento $1000 \mathrm{R} \$$.ha/ano e tempo 40 anos, que parece evidenciar uma maior concentração de propriedades não dispostas a participar na região nordeste do estado, mas esse padrao não é tão acentuado a ponto de caracterizar uma tendência geral. A implicação direta desse resultado no âmbito da elaboração de políticas é de que não há uma região do estado para a qual um programa de PSA para restauração seja mais eficaz do que para as demais.

Considerando essas participações individuais no âmbito estadual, a Figura 19 apresenta a superfície da área resultante de participação resultante da variação do tempo de contrato e o pagamento propostos. Essa visualização tridimensional também não apresenta os intervalos de confiança das predições, mas facilita uma compreensão mais abrangente da decisão dos proprietários.

Percebe-se que tanto o crescimento do tempo quanto do pagamento estão relacionados, no geral, com respostas mais positivas dos proprietários, o que pode ser percebido pelo aumento da área total de participação. A variação unitária da participação relacionada à variação unitária do pagamento cresce à medida em que o tempo proposto também aumenta. Isso pode ser percebido mais nitidamente comparando as curvas de tempo igual a 5 e 40 anos. Na prática, isso significa, com a mesma variação no pagamento proposto, a disposição à participação é maior quando valores mais altos de tempo são propostos. 

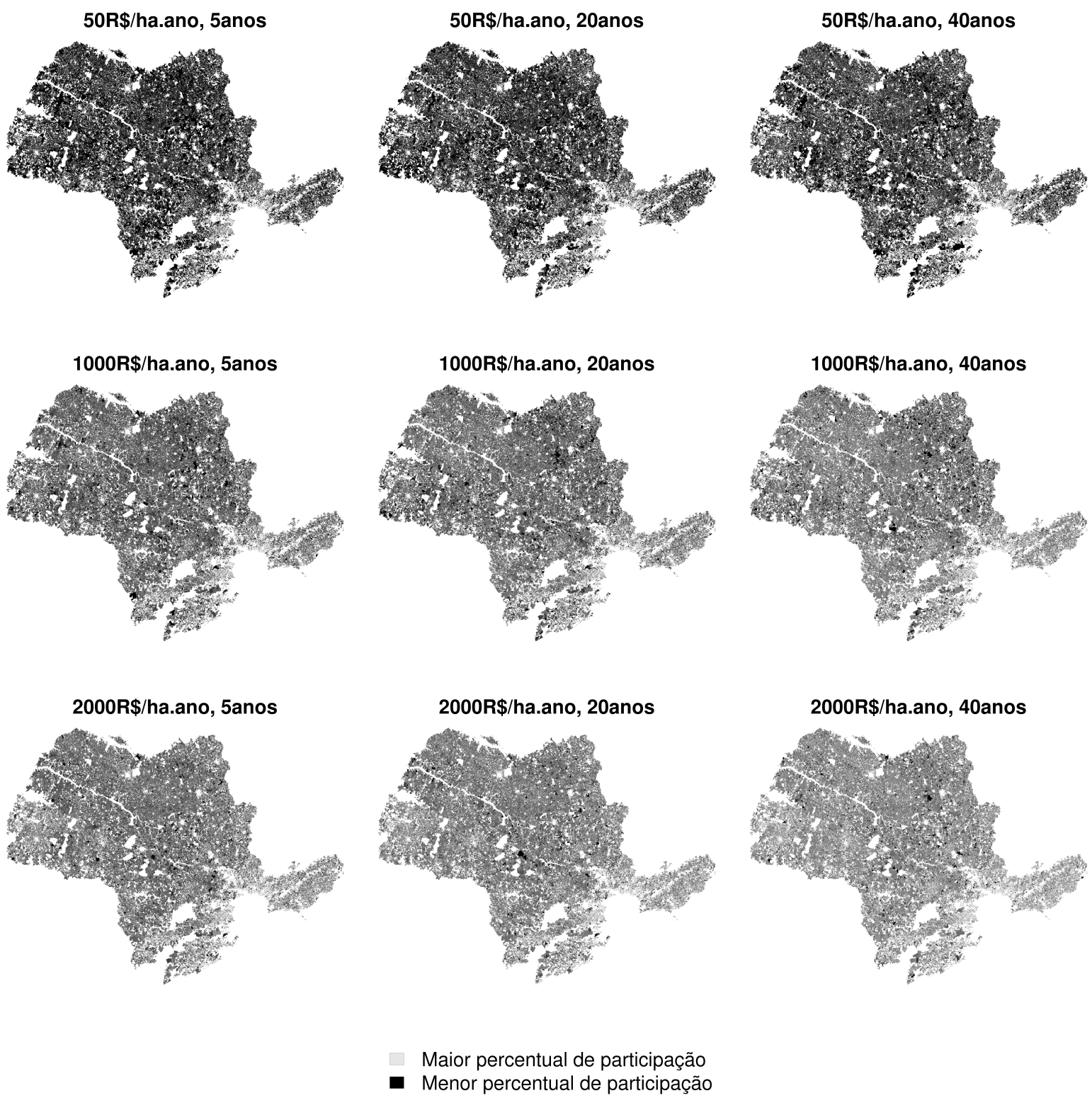

Figura 18 - Predições da disposição à participação espacializadas

Fonte: Elaboração própria

Efeito semelhante parece ocorrer para a variação unitária da participação quando se varia o tempo. Comparando as curvas de pagamento igual a 50 e $200 \mathrm{R} \$ /$ ha.ano, percebe-se uma inclinação muito maior na segunda do que na primeira. Sabe-se que:

Para maximizar a custo-eficácia pagamentos precisam ser dirigidos para localizações onde o maior ganho pode ser obtido por unidade de pagamento. A escolha tambem envolve os custos, contudo, e a estratégia ideal deve se beasear nos melhores tradeoffs entre esses custos e a eficiência adicionada obtida. Como a provisão do serviço ambiental é vinculada a uma localização, estratégias focadas nessas áreas com custos relativamente baixos de provisão oferecem uma solução promissora. ${ }^{20}$

(FAO, 2007, p.95)

20 Original: "To maximize cost-effectiveness, payments must be targeted to locations where the biggest 


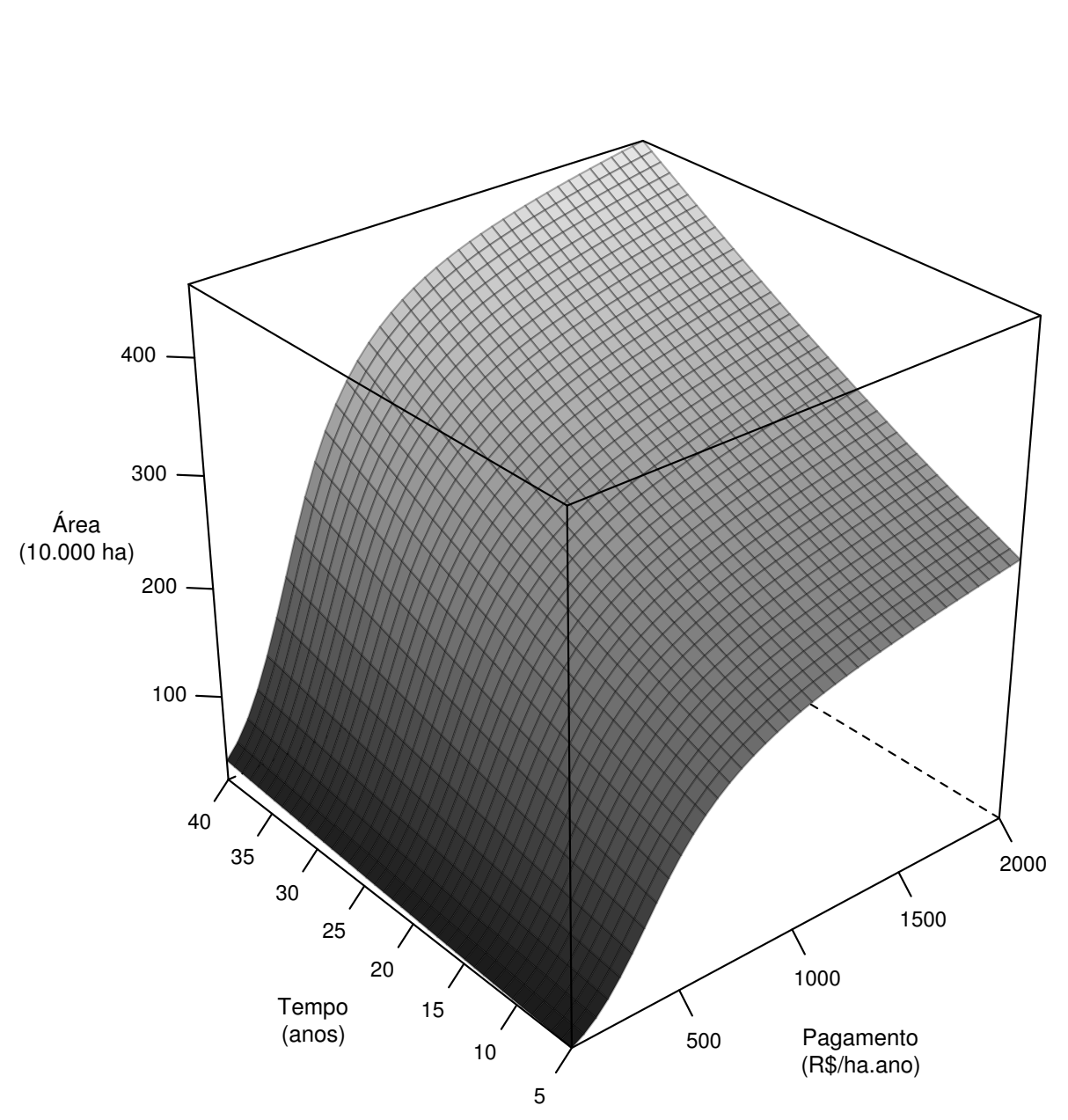

Figura 19 - Valores preditos: superfície de participação em função do tempo e pagamento propostos

\section{Fonte: Elaboração própria}

A taxa de variação da resposta em função do pagamento indica onde o maior ganho pode ser obtido por cada variação na unidade de pagamento. Como se pode ver na curva de área de participação acumulada para diferentes pagamentos propostos (Figura 20), essa taxa não é constante. Neste gráfico, o eixo vertical apresenta como varia a área total a ser restaurada em função do incremento unitário do pagamento proposto. A linha seria reta se a relação fosse direta, pois um aumento de, por exemplo, $10 \%$ no

gain can be obtained per unit of payment. Targeting also involves costs, however, and the ideal strategy must be based on the best tradeoffs between these costs and the added efficiency achieved. Because environmental service provision is linked to location, strategies aimed at areas with relatively low costs of provision offer a promising solution." 
pagamento oferecido estaria relacionado com um aumento de $10 \%$ na área total restaurada predita. Conforme mencionado anteriormente, a relação não é linear e se nota para todos os anos um padrão semelhante: o aumento do pagamento até cerca de $450 \mathrm{R} \$ /$ ha.ano seria responsável pela restauração de cerca de $50 \%$ do máximo possível de ser obtido por meio desse instrumento. De maneira análoga, um pagamento de cerca de $800 \mathrm{R} \$ /$ ha.ano está associado à restauração de cerca de 75 a $80 \%$ do total possível, a depender do tempo proposto em questão. Em termos absolutos, a região de maior custo-eficácia pode ser dividida nos valores de 450 e $800 \mathrm{R} \$ /$ ha.ano, pois as predições indicam que a área para restauração cresce rapidamente até $450 \mathrm{R} \$ /$ ha.ano e passa a diminuir após esse valor. O pagamento de $800 \mathrm{R} \$ /$ ha.ano (77,78\% maior que $450 \mathrm{R} \$ /$ ha.ano) está relacionado a um incremento de $30 \%$ (de $50 \%$ para $80 \%$ ) no percentual de área total restaurada e o crescimento é ainda mais desacelerado após esse valor. Esse resultado pode ser considerado uma diretriz importante para a elaboração de políticas de incentivos: de $800 \mathrm{R} \$$ /ha.ano em diante se torna necessária a adição de muito dinheiro para a obtenção de relativamente pouca área restaurada, pois os proprietários que optam por restaurar apenas com valores altos representam apenas uma pequena parcela de área.

A superfície da Figura 19 foi seccionada em tempos de contrato fixos e as curvas resultantes são apresentadas na Figura 21. Essa visualização permite a inclusão dos intervalos de confiança e é possível notar que eles são bastante estreitos. Os valores do eixo vertical também permitem comparar, em termos relativos, a área máxima disponível para restauração por meio desse instrumento com o valor de 14.360 .703 ha, que corresponde à área disponível dos 275.566 imóveis rurais da base sob a qual foram feitas as predições. Tendo em vista essa comparação, nota-se que as áreas máximas a serem restauradas equivalem a 17,94\% (IC 99\%: 17,74 a 18,16), 19,60\% (IC 99\%: 19,42 a 19,80), 21,40\% (IC 99\%: 21,23 a 21,58), 23,33\% (IC 99\%: 23,17 a 23,48), 25,37\% (IC 99\%: 25,23 a 25,51), 27,51\% (IC 99\%: 27,38 a 27,63), 29,73\% (IC 99\%: 29,62 a 29,85) e 32,02\% (IC 99\%: 31,92 a 32,13$)$, para $5,10,15,20,25,30,35$ e 40 anos, respectivamente.

Em conjunto com os resultados já apresentados anteriormente, de que o pagamento de $450 \mathrm{R} \$$ /ha.ano está associado à conservação de $50 \%$ da área máxima passível de restauração e de que esse valor e o valor de $800 \mathrm{R} \$ /$ ha.ano podem ser vistos como limites para a região na qual o instrumento possui maior custo-eficácia, os percentuais aqui apresentados são ainda menores. Considerando essa região mais custo-eficaz, o PSA para restauração nativa apresenta os limites de: $17,94 \% \cdot 50 \% \approx 8,97 \%$, no programa de 5 anos e $450 \mathrm{R} \$ /$ ha.ano, $17,94 \% \cdot 75 \% \approx 13,45 \%$, no programa de 5 anos e $800 \mathrm{R} \$ /$ ha.ano, $32,02 \% \cdot 50 \% \approx 16,01 \%$, no programa de 40 anos e $450 \mathrm{R} \$ /$ ha.ano, e $32,02 \% \cdot 80 \% \approx 25,62 \%$, no melhor dos cenários que é o programa de 40 anos e 800 $\mathrm{R} \$ /$ ha.ano.

Os percentuais calculados, de cerca de 13 a 26\%, parecem indicar algum potencial do PSA para a restauração de vegetação nativa nas propriedades particulares do estado de 


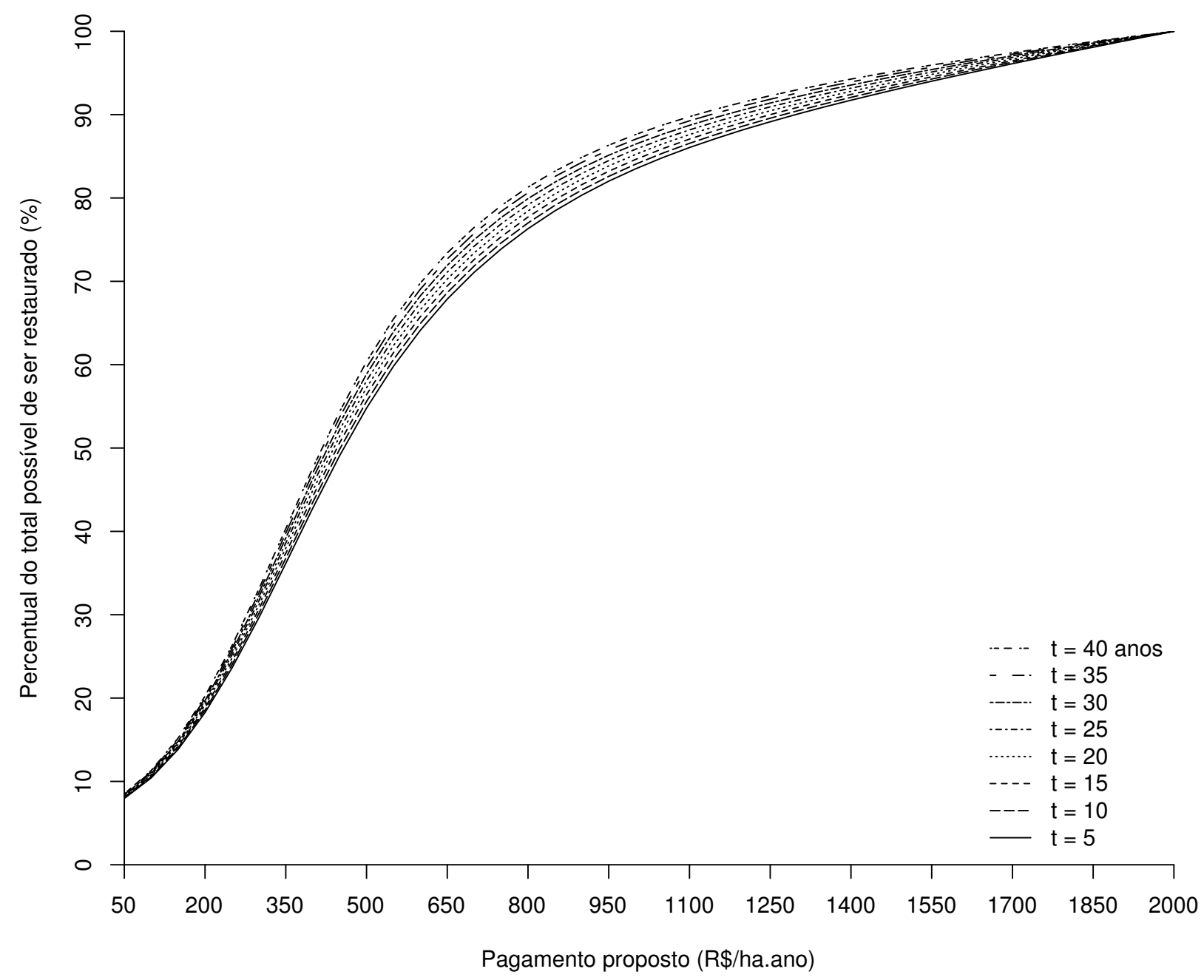

Figura 20 - Valores preditos: área de participação acumulada em função do pagamento proposto

Fonte: Elaboração própria

São Paulo. No entanto, não é possível tirar essa conclusão sem avaliar qual seria a magnitude de dinheiro necessária para sustentar um programa com os valores envolvidos. De acordo com Cellini e Kee (2015), "a maior dificuldade com a análise de custo-eficácia é que ela não providencia um valor [monetário] para o output, deixando isso ao julgamento subjetivo do elaborador de políticas". Para contornar essa subjetividade, a maneira utilizada para verificar o quão representativos são esses valores em termos de área e de valor a ser pago foi compara-los com valores relevantes de área preservada encontrados na literatura e com orçamentos públicos. A Figura 22 apresenta essa informação de forma unificada, considerando a possibilidade de execução plena dos programas propostos, isso é: todos os proprietários executariam $100 \%$ do seu potencial de participação e o proponente pagaria a todos esses proprietários.

As curvas tracejadas da Figura 22, que decrescem com o crescimento do pagamento 


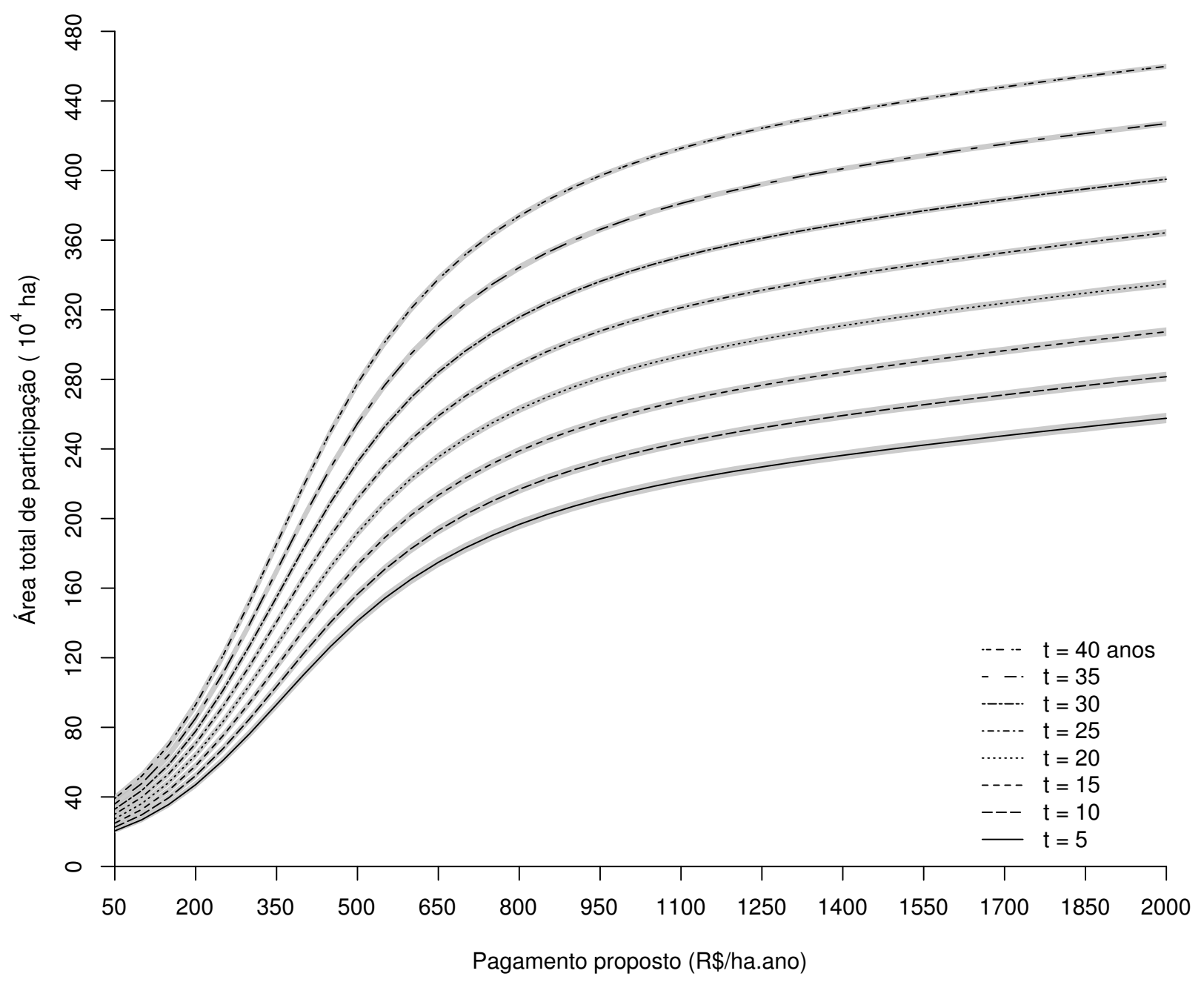

Figura 21 - Valores preditos: curvas de participação para determinados valores fixos de tempo proposto

Fonte: Elaboração própria

proposto, representam valores fixos anuais ( $\mathrm{R} \$ /$ ano) e foram adicionadas ao gráfico para permitir uma comparação da magnitude dos gastos envolvidos nos programas planejados. Essas curvas estão representadas pelas letras a até e. As linhas horizontais do gráfico representam valores fixos de área a ser restaurada, que devem servir para nortear a compreensão da magnitude das áreas obtidas com os programas. Essas linhas estão numeradas de 1 a 4 e seus valores estão em 10.000 ha, por exemplo: como a linha 4 está próximo de 400 , representa um valor próximo a 4.000.000 ha.

As primeiras curvas, a e b, estão associadas a poucos resultados e serão analisadas em conjunto. A curva a é muito insuficiente para sustentar um programa em âmbito estadual, uma vez que seus valores se localizam muito abaixo das curvas possíveis dos programas estudados. Apesar da baixa expressividade dessa curva nesse contexto, ela representa um valor bastante expressivo: o total de investimentos da Secretaria do Meio 


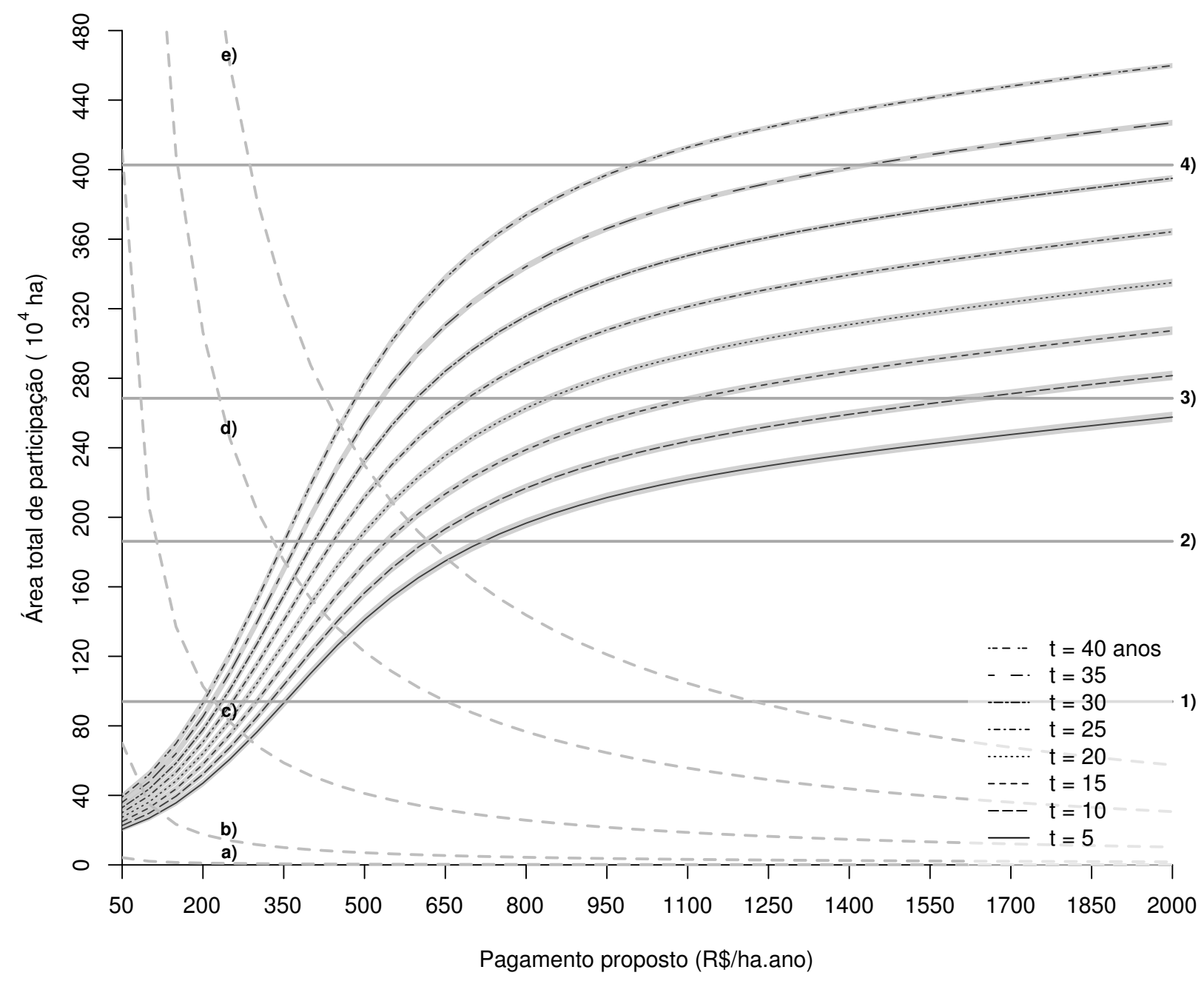

Figura 22 - Valores preditos: curvas de participação sobrepostas a valores notáveis de orçamento ou área para restauração.

A interseção das três curvas indica que um programa proposto pelo tempo representado na curva crescente seria viável para restaurar a quantidade de vegetação representada pela linha horizontal, com os recursos apresentados na curva decrescente. As linhas horizontais representam: a área das Unidades de Conservação de Proteção Integral estaduais do estado de São Paulo (1), a área de restauração necessária para o incremento do percentual de vegetação nativa do estado de São Paulo para 25\% (2), a área aproximada de APPs tornadas desprotegidas com o advento da Lei 12.641/2012 - Novo Código Florestal (3) e a área aproximada de APPs mais Reserva Legal que se tornaram desprotegidas com o advento do Novo Código Florestal (4). As curvas decrescentes representam: o total de investimentos da SMA para a restauração em 2014, o maior dos últimos cinco anos (a), o orçamento destinado para 'pessoal' da Fundação Florestal em 2017 (b), o orçamento total da Fundação Florestal em 2017 (c), o orçamento destinado ao pessoal da SMA em 2017 (d) e, por fim, o orçamento total da SMA em 2017 (e).

Fonte: Elaboração própria 
Ambiente para a restauração de vegetação no ano de 2014, R $\$ 2.096 .277,00$, o maior desses orçamentos no período 2013 2017. Situação semelhante ocorre com a curva b, cujo potencial de restauração varia entre cerca de 200.000 e 400.000 ha, a depender do tempo de contrato em questão. Essa área é bastante baixa, pois considerando toda a área disponível para a restauração no estado de São Paulo, esses valores representam apenas $200.000 / 14.360 .703 \approx 1,39 \%$ e 400.000/14.360.703 $2,79 \%$. Apesar dos baixos percentuais, o valor expresso também é bastante relevante, pois se trata de todo o orçamento da Secretaria do Meio Ambiente para 'Pessoal' (isso é, para manter os funcionários) da Fundação Florestal em 2017, R $\$ 35.001 .350,00$.

A curva c é a primeira a apresentar uma interseção com as linha horizontais, mais especificamente a linha 1. Para os programas de 30 e 35 anos de duração, a quantidade de recursos representada pela curva parecem suficientes para restaurar uma área equivalente à representada pela linha horizontal. O valor da curva c em questão é todo o orçamento da SMA destinado em 2017 à Fundação Florestal, enquanto a linha horizontal 1 representa a área das Unidades de Conservação de Proteção Integral estaduais do estado de São Paulo, de acordo com a base de dados do i3geo (MMA, 2017). Em outras palavras, seria necessário que a Fundação Florestal deixasse de existir por 30 a 35 anos para que os recursos da Secretaria fossem suficientes para convencer os proprietários rurais a restaurarem uma área equivalente à das UCs estaduais de Proteção Integral.

O objetivo de área da linha 2 é a quantidade de vegetação nativa a ser restaurada para que se atinja $25 \%$ da área estadual vegetada (o valor de área vegetada atual utilizado foi o de SMA (2009)). Esse percentual, embora elevado, ainda é inferior ao percentual de $30 \%$, que de acordo com Banks-Leite et al. (2014) é o valor limite acima do qual são obtidos muitos benefícios para a biodiversidade. Nota-se que com tempo de contrato igual a 40 anos seria necessário pouco mais do que a quantidade de recursos da curva d, que representa o orçamento da SMA destinado em 2017 à manutenção de todos seus funcionários. O mencionado estudo foi realizado para toda a Mata Atlântica e obteve que seria necessário a restauração de 32,11 milhões de hectares para se obter $30 \%$ de área de Mata Atlântica vegetada, valor considerado inviável pelos próprios autores (BANKSLEITE et al., 2014). O resultado apresentado acima mostra que mesmo em dimensões bem menores e para um percentual abaixo de 30\% (o valor da linha 2 corresponde a 1,86 milhões de hectares), a restauração parece ser inviabilizada pelo baixo orçamento ambiental.

De maneira semelhante, a linha $\mathbf{3}$, que representa a quantidade aproximada de $\mathrm{APPs}^{21}$ que deixaram de ser protegidas pela lei com o advento da Lei de Proteção de Vegetação Nativa em 2012 (cf. Sparovek et al. (2011)), necessita de mais recursos em um programa de PSA de 40 anos do que a curva e, que representa todo o orçamento da SMA em 2017. Por fim, a linha 4 representa a área de RL e APP que deixaram de ser consideradas protegidas pelo advento da Lei de 2012 e nenhum orçamento ambiental do estado de São 
Paulo o atinge. Esses resultados ressaltam a grande perda ambiental ocasionada pelo advento da nova Lei, mas mais importante que isso: indicam que se realizado de forma plena no estado de São Paulo o PSA para restauração de vegetação nativa é uma opção bastante cara e de baixa eficácia para o fim a que se propõe.

É bastante relevante dizer que a mencionada execução de forma plena abrange também uma execução fracionada cumulativa, que não parasse de pagar por áreas já restauradas pelo programa. Um exemplo dessa estratégia seria começar escolhendo 5.000 proprietários para pagar em um ano, no ano seguinte pagar esses mesmos 5.000 mais outros 5.000, no próximo os 10.000 proprietários mais outros 5.000, e assim em diante. Os valores necessários para sustentar esse programa no final do processo, quando todos os proprietários estivessem sendo abrangidos, seria o mesmo da Figura 22 e portanto essa abordagem também é inviável. Duas possíveis estratégias alternativas seriam: 1) pagar uma determinada quantidade de proprietários por um determinado tempo, terminar os contratos (finalizar os pagamentos), passar para outra quantidade de proprietários por outro determinado tempo e assim por diante; e 2) pagar a restauração de um determinado percentual da área total de participação dos proprietários por um determinado tempo, terminar os contratos (finalizar os pagamentos), passar para outro percentual e assim por diante. Ambas estratégias dividem a execução do programa em parcelas e possuem a potencialidade de demandarem menores recursos para sua execução, ao passo que aumentaria o tempo de execução.

Para avaliar a alternativa 1 mencionada acima é necessário realizar um estudo de simulação, pois o resultado depende de como é feita a seleção dos proprietários de cada etapa. Como esse estudo seria muito dispendioso, optou-se por avaliar um caso da alternativa 2, que consiste em viabilizar a execução desses programas executando o programa em parcelas. Em cada parcela, os proprietários paulistas devem restaurar e receber, em uma etapa, apenas um determinado percentual de sua participação máxima. Após o término dessa primeira etapa, o proponente pode escolher outro percentual da propriedade para executar e pagar pela restauração e assim em diante, até que um determinado objetivo de área a ser restaurada fosse atingido.

O cenário escolhido para avaliar essa estratégia 2 dentro dos limites impostos pela falta de recursos foi definindo que apenas $10 \%$ do total de área possível fosse restaurada a cada etapa do programa, com cada etapa durando cinco anos. Esse cenário foi escolhido pois a duração total do programa seria de 10 etapas $\cdot 5$ anos/etapa $=50$ anos (como a cada etapa será executado $10 \%$ do programa, 10 etapas totalizam $100 \%$ da execução). A curva desse programa deve se assemelhar à curva de tempo $=5$ anos da Figura 22 dividida por dez (Figura 23).

De fato, pagando cerca de $100 \mathrm{R} \$ /$ ha.ano o orçamento da SMA para a restauração

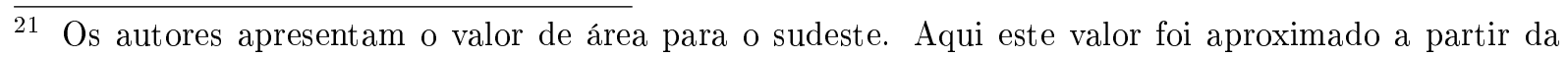
divisão da área do estado de São Paulo pela soma das áreas de todos os estados da região sudeste. 


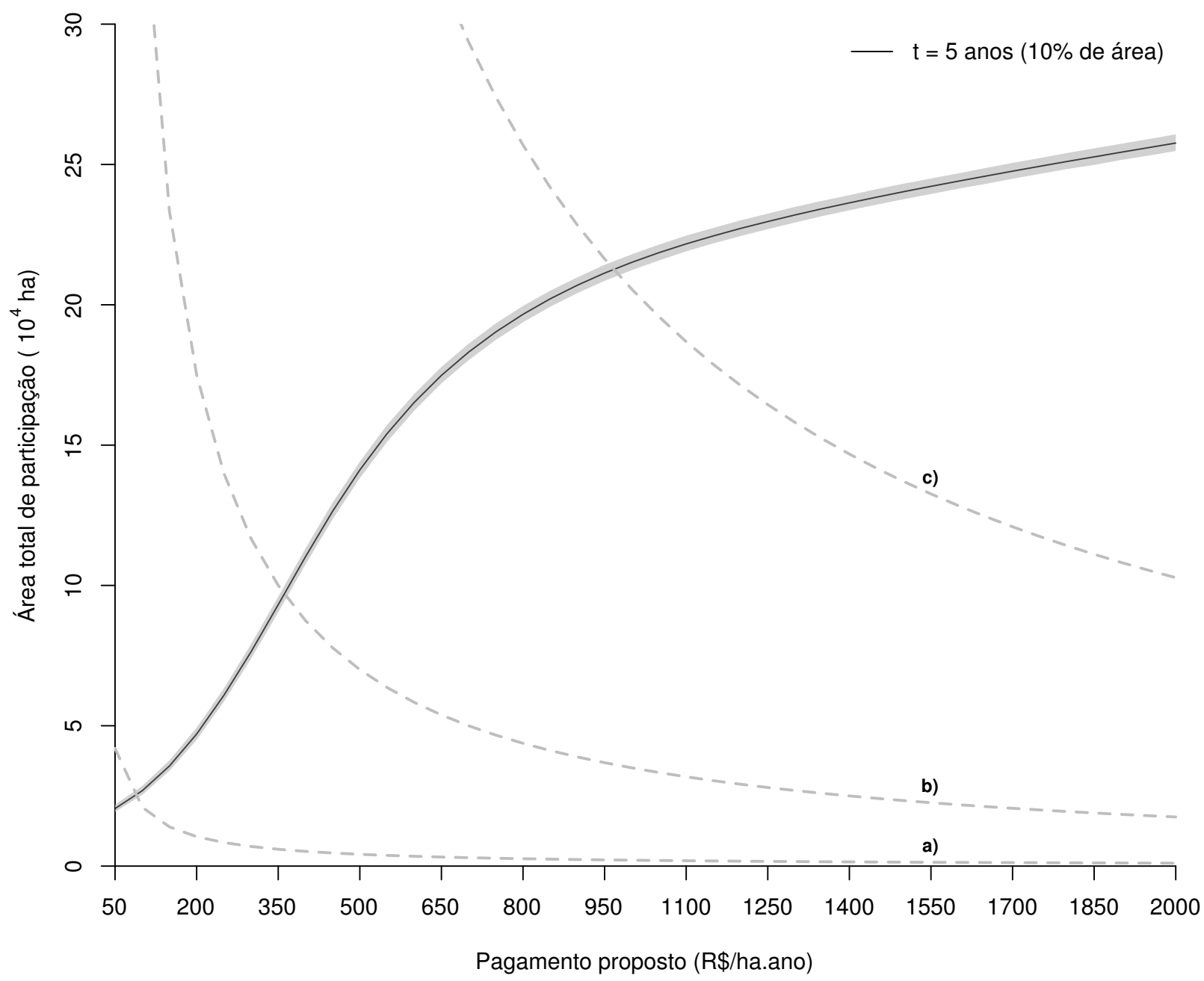

Figura 23 - Valores preditos: curva de participação de cinco anos divida por dez e sobreposta a valores notáveis de orçamento

Fonte: Elaboração própria

de vegetação (curva a) se torna viável para restaurar aproximadamente 25.000 ha a cada etapa do programa. No entanto, após as 10 etapas (10 etapas de $10 \%$ para cumprir $100 \%$ do programa proposto), teriam sido decorridos 50 anos e a área restaurada total, supondo que nenhum dos proprietários tivesse desmatado as áreas restauradas nas primeiras etapas do programa, seria de apenas 250.000 ha, o equivalente à aproximadamente um quarto da área das UCs de PI estaduais no estado de São Paulo. Ou seja, embora essa estratégia viabilize o pagamento de menores quantias de dinheiro para maiores valores de restauração (o que no caso do exemplo seria equivalente a 'puxar para cima' a curva a da Figura 22), demanda um tempo muito elevado de execução e também produz poucos resultados. Assim, embora somente um cenário tenha sido avaliado, os valores obtidos nessa avaliação e nas outras apresentadas até o momento sugerem que mesmo os cenários de execução parcelada do programa são também pouco sustentáveis. Contribui 
também para essa conclusão o fato de que na execução fracionada as áreas restauradas se tornariam desprotegidas após o término de cada etapa de execução do contrato, o que não garante que as florestas restauradas seriam mantidas.

É de suma importância recordar que todos os resultados apresentados concernem apenas os valores necessários para que os proprietários declarem interesse nos programas propostos. A execução de fato dos programas teria associado uma série de custos (e.g. custo de transação, de monitoramento, de fiscalização etc.) que deveriam aumentar ainda mais a quantia de recursos necessária. Tomando como exemplo o custo de restauração, Finney (2015) sugere a utilização de um valor próximo a 20\%, enquanto o levantamento de Alston, Andersson e Smith (2013) mostra que o valor pode variar muito, de 1 a $66 \%$ do valor total do projeto. Isso significa que os valores das figuras apresentadas mais do que dobrariam em alguns casos e isso diminuiria ainda mais a viabilidade dos programas. Também é bastante relevante recordar que os proprietários não foram informados se seriam responsabilizados pela execução da restauração ou se esta ficaria a cargo do proponente dos programas. É plausível concluir que em ambos os casos a quantidade de recursos para execução dos programas seria maior do que a prevista pelo modelo atual, pois seria necessário somar os custos de execução, caso se considere que a restauração fica a cargo do proponente, e seria possível especular que as participações declaradas seriam ainda menores caso tivesse sido anunciado no questionário que os custos estariam a cargo dos proprietários. Nesse segundo caso, as predições do modelo indicariam que maiores quantidades de recursos seriam necessárias para restaurar os mesmos valores de área.

Abaixo é apresentado o comportamento dos proprietários, segmentados a partir da estrutura fundiária. Como já foi mencionado anteriormente, o modelo não selecionou variáveis relacionadas ao tempo para a probabilidade de não participação e por esse motivo apenas a variação em relação ao pagamento é apresentada na Figura 24. As curvas apresentadas mostram que os grandes proprietários são mais propensos a aceitarem os programas, se aproximando de zero a proporção de não participantes à medida em que cresce o pagamento proposto. O mesmo padrão não ocorre para os pequenos proprietários, que parecem sempre possuir um determinado percentual de proprietários que se negam a participar.

A informação da Figura 24 é complementada com a Figura 25, que não analisa se os proprietários participariam, mas com qual qual intensidade, na média, isso deveria ocorrer. Esse cálculo varia com o tempo de contrato proposto e foi escolhido o valor intermediário (20 anos) para a exibição. A intensidade de participação dos grandes é superior em relação aos pequenos proprietários no início das curvas, mas tendem a se saturar em aproximadamente $800 \mathrm{R} \$$ / ha.ano. Por outro lado, os pequenos proprietários parecem não saturar sua participação tão rapidamente, de forma que os valores continuam a aumentar à medida em que o pagamento proposto também aumenta. Levando em conta o fato de que a base de predição é composta por 44.930 grandes proprietários $(16,30 \%$ 


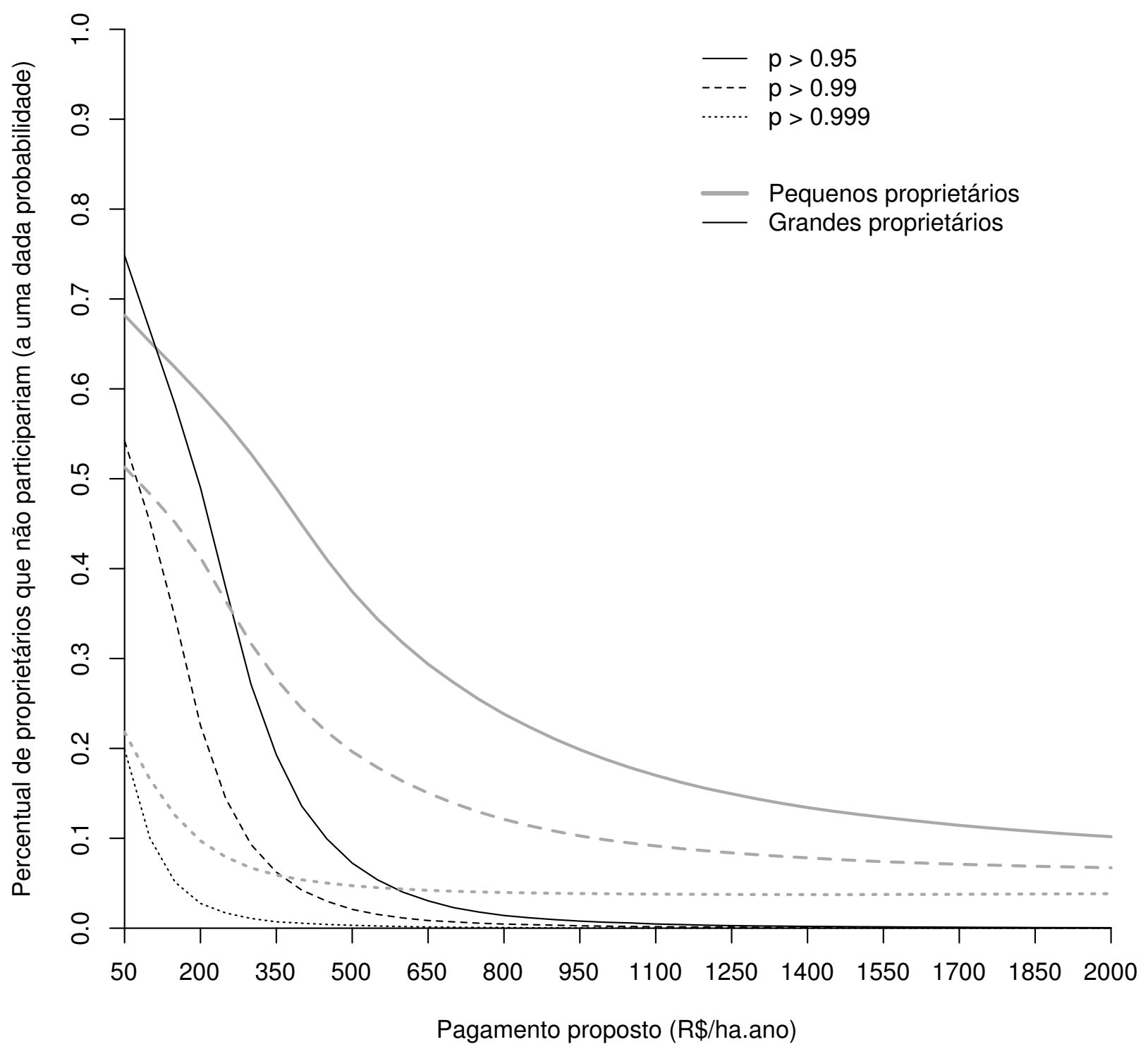

Figura 24 - Relação da probabilidade de não participação com o tamanho da propriedade Fonte: Elaboração própria

do total de proprietários) que possuem uma área disponível de 10.320 .830 ha (71,86\% do total de área disponível), isso explica o motivo pelo qual a região de maior custo-eficácia da Figura 20 termina em torno de $800 \mathrm{R} \$ /$ ha.ano: esse valor está relacionado a uma área próxima à máxima que os grandes proprietários estão dispostos a participar e após esse valor a principal fonte de incremento na área a ser restaurada pelos programas passa a ser os pequenos proprietários, que detém uma porção muito menor da área disponível no estado.

Comparando as curvas da Figura 25 com os valores absolutos de área da Tabela 7, nota-se também que as atividades com maior área disponível - agropecuária e silvicultura - são as que participam com menores áreas dos programas propostos. As atividades de 


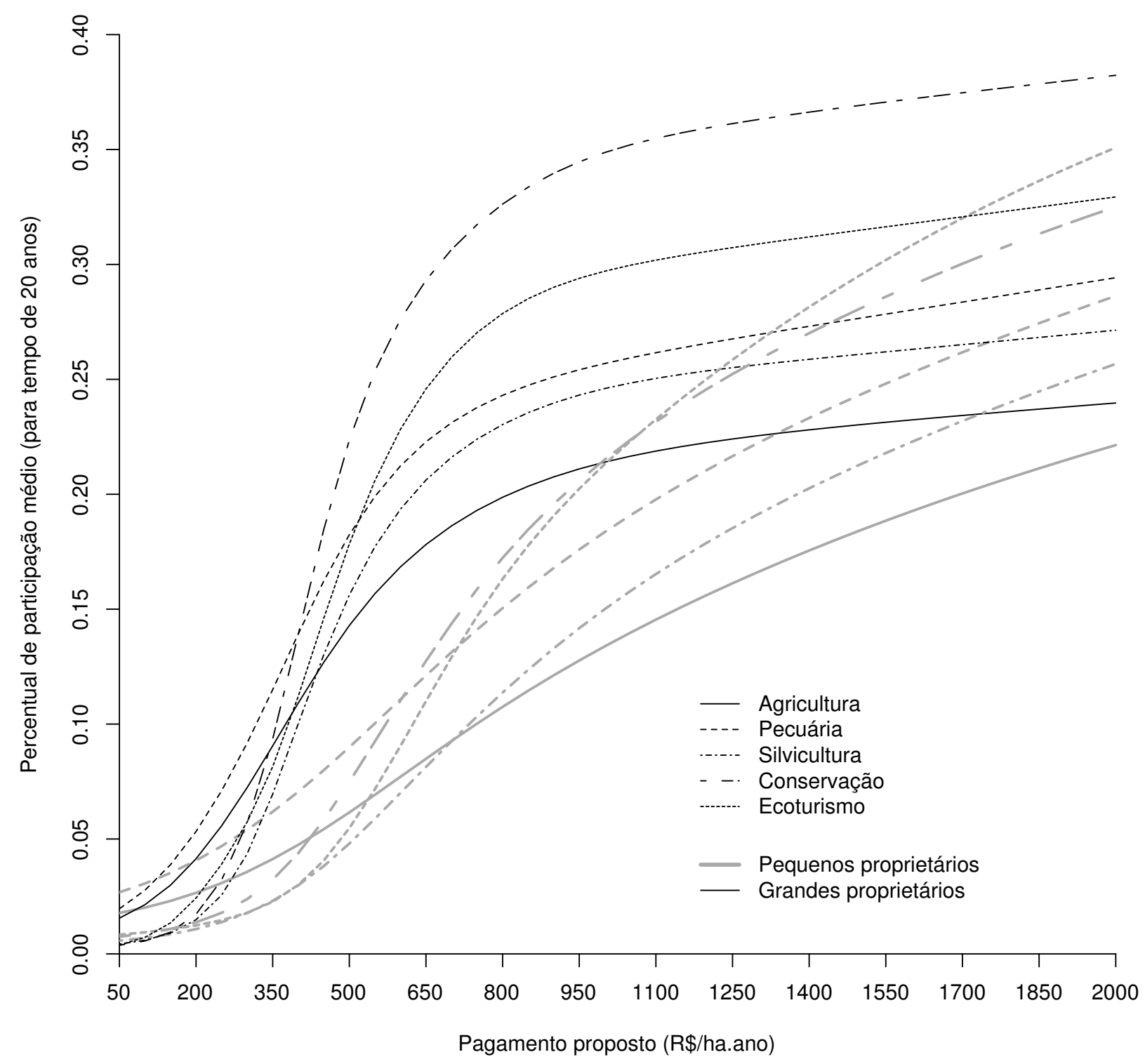

Figura 25 - Valor médio predito da participação segmentado pelo uso do solo e o tamanho da propriedade

Fonte: Elaboração própria

ecoturismo e conservação possuem intensidades médias de participação maiores, porém suas áreas disponíveis são insignificantes em relação às demais atividades. Esse resultado também aponta para a baixa eficácia do PSA, uma vez que indica que tende a induzir a conservação em áreas que já possuem uma tendência maior de conservar independentemente do recebimento de incentivos econômicos - portanto, acarretando em baixo retorno para a conservação. Nota-se também que o instrumento é pouco atrativo especialmente para a atividade agrícola, que consiste no uso do solo predominante no estado de São Paulo.

Nossos resultados encontram embasamento na literatura, pois corroboram com tra- 
Tabela 7 - Áreas disponíveis na base de predição, separado por cultura e tamanho da propriedade

\begin{tabular}{ccrr}
\hline Uso & Tamanho da propriedade & Número & Área disponível (ha) \\
\hline \hline \multirow{2}{*}{ Agricultura } & Pequena & 129.782 & $2.443 .059,04$ \\
& Grande & 31.158 & $7.456 .748,67$ \\
\hline \multirow{2}{*}{ Pecuária } & Pequena & 70.809 & $1.331 .947,69$ \\
& Grande & 9.903 & $1.886 .018,26$ \\
\hline \multirow{2}{*}{ Silvicultura } & Pequena & 4.959 & $85.323,21$ \\
& Grande & 1.839 & $669.236,41$ \\
\hline \multirow{2}{*}{ Conservação } & Pequena & 728 & 8,45 \\
& Grande & 220 & 160,05 \\
\hline \multirow{2}{*}{ Ecoturismo } & Pequena & 172 & 8,98 \\
& Grande & 32 & 101,43 \\
\hline
\end{tabular}

balhos que verificaram anteriormente a baixa eficiência de programas de PSA para a conversão do uso do solo ou em regiões cujos custos de oportunidade sejam altos. É o caso do trabalho de Pagiola, Zhang e Colom (2010), que ao analisar os pagamentos por serviços ambientais com enfoque na provisão de serviços hídricos concluíram que programas que "encoragem a substituição de um uso agrícola do solo por outro são mais suscetíveis a terem menores benefícios", e do trabalho de Young et al. (2016), que menciona que "o PSA seria muito pouco eficaz para reduzir o desmatamento na Mata Atlântica, onde os custos de oportunidade da terra nos municípios em geral superam o valor máximo anual do benefício que seria pago por hectare".

Além disso, a nossa pesquisa simulou uma situação real dos programas, propondo diferentes programas com diferentes valores de pagamento para um mesmo proprietário. Ao observar que o programa de PSA em larga-escala possuiria maior capacidade de restauração com aumento do tempo e pagamento propostos e demandaria uma grande quantidade de recursos para recuperar uma parcela pequena de área em comparação com o que já foi feito com os tradicionais instrumentos de comando e controle, nossos resultados se mostram em consonância com a armadilha da lógica da compensação, descrita por Muradian et al. (2013):

A expectativa de contrariar atividades econômicas altamente rentáveis (ainda que ambientalmente prejudiciais) com pagamentos (compensação) pode criar cenários onde a proteção de ecossistemas é somente possível com níveis crescentes de compensação devido ao aumento no custo de oportunidade da conservação. Esses cenários são suscetíveis a criar resultados injustos e/ou muito custosos, uma vez que o custo da compensação pode ser consideravelmente maior que o custo de políticas alternativas (Gregersen et al. 2010). ${ }^{22}$

(MURADIAN et al., 2013, p.8)

$\overline{22}$ Original: "The expectation to counteract highly profitable (yet environmentally damaging) economic activities with payments (compensation) may create scenarios where the protection of ecosystems is only possible with increasing levels of compensation due to the increased opportunity cost of conservation. Such scenarios are likely to create unjust and/or very costly outcomes, since the cost of compensation might be considerably higher than the cost of alternative policies (Gregersen et al. 2010)." 
Nosso resultados também dialogam com outro artigo recente de grande destaque. Banks-Leite et al. (2014) subdividiram a Mata Atlântica em unidades de 200 hectares para avaliar como um programa de larga escala de PSA para restauração poderia contribuir para a proteção da biodiversidade. De acordo com os autores, priorizar unidades com mais de $20 \%$ de vegetação de forma a aumentar seus percentuais para $30 \%$ restauraria uma área de 424.000 ha, providenciaria benefícios para a biodiversidade e seria viável por meio de um programa de PSA que pagasse cerca de 224,14 $\mathrm{R} \$$ / ha.ano, custando $424.000 h a \cdot 224,14 R \$ /$ ha.ano $=95.035 .360 R \$$ /ano (na cotação do dólar utilizada pelo estudo: 56.300 .000 US\$/ano). Está implícito neste cálculo o pressuposto de que $100 \%$ dos proprietários das unidades aceitariam participar de um programa que propusesse 224,14 $\mathrm{R} \$ /$ ha.ano para que seus percentuais de vegetação nativa aumentassem para $30 \%$ da área total da propriedade. Os resultados da presente pesquisa permitem questionar esse pressuposto, pois mostram que a disposição à participação dos proprietários é geralmente baixa, pelo menos no estado de São Paulo, se considerarmos o programa de PSA para restauração nas áreas que vão além das legalmente protegidas.

Para demonstrar como a contribuição do nosso trabalho pode afetar a forma como a mencionada pesquisa tratou o PSA para restauração, o cálculo foi refeito considerando o refinamento proveniente da utilização das propriedades rurais paulistas do bioma Mata Atlântica e um cenário semelhante ao da citada pesquisa: aumentar a vegetação nativa das propriedades com mais de $20 \%$ da área total composta por vegetação, com o objetivo de tornar $30 \%$ da área total dessas propriedades vegetada. Os resultados apresentados na Tabela 8 mostram que o programa proposto pelos autores não deve ter a eficácia desejada pelo custo mencionado, pois o percentual de proprietários cuja participação atingiria os $30 \%$ de vegetação nativa são muito baixos para valores pequenos. A forma de chegar próximo do pressuposto feito seria aumentar os pagamentos, mas isso aumentaria substancialmente os custos envolvidos e poderia inviabilizar a execução do programa de PSA. Cabe ressaltar que esse cenário calculado é o de tempo igual a 40 anos, ou seja o de maior participação possível. Espera-se que os resultados da presente pesquisa sejam levados em conta na proposição de programas ou em estudos futuros.

Por fim, de acordo com Muradian et al. (2013), a adoção de instrumentos baseados em criação de mercado dividem opiniões, sendo vistos tanto como uma opção promissora, por uma vertente, quanto como um exemplo de neoliberalização da natureza, por outra vertente de pensamento. Neste caso, a transformação da natureza em uma forma de capital e a publicidade para torna-la atrativa para investidores são vistas como "somente um passo em um projeto político econômico muito maior, porém desigual, de estabelecer a supremacia da lógica de acumulação do capital sobre as relações da sociedade com a natureza" (ARSEL; BUSCHER, 2012).

Embora o PSA não tenha surgido com o intuito de ser uma panacea dentre as opções para conservação ambiental (WUNDER, 2013), sua adoção por diferentes agentes políticos 
Tabela 8 - Análise do pressuposto de Banks-Leite et al. (2014): percentual de proprietários que atingiria $30 \%$ da propriedade com vegetação nativa. Tempo considerado: 40 anos.

\begin{tabular}{rr}
\hline Pagamento (R\$/ha.ano) & Percentual obtido \\
\hline \hline 50 & $8,16 \%$ \\
100 & $10,71 \%$ \\
150 & $14,14 \%$ \\
200 & $18,23 \%$ \\
250 & $23,15 \%$ \\
500 & $52,85 \%$ \\
750 & $74,42 \%$ \\
1000 & $83,15 \%$ \\
1500 & $90,66 \%$ \\
1750 & $92,26 \%$ \\
2000 & $93,47 \%$ \\
\hline
\end{tabular}

tem se dado em larga escala e frequentemente suportada pela suposição de se tratar de uma situação em que todos os envolvidos se beneficiam. A validade desse pressuposto é questionável em diversos contextos, devendo a aplicação do PSA ser considerada apenas em situações específicas, em conjunto com outras abordagens complementares para a conservação (WUNDER, 2013; MURADIAN et al., 2013).

O perigo da aplicação irrestrita do PSA é particularmente nocivo no Brasil, onde há um contexto caracterizado pela busca de soluções fáceis para questões ambientais complexas e o conhecimento científico é frequentemente desconsiderado na tomada de decisões. Ambas essas deficiências integram o perverso interesse de priorizar o desenvolvimento de atividades econômicas em detrimento do fortalecimento de instrumentos capazes de acarretar melhorias na qualidade ambiental (FEARNSIDE, 2016; AZEVEDO-SANTOS et al., 2017).

Mesmo levando em conta apenas as questões financeiras, todos os resultados da presente pesquisa apontam para a sugestão de que o PSA não deve ser considerado como alternativa única para a restauração de vegetação nativa no estado de São Paulo. 



\section{Conclusões e recomendações}

Os resultados da presente pesquisa atenderam os objetivos específicos propostos, pois compreendem a curva de área preservada por investimento aplicado e a comparação dessa curva com os orçamentos ambientais paulistas. Os resultados também suportam outras conclusões:

- Não deve haver uma determinada região do estao de São Paulo cuja custo-eficácia do PSA para restauração de vegetação nativa seja maior do que as demais regiões.

- O intervalo de maior custo-eficácia do PSA para restauração de vegetação nativa no estado de São Paulo possui dois pontos relevantes: $450 \mathrm{R} \$ /$ ha.ano, em que $50 \%$ da área potencial é restaurada, e $800 \mathrm{R} \$ /$ ha.ano, em que o valor sobe para cerca de 75 a $80 \%$. A partir desses valores, o incremento de dinheiro aumenta muito pouco a área restaurada.

- O orçamento ambiental do estado de São Paulo é muito insuficiente para um programa estadual significativo de restauração de vegetação nativa.

- Estratégias de execução parcelada dos programas também devem ser pouco custoeficazes

- O PSA possui um potencial baixo para restaurar vegetação nativa em áreas agrícolas, uso que corresponde ao predominante no estado de São Paulo.

O modelo estatístico aqui aplicado utilizou pressupostos mais realísticos do que os encontrados na literatura, tendo sido essa também uma contribuição para a área do conhecimento. Mesmo que se considere uma possível superestimativa nos valores preditos, as conclusões devem ser pouco afetadas, uma vez que a maioria dos resultados apontou que baixos valores de área obtidos. Ressalta-se ainda que os valores financeiros obtidos subestimam os valores reais por desconsiderarem os custos de transação e de execução, de fato, da restauração.

De uma forma mais ampla, a pesquisa também contribuiu para evidenciar a potencialidade da elaboração de políticas públicas a partir de dados. A utilização de arquivos espacializados e de um modelo estatístico com fundação sólida permitiram a elaboração de cenários para um instrumento complexo. Os resultados do trabalho permitiram uma estimativa dos resultados esperados antes da execução dos programas, o que é de grande valia para os tomadores de decisão.

As principal recomendações para trabalhos futuros são:

- O desenvolvimento de um modelo que leve em conta a possível dependência espacial dos dados. 
- O estudo para a incorporação do retorno financeiro que pode ser gerado a partir das florestas restauradas. Esse valor pode, em parte, ajudar o custeio dos programas. Por isso, merece atenção em pesquisas futuras.

- A realização de uma análise da custo-efetividade do PSA para restauração de vegetação nativa em relação a outros instrumentos. A comparação e a eventual combinação de aproximações devem apontar os caminhos que levem a soluções mais baratas e que potencializem o ganho ambiental desejado. Essa recomendação também visa suprir uma das deficiências levantadas por Bernardo (2016): a ausência de uma análise de custo-efetividade nos programas de PSA existentes na Mata Atlântica. 


\section{Referências}

AGUIAR, P. F. de et al. D-optimal designs. Chemometrics and Intelligent Laboratory Systems, Elsevier, v. 30, n. 2, p. 199-210, 1995. Citado em: 36.

ALSTON, L. J.; ANDERSSON, K.; SMITH, S. M. Payment for environmental services: Hypotheses and evidence. Annu. Rev. Resour. Econ., Annual Reviews, v. 5, n. 1, p. 139-159, 2013. Citado em: 84.

ARRIAGADA, R. A. et al. Combining qualitative and quantitative methods to evaluate participation in costa rica's program of payments for environmental services.

Journal of Sustainable Forestry, Taylor \& Francis, v. 28, n. 3-5, p. 343-367, 2009. Citado em: 64 .

ARSEL, M.; BUSCHER, B. Nature ${ }^{\mathrm{TM}}$ inc.: Changes and continuities in neoliberal conservation and market-based environmental policy. Development and Change, Blackwell Publishing Ltd, v. 43, n. 1, p. 53-78, 2012. ISSN 1467-7660. Disponível em: <http://dx.doi.org/10.1111/j.1467-7660.2012.01752.x>. Citado em: 88.

ATKINSON, G.; MOURATO, S. Cost-benefit analysis and the environment. OECD Publishing, Paris, 2015. Citado em: 23.

AZEVEDO-SANTOS, V. M. et al. Removing the abyss between conservation science and policy decisions in brazil. Biodiversity and Conservation, v. 26, n. 7, p. 1745-1752, Jun 2017. ISSN 1572-9710. Disponível em: < https: //doi.org/10.1007/s10531-017-1316-x>. Citado em: 89.

BALMFORD, A. et al. Integrating costs of conservation into internationalpriority setting. Conservation Biology, Wiley Online Library, v. 14, n. 3, p. 597-605, 2000. Citado em: 23.

BANKS-LEITE, C. et al. Using ecological thresholds to evaluate the costs and benefits of set-asides in a biodiversity hotspot. Science, American Association for the Advancement of Science, v. 345, n. 6200, p. 1041-1045, 2014. Citado em: 15, 81, 88 e 89.

BARNOSKY, A. D. et al. Has the earth/'s sixth mass extinction already arrived? Nature, Nature Research, v. 471, n. 7336, p. 51-57, 2011. Citado em: 19.

BEHARRY-BORG, N. et al. Evaluating farmers' likely participation in a payment programme for water quality protection in the uk uplands. Regional Environmental Change, Springer, v. 13, n. 3, p. 633-647, 2013. Citado em: 64.

BERNARDO, K. d. T. Avaliação da efetividade de esquemas de pagamentos por serviços ambientais hidricos: proposta metodológica. Tese (Doutorado) - Universidade de São Paulo, 2016. Citado em: 23 e 92.

BIVAND, R.; KEITT, T.; ROWLINGSON, B. rgdal: Bindings for the Geospatial Data Abstraction Library. [S.1.], 2016. R package version 1.2-5. Disponível em: $<$ https: $/ /$ CRAN.R-project.org $/$ package $=$ rgdal $>$. Citado em: 57. 
BIVAND, R.; RUNDEL, C. rgeos: Interface to Geometry Engine - Open Source (GEOS). [S.1.], 2017. R package version 0.3-22. Disponível em: <https: $/ /$ CRAN.R-project.org/package $=$ rgeos $>$. Citado em: 57.

BOLKER, B. M. Ecological models and data in R. Princeton: Princeton University Press, 2008. Citado em: 27.

BONAT, W. H.; RIBEIRO-JR, P. J.; ZEVIANI, W. M. Likelihood analysis for a class of beta mixed models. Journal of Applied Statistics, Taylor \& Francis, v. 42, n. 2, p. 252-266, 2015. Citado em: 51.

BRASIL. Lei $n^{o}$ 8.666, Regulamenta o art. 37, inciso XXI, da Constituição Federal, institui normas para licitações e contratos da Administração Pública e dá outras providências. Diário Oficial, 1993. Acesso em: 15 ago. 2017. Disponível em: <http://www.planalto.gov.br/ccivil_03/leis/L8666cons.htm>. Citado em: 57.

BRASIL. Lei no 12.651, Dispõe sobre a proteção da vegetação nativa. Diário Oficial, 2012. Acesso em: 9 out. 2016. Disponível em: <http://www.planalto.gov.br/ ccivil_03/_ato2011-2014/2012/lei/112651.htm>. Citado em: 33.

BROCH, S. W.; VEDEL, S. E. Using choice experiments to investigate the policy relevance of heterogeneity in farmer agri-environmental contract preferences. Environmental and Resource Economics, Springer, v. 51, n. 4, p. 561-581, 2012. Citado em: 64 e 66.

BUUREN, S. v.; FREDRIKS, M. Worm plot: a simple diagnostic device for modelling growth reference curves. Statistics in medicine, Wiley Online Library, v. 20, n. 8, p. 1259-1277, 2001. Citado em: 71.

CAMPANHÃO, L. M. B. Identificação de áreas prioritárias para a implantação de esquemas de pagamentos por serviços ambientais hidrológicos: uma proposta metodológica. Dissertação (Mestrado) — Universidade de São Paulo, 2016. Citado em: 23 .

CARDOSO, J. C.; SILVA, J. A. T. da; VENDRAME, W. A. Impacts of deforestation on some orchids of são paulo state, brazil. Natureza $\&$ Conservação, v. 14, n. 1, p. 28 - 32, 2016. ISSN 1679-0073. Disponível em: < http: //www.sciencedirect.com/science/article/pii/S1679007316000050>. Citado em: 31.

CELLINI, S. R.; KEE, J. E. Cost-effectiveness and cost-benefit analysis. In: Handbook of Practical Program Evaluation. Hoboken: John Wiley \& Sons, 2015. p. 636-672. ISBN 9781119171386. Citado em: 23 e 78.

CHAN, K. M. et al. Opinion: Why protect nature? rethinking values and the environment. Proceedings of the National Academy of Sciences, National Acad Sciences, v. 113, n. 6, p. 1462-1465, 2016. Citado em: 20.

ClAASSEN, R.; TEGENE, A. Agricultural land use choice: A discrete choice approach. Agricultural and Resource Economics Review, Cambridge University Press, v. 28, n. 1, p. 26-36, 1999. Citado em: 30. 
COOPER, J. C. A joint framework for analysis of agri-environmental payment programs. American journal of agricultural economics, Oxford University Press, v. 85, n. 4, p. 976-987, 2003. Citado em: 30.

COOPER, J. C.; KEIM, R. W. Incentive payments to encourage farmer adoption of water quality protection practices. American Journal of Agricultural Economics, Oxford University Press, v. 78, n. 1, p. 54-64, 1996. Citado em: 30.

COOPER, J. C.; OSBORN, C. T. The effect of rental rates on the extension of conservation reserve program contracts. American Journal of Agricultural Economics, Oxford University Press, v. 80, n. 1, p. 184-194, 1998. Citado em: 30.

DAEE/IPT. Cadastramento de pontos de erosão e inundação no Estado de São Paulo. São Paulo, 2012. Citado em: 67.

DEFRANCESCO, E. et al. Factors affecting farmers' participation in agri-environmental measures: A northern italian perspective. Journal of agricultural economics, Wiley Online Library, v. 59, n. 1, p. 114-131, 2008. Citado em: 64 e 66.

DNIT. Shapefiles - Departamento Nacional de Infraestrutura de Transportes. 2017. $<$ http://www.dnit.gov.br/mapas-multimodais/shapefiles $>$. Acesso em: 10 jun. 2017. Citado em: 67.

DUKE, J. M. Participation in agricultural land preservation programs: parcel quality and a complex policy environment. Agricultural and Resource Economics Review, Cambridge University Press, v. 33, n. 1, p. 34-49, 2004. Citado em: 64.

DUNN, P. K.; SMYTH, G. K. Randomized quantile residuals. Journal of Computational and Graphical Statistics, Taylor \& Francis, v. 5, n. 3, p. 236-244, 1996. Citado em: 54.

DURAIAPPAH, A. K. Ecosystem services and human well-being: Do global findings make any sense? BioScience, American Institute of Biological Sciences Circulation, AIBS, 1313 Dolley Madison Blvd., Suite 402, McLean, VA 22101. USA, v. 61, n. 1, p. 7-8, 2011. Citado em: 20.

ENGEL, S.; PAGIOLA, S.; WUNDER, S. Designing payments for environmental services in theory and practice: An overview of the issues. Ecological economics, Elsevier, v. 65 , n. 4 , p. 663-674, 2008. Citado em: 20 e 21.

FAO. The State of Food and Agriculture: Paying Farmers for Environmental Services. Rome: FAO, 2007. ISSN 0081-4539. Citado em: 75.

FEARNSIDE, P. M. Brazilian politics threaten environmental policies. Science, American Association for the Advancement of Science, v. 353, n. 6301, p. 746-748, 2016. ISSN 0036-8075. Disponível em: < http://science.sciencemag.org/content/ 353/6301/746>. Citado em: 89.

FERRARI, S.; CRIBARI-NETO, F. Beta regression for modelling rates and proportions. Journal of Applied Statistics, Taylor \& Francis, v. 31, n. 7, p. 799-815, 2004. Citado em: 71. 
FERRARO, P. J. Asymmetric information and contract design for payments for environmental services. Ecological economics, Elsevier, v. 65, n. 4, p. 810-821, 2008. Citado em: 28.

FIANI, R. Teoria dos jogos. São Paulo: Elsevier Brasil, 2006. Citado em: 27 e 28.

FICK, S. E.; HIJMANS, R. J. Worldclim 2: new 1-km spatial resolution climate surfaces for global land areas. International Journal of Climatology, John Wiley \& Sons, 2017. ISSN 1097-0088. Disponível em: < http://dx.doi.org/10.1002/joc.5086>. Citado em: 67.

FIGUEROA, F. et al. "I like to conserve the forest, but I also like the cash". socioeconomic factors influencing the motivation to be engaged in the mexican payment for environmental services programme. Journal of Forest Economics, Elsevier, v. 22, p. 36-51, 2016. Citado em: 57, 64 e 66.

FINNEY, C. Comment on "using ecological thresholds to evaluate the costs and benefits of set-asides in a biodiversity hotspot". Science, American Association for the Advancement of Science, v. 347, n. 6223, p. 731-731, 2015. Citado em: 84.

FOLEY, J. A. et al. Global consequences of land use. science, American Association for the Advancement of Science, v. 309, n. 5734, p. 570-574, 2005. Citado em: 19.

FORBES, C. et al. Statistical distributions. 4. ed. Hoboken: John Wiley \& Sons, 2011. Citado em: 48.

FOREST TRENDS. Incentivos econômicos para Serviços Ecossistêmicos no Brasil. Rio de Janeiro, 2015. Citado em: 20.

GAO, T. Payments for environmental service contract design with asymmetric information. Dissertação (Mestrado) - University of Delaware, 2015. Citado em: 29 .

GAUVIN, C. et al. Cost-effectiveness of payments for ecosystem services with dual goals of environment and poverty alleviation. Environmental management, Springer, v. 45, n. 3 , p. 488-501, 2010. Citado em: 64 .

GELMAN, A.; HILL, J. Data Analysis Using Regression and Multilevel/Hierarchical Models. New York: Cambridge University Press, 2007. Citado em: 50 e 51.

GILMOUR, A. et al. An efficient computing strategy for prediction in mixed linear models. Computational Statistics \& Data Analysis, v. 44, n. 4, p. 571 - 586, 2004. ISSN 0167-9473. Citado em: 55.

GREINER, R. Motivations and attitudes influence farmers' willingness to participate in biodiversity conservation contracts. Agricultural Systems, Elsevier, v. 137, p. 154-165, 2015. Citado em: 64.

GREINER, R. Factors influencing farmers' participation in contractual biodiversity conservation: a choice experiment with northern australian pastoralists. Australian Journal of Agricultural and Resource Economics, Wiley Online Library, v. 60, n. 1, p. 1-21, 2016. Citado em: 64. 
GROVES, R. M. Survey errors and survey costs. Hoboken: John Wiley \& Sons, 2004. Citado em: 44.

GUO, H. et al. Rural households' willingness to participate in the grain for green program again: A case study of zhungeer, china. Forest Policy and Economics, Elsevier, v. 44, p. 42-49, 2014. Citado em: 64 e 66.

HENGL, T. et al. SoilGrids250m: Global gridded soil information based on machine learning. PLOS ONE, Public Library of Science, v. 12, n. 2, fev. 2017. ISSN 1932-6203. Citado em: 66.

HIJMANS, R. J. raster: Geographic Data Analysis and Modeling. [S.l.], 2016. R package version 2.5-8. Disponível em: < https://CRAN.R-project.org/package=raster $>$. Citado em: 57.

IBGE. Produto Interno Bruto dos Municípios. 2012. < https://sidra.ibge.gov.br/Tabela/ 21>. Acesso em: 10 jun. 2017. Citado em: 67.

IBGE. Censo Agropecuário. 2015. <www.sidra.ibge.gov.br/bda/acervo/acervo2.asp?e= $\mathrm{v} \& \mathrm{p}=\mathrm{CA} \& \mathrm{z}=\mathrm{t} \& \mathrm{o}=11>$. Acesso em: 20 abr. 2016. Citado em: 45 e 66.

IBGE. Estados - São Paulo. 2015. < http://www.ibge.gov.br/estadosat/perfil.php?sigla= sp>. Acesso em: 20 abr. 2016. Citado em: 31.

IBGE. Produção Agrícola Municipal. 2015. < https://sidra.ibge.gov.br/Tabela/5457> . Acesso em: 10 jun. 2017. Citado em: 67.

INCRA. Tabela com módulo fiscal dos municípios. 2017. < http://www.incra.gov.br/ tabela-modulo-fiscal $>$. Acesso em: 06 ago. 2017. Citado em: 67.

JIANG, Y.; KOO, W. Producer preference for land-based biological carbon sequestration in agriculture: Some implications from a sample of north dakota farmers. Journal of Soil and Water Conservation, Soil and Water Conservation Society, v. 69, n. 3, p. 231-242, 2014. Citado em: 64 e 66.

JOPPA, L. N.; PFAFF, A. High and far: Biases in the location of protected areas. PLOS ONE, Public Library of Science, v. 4, n. 12, p. 1-6, 12 2009. Disponível em: $<$ https://doi.org/10.1371/journal.pone.0008273>. Citado em: 48.

KACZAN, D.; SWALLOW, B. M. et al. Designing a payments for ecosystem services (pes) program to reduce deforestation in tanzania: An assessment of payment approaches. Ecological Economics, Elsevier, v. 95, p. 20-30, 2013. Citado em: 64.

KINZIG, A. P. et al. Paying for ecosystem services-promise and peril. Science, American Association for the Advancement of Science, v. 334, n. 6056, p. 603-604, 2011. Citado em: 22.

KROES, E. P.; SHELDON, R. J. Stated preference methods: An introduction. Journal of Transport Economics and Policy, JSTOR, p. 11-25, 1988. Citado em: 35.

LANGPAP, C. Conservation incentives programs for endangered species: an analysis of landowner participation. Land Economics, University of Wisconsin Press, v. 80, n. 3, p. 375-388, 2004. Citado em: 30. 
LAYTON, D. F.; SIIKAMÄKI, J. Payments for ecosystem services programs: predicting landowner enrollment and opportunity cost using a beta-binomial model. Environmental and Resource Economics, Springer, v. 44, n. 3, p. 415-439, 2009. Citado em: 22, 30, 35, 36, 48, 49, 52, 53, 64 e 66.

LEEUW, E. D. de; DILLMAN, D. A. International Handbook of Survey Methodology. Hove: Taylor \& Francis, 2008. Citado em: 43.

LIU, W.-Y. Landowners' participation behavior on the payment for environmental service (pes). In: PUJOL, J. L. (Ed.). The Importance of Biological Interactions in the Study of Biodiversity. Rijeka: InTech, 2011. ISBN 978-953-307-751-2. Citado em: 64 e 66.

LOHR, L.; PARK, T. Discrete/continuous choices in contingent valuation surveys: Soil conservation decisions in michigan. Review of Agricultural Economics, Oxford University Press, v. 16, n. 1, p. 1-15, 1994. Citado em: 29, 30, 35 e 48.

LOHR, L.; PARK, T. A. et al. Utility-consistent discrete-continuous choices in soil conservation. Land Economics, University of Wisconsin Press, v. 71, n. 4, p. 474-490, 1995. Citado em: 29, 30, 35 e 48.

LUECK, D.; MICHAEL, J. A. Preemptive habitat destruction under the endangered species act. The Journal of Law and Economics, The University of Chicago Press, v. 46, n. 1, p. 27-60, 2003. Citado em: 23.

LUZAR, E. J.; DIAGNE, A. Participation in the next generation of agriculture conservation programs: the role of environmental attitudes. The Journal of Socio-Economics, Elsevier, v. 28, n. 3, p. 335-349, 1999. Citado em: 64 e 66.

LYNCH, L.; LOVELL, S. J. Combining spatial and survey data to explain participation in agricultural land reservation programs. Land Economics, University of Wisconsin Press, v. 79, n. 2, p. 259-276, 2003. Citado em: 30.

MA, S. et al. Farmers' willingness to participate in payment-for-environmental-services programmes. Journal of Agricultural Economics, Wiley Online Library, v. 63, n. 3, p. 604-626, 2012. Citado em: 64 .

MANCO, O. C. U. Modelos de regressão beta com efeitos aleatórios normais e não normais para dados longitudinais. Tese (Doutorado) - Universidade de São Paulo, 2013. Citado em: 55.

MATTA, J. R.; ALAVALAPATI, J. R.; MERCER, D. E. Incentives for biodiversity conservation beyond the best management practices: are forestland owners interested? Land Economics, University of Wisconsin Press, v. 85, n. 1, p. 132-143, 2009. Citado em: 64 e 66.

MEA, M. E. A. Ecosystems and human well-being: synthesis. Island, Washington, DC, 2005. Citado em: 19.

MINISTÉRIO DO MEIO AMBIENTE. Mapeamento do Uso e Cobertura da Terra do Cerrado: Projeto TerraClass Cerrado 2013. Brasília, 2015. Citado em: 31.

MMA. Download de dados geográficos. 2017. Acesso em: 26 jul. 2017. Disponível em: $<$ http://mapas.mma.gov.br/i3geo/datadownload.htm>. Citado em: 67 e 81. 
MOXEY, A.; WHITE, B.; OZANNE, A. Efficient contract design for agri-environment policy. Journal of agricultural economics, Wiley Online Library, v. 50, n. 2, p. 187-202, 1999. Citado em: 28.

MURADIAN, R. et al. Payments for ecosystem services and the fatal attraction of win-win solutions. Conservation Letters, Wiley Online Library, v. 6, n. 4, p. 274-279, 2013. Citado em: 87, 88 e 89.

MURADIAN, R. et al. Reconciling theory and practice: An alternative conceptual framework for understanding payments for environmental services. Ecological economics, Elsevier, v. 69, n. 6, p. 1202-1208, 2010. Citado em: 21 e 57.

MURDOCH, W. et al. Maximizing return on investment in conservation. Biological Conservation, Elsevier, v. 139, n. 3, p. 375-388, 2007. Citado em: 23.

MURPHY, G. et al. An investigation into the type of farmer who chose to participate in rural environment protection scheme (REPS) and the role of institutional change in influencing scheme effectiveness. Land use policy, Elsevier, v. 39, p. 199-210, 2014. Citado em: 64 e 66.

MYERS, N. et al. Biodiversity hotspots for conservation priorities. Nature, Nature Publishing Group, v. 403, n. 6772, p. 853, 2000. Citado em: 24 e 31.

NAEEM, S. et al. Get the science right when paying for nature's services. Science, v. 347, n. 6227,2015 . Citado em: 22.

OSBORnE, M. J.; RUBINSTEIN, A. A course in game theory. Cambridge: MIT press, 1994. Citado em: 28.

OSPINA, R.; FERRARI, S. L. Inflated beta distributions. Statistical Papers, Springer, v. 51, n. 1, p. 111-126, 2010. Citado em: 52 e 53.

OSPINA, R.; FERRARI, S. L. A general class of zero-or-one inflated beta regression models. Computational Statistics \& Data Analysis, Elsevier, v. 56, n. 6, p. 1609-1623, 2012. Citado em: 54.

OZANNE, A.; HOGAN, T.; COLMAN, D. Moral hazard, risk aversion and compliance monitoring in agri-environmental policy. European review of agricultural economics, Oxford University Press, v. 28, n. 3, p. 329-348, 2001. Citado em: 29.

OZANNE, A.; WHITE, B. Equivalence of input quotas and input charges under asymmetric information in agri-environmental schemes. Journal of Agricultural Economics, Wiley Online Library, v. 58, n. 2, p. 260-268, 2007. Citado em: 29.

OZANNE, A.; WHITE, B. Hidden action, risk aversion and variable fines in agri-environmental schemes. Australian Journal of Agricultural and Resource Economics, Wiley Online Library, v. 52, n. 2, p. 203-212, 2008. Citado em: 29.

PAGIOLA, S.; GLEHN, H. C. V.; TAFFARELLO, D. Experiências de pagamentos por serviços ambientais no brasil. São Paulo: SMA/CBRN, p. 274, 2013. Citado em: 20 e 36 . 
PAGIOLA, S.; ZHANG, W.; COLOM, A. Can payments for watershed services help finance biodiversity conservation? a spatial analysis of highland guatemala. Journal of Natural Resources Policy Research, Taylor \& Francis, v. 2, n. 1, p. 7-24, 2010. Citado em: 87.

PETERSON, J. M.; BOISVERT, R. N. Incentive-compatible pollution control policies under asymmetric information on both risk preferences and technology. American Journal of Agricultural Economics, Oxford University Press, v. 86, n. 2, p. 291-306, 2004. Citado em: 29.

PINHEIRO, J. C.; BATES, D. M. Mixed-Effect Models in S and S-PLUS. New York: Springer, 2000. Citado em: 50, 51 e 55.

POLASKY, S.; DOREMUS, H. When the truth hurts: endangered species policy on private land with imperfect information. Journal of Environmental Economics and Management, Elsevier, v. 35, n. 1, p. 22-47, 1998. Citado em: 28.

R Core Team. R: A Language and Environment for Statistical Computing. Vienna, Austria, 2016. Disponível em: <https://www.R-project.org/>. Citado em: 57.

RAUDENBUSH, S. W.; BRYK, A. S. Hierarchical linear models: Applications and data analysis methods. Thousand Oaks: Sage, 2002. v. 1. Citado em: 50.

RAUDSEPP-HEARNE, C. et al. Untangling the environmentalist's paradox: Why is human well-being increasing as ecosystem services degrade? BioScience, American Institute of Biological Sciences Circulation, AIBS, 1313 Dolley Madison Blvd., Suite 402, McLean, VA 22101. USA, v. 60, n. 8, p. 576-589, 2010. Citado em: 19.

RIGBY, R. A.; STASINOPOULOS, D. M. Generalized additive models for location, scale and shape. Journal of the Royal Statistical Society: Series C (Applied Statistics), Wiley Online Library, v. 54, n. 3, p. 507-554, 2005. Citado em: 49.

RIGBY, R. A.; STASINOPOULOS, D. M. Generalized additive models for location, scale and shape,(with discussion). Applied Statistics, v. 54, p. 507-554, 2005. Citado em: 57.

ROCKSTRÖM, J. et al. A safe operating space for humanity. nature, Nature Publishing Group, v. 461, n. 7263, p. 472-475, 2009. Citado em: 19.

ROSS, S. M. Introduction to Probability Models. 9. ed. Amsterdam: Elsevier, 2007. Citado em: 56.

RUTO, E.; GARROD, G. Investigating farmers' preferences for the design of agrienvironment schemes: a choice experiment approach. Journal of Environmental Planning and Management, Taylor \& Francis, v. 52, n. 5, p. 631-647, 2009. Citado em: 64 e 66.

SCHOMERS, S.; MATZDORF, B. Payments for ecosystem services: A review and comparison of developing and industrialized countries. Ecosystem services, Elsevier, v. 6, p. 16-30, 2013. Citado em: 23.

SEADE. Informação dos Municípios Paulistas. 2016. <www.imp.seade.gov.br/>. Acesso em: 10 out. 2016. Citado em: 31, 32 e 66. 
SFB. Boletim Informativo: até 31 de agosto de 2016. Sociedade Florestal Brasileira, 2016. Acesso em: 12 out. 2016. Disponível em: <http://www.florestal.gov.br/ documentos/car/boletim-do-car/71-boletim-informativo-agosto-de-2016/file> . Citado em: 33 e 43.

SHAPIRO, S.; WILK, M. An analysis of variance test for normality (complete samples). Biometrika, Oxford University Press, v. 52, n. 3-4, p. 591-611, 1965. Citado em: 54.

SMA. Sistema de Informações Florestais do Estado de São Paulo: Quantificação da vegetação natural remanescente para os municipios do Estado de São Paulo. Legenda IBGE - RADAM - 2009. 2009. Acesso em: 26 jul. 2017. Disponível em: $<$ http://www.iflorestal.sp.gov.br/sifesp/tabelas/municipio_maior_porc.pdf $>$. Citado em: 81.

SMA. Manual de Orientações para o Cadastro no Sistema de Cadastro Ambiental Rural do Estado de São Paulo (SICAR-SP). São Paulo, 2016. Acesso em: 15 ago. 2017. Disponível em: <http://arquivos.ambiente.sp.gov.br/sicar/2016/07/ MANUAL-SiCAR-COMPLETO_2016-07-15.pdf $>$. Citado em: 47.

SMA. Serviço Estadual de Informações ao Cidadão. 2017. Acesso em: 15 ago. 2017. Protocolo: 31735174745. Disponível em: < http://www.sic.sp.gov.br/ BuscaProtocolo.aspx >. Citado em: 44.

SMA. Serviço Estadual de Informações ao Cidadão. 2017. Acesso em: 15 ago. 2017. Protocolo: 68351177691. Disponível em: <http://www.sic.sp.gov.br/ BuscaProtocolo.aspx $>$. Citado em: 56.

SMA. Sistema Integrado de Gestão Ambiental. 2017. Acesso em: 15 ago. 2017. Disponível em: <http://www.sigam.ambiente.sp.gov.br/>. Citado em: 63.

SMITH, R. B. The conservation reserve program as a least-cost land retirement mechanism. American Journal of Agricultural Economics, Oxford University Press, v. 77, n. 1, p. 93-105, 1995. Citado em: 28 e 29.

SMITH, R. B.; SHOGREN, J. F. Voluntary incentive design for endangered species protection. Journal of Environmental Economics and Management, Elsevier, v. 43, n. 2, p. 169-187, 2002. Citado em: 28.

SMITHSON, M.; MERKLE, E. C. Generalized linear models for categorical and continuous limited dependent variables. Boca Raton: CRC Press, 2013. Citado em: 49.

SOSMA/INPE. Atlas dos remanescentes florestais da Mata Atlântica: Período 2012-2013. São Paulo, 2014. Citado em: 31.

SPAROVEK, G. et al. A revisão do código florestal brasileiro. Novos Estudos - CEBRAP, SciELO, p. 111 - 135, mar. 2011. Citado em: 81.

STASINOPOULOS, D. M.; RIGBY, R. A. et al. Generalized additive models for location scale and shape (gamlss) in r. Journal of Statistical Software, v. 23, n. 7, p. 1-46, 2007. Citado em: 49, 52 e 68. 
STASINOPOULOS, M. D. et al. Flexible Regression and Smoothing: Using GAMLSS in R. Boca Raton: CRC Press, 2017. Citado em: 49, 50, 51, 52, 53, 54 e 55.

STEFFEN, W. et al. Planetary boundaries: Guiding human development on a changing planet. Science, American Association for the Advancement of Science, v. 347, n. 6223, p. 736-736, 2015. Citado em: 19.

SÃO PAULO. Lei no 13.798, Institui a Política Estadual de Mudanças Climáticas - PEMC. Diário Oficial, 2009. Acesso em: 10 out. 2016. Disponível em: $<$ http://www.al.sp.gov.br/norma/?id=158351>. Citado em: 33.

SÃO PAULO. DataGEO. Infraestrutura de Dados Espaciais Ambientais do Estado de São Paulo, 2016. Acesso em: 20 abr. 2016. Disponível em: $<$ http://datageo.ambiente.sp.gov.br $>$. Citado em: 33, 47 e 67.

TAEGER, D.; KUHNT, S. Statistical hypothesis testing with SAS and R. Hoboken: John Wiley \& Sons, 2014. Citado em: 44 e 45.

THACHER, T.; LEE, D. R.; SCHELHAS, J. W. Farmer participation in reforestation incentive programs in costa rica. Agroforestry Systems, Springer, v. 35, n. 3, p. 269-289, 1996. Citado em: 64 e 66.

TORABI, N. et al. The money or the trees: What drives landholders' participation in biodiverse carbon plantings? Global Ecology and Conservation, Elsevier, v. 7, p. 1-11, 2016. Citado em: 57 e 64.

USGS. EarthExplorer. 2017. Acesso em: 15 ago. 2017. Disponível em: < https: //earthexplorer.usgs.gov/>. Citado em: 67.

WAYBACK MACHINE. Wayback Machine: Proprietários Rurais - Questionário. 2017. Acesso em: 14 ago. 2017. Disponível em: < https://web.archive.org/web/ 20170412002231/http://questionariorural.link>. Citado em: 40.

WU, J.; BABCOCK, B. A. Optimal design of a voluntary green payment program under asymmetric information. Journal of Agricultural and Resource Economics, JSTOR, p. 316-327, 1995. Citado em: 28.

WU, J.; BABCOCK, B. A. Contract design for the purchase of environmental goods from agriculture. American Journal of Agricultural Economics, Oxford University Press, v. 78, n. 4, p. 935-945, 1996. Citado em: 28.

WUNDER, S. Payments for environmental services: some nuts and bolts. Jakarta, 2005. Citado em: 20.

WUNDER, S. When payments for environmental services will work for conservation. Conservation Letters, v. 6, n. 4, p. 230-237, 2013. ISSN 1755-263X. Disponível em: $<$ http://dx.doi.org/10.1111/conl.12034>. Citado em: 88 e 89.

WUNDER, S. Revisiting the concept of payments for environmental services. Ecological Economics, Elsevier, v. 117, p. 234-243, 2015. Citado em: 20 e 21.

YANG, A. L. et al. Spatial analysis of agri-environmental policy uptake and expenditure in scotland. Journal of environmental management, Elsevier, v. 133, p. 104-115, 2014. Citado em: 64 . 
YOUNG, C. E. F. et al. Estudos e produção de subsídios técnicos para a construção de uma Política Nacional de Pagamentos por Serviços Ambientais. Rio de Janeiro, 2016. Citado em: 87.

ZBINDEN, S.; LEE, D. R. Paying for environmental services: an analysis of participation in costa rica's psa program. World development, Elsevier, v. 33, n. 2, p. 255-272, 2005. Citado em: 64 e 66.

ZERBETO, A. P. Melhor preditor empírico aplicado aos modelos beta mistos. Dissertação (Mestrado) - Universidade de São Paulo, 2014. Citado em: 50. 



\section{APÊNDICE A - Variáveis de artigos semelhantes}


- Necessária exclusão de todo o gado para conservar a biodiversidade?

- Os gados precisariam ser removidos por longos períodos de tempo cada ano?

- Pagamento proposto

Northern Australia (Austrália)

Direito de negociar o término do contrato em situações excepcionais?

- Quem monitora a área?

Constante de alternativa: adotar uma alternativa ou o status quo?

Produtividade da terra

- Atitude em relação à importância da biodiversidade

- Atitude em relação aos pagamentos para fazendeiros visando a conservação

Pagamento proposto para o proprietário realizar manutenção na agrofloresta

- Pagamento proposto para um fundo coletivo destinado à manutenção da agrofloresta

East Usambara Mountains (Tanzânia)

Pagamento único para a aquisiçâao de fertilizantes

- Ausência de inspeções: os proprietários manterão um diário das atividades, que poderá ser auditado

- Inspeções leves: um funcionário verificará anualmente se árvores não foram derrubadas

feram derrubadas e se apareceram espécies exóticas

Os contratos propostos eram decrescentes no sentido de rigor e pagamento?

Pagamento ofertado

Pe PSA

- Atitude em relação à provisão de serviços ecossistêmicos para seu próprio benefício

- Percentual de area sem plantio direto

- Proporção de trigo no plantio

Michigan (Estados Unidos)

- Uso reduzido de fertilizantes?

Participou do Michigan Agriculture Environmental Assurance Programme?

- Participou do Environmental Quality Incentives Programme?

- Participou do Conservation Reserve Programme?

- Participou do Conservation Security Programme?

- Educação formal

Proporção do preço do trigo sobre o preço do milho

Gênero do respondente

Idade do respondente

Educação do respondente

Ocupação do respondente

Renda anual do respondente

Número de familiares

Ping-Tung County (Taiwan)

- Área agricultável

Valor do aluguel da área agricultável

Dreço da área agricultável

Distância da área agricultável para a administração pública local

Distância da área agricultável para o escritório do proprietário

- Numero de parcelas da área agricultável

Cumprimento da legislação local sobre áreas agricultáveis

Concordância com a duração do subsídio do programa proposto

Concordância com a proposta do programa

O proprietário substituiu temporaria ou permanentemente a exploração madeireira para usar em outros fins?

As atividades agricolas ocorrem no entorno do local em que o proprietário reside?

Finlândia

- O proprietário é fazendeiro full-time?

- Gênero do respondente

- Renda mensal não proveniente da fazenda

- Idade do respondente

- Proprietário recebeu educação ou treinamento formal em silvicultura?

Factors influencing

farmers' participation in

contractual biodiversity

conservation: A choice

Australian pastoralists

Designing a payments for ecosystem services (PES)

program to reduce

eforestation in Tanzania:

An assessment of paymen 
- Extrai madeira a mais de 30 anos?

Protege mata ciliar com pelo menos 100 pés de largura?

Protege mata ciliar com pelo menos 100 pés de largura?

- Conduziu incêndio controlado pelo menos uma vez nos últimos 2-3 anos?

- Conduziu incêndio controlado pelo menos uma vez nos últimos 4-6 anos?

Realiza controle de espécies invasoras pelo menos uma vez a cada 2-4 anos?

- Realiza controle de espécies invasoras pelo menos uma vez a cada 5-7 anos?

$-10 \%$ dos proprietários no seu condado participam do PSA?
$-20 \%$ dos proprietários no seu condado participam do PSA?

Florida (Estados Unidos)

- Incentivo proposto

Constante de alternativa: adotar uma alternativa ou o status quo?

Distância para a cidade mais próxima

Tempo de propriedade da terra

Gênero do respondente

Renda do respondente

Membro de uma organização florestal ou de conservação?

Idade do respondente

Grau de educação formal do respondente

Grupo* 1: Situação do proprietário em relação à aquisição da terra

Grupo 2. Situação da trra em relac̃o lação à aquisçaltura tera

Grupo 3: Situação da terra em relação à pecuária

Grupo 3: Situação empregatícia nas unidades

Escócia

- Grupo 4: Capacidade biofísica do solo

Grupo 6: Situação da terra em relação à zona em que se insere (p.ex. rural acessível, rural remoto, grande centro urbano etc.)

Spatial analysis of agri

entake and expenditure

(Scotland

*Cada grupo representa uma série de variáveis. Por exemplo no Grupo 1: percentual da área de cada unidade em que o proprietário aluga a terra/é dono da terra/etc Neste caso, 'unidade' se revere a cada 'parish', que seria análoga ao setor censitário brasileiro.

Exclusão parcial das atividades por um longo periodo de tempo na área a participar do programa?

Duração do contrato

Flexibilidade para negociação do contrato em circunstâncias excepcionais?

Monitoramento da execução

Pagamento

Savanas da Austrália

\section{(1)}

(icipação: estilo de vida

a participação: financeira/econômica

Motivação para a participação: social

- Atitude perante a biodiversidade: outras causas além da atividade agrícola são responsáveis pelo declínio da biodiversidade

ncentives for biodiversity conservation beyon

practices: Are forestland

owners interested?

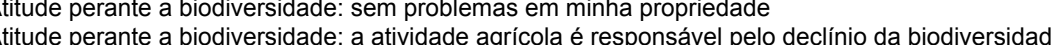

- Influências externas

- Percepção da eficácia dos Pagamentos por Serviços Ambientais

Motivations and attitudes

influence farmers'

willingness to participate in

biodiversity conservation

contracts 
Atratividade do programa
Reconhecimento dos co-benefícios da plantação de carbono

Avaliação da adequabilidade dos recursos financeiros oferecidos para o programa

- Duração/longevidade do programa

Confiabilidade do proponente

- Tipo de programa proposto

Conhecimento a respeito das plantações necessárias

Victoria (Austrália)

- Fonte de renda principal provém da propriedade

Tempo necessário para os processos administrativos antes da implementação do programa

- Participação dos proprietários em outros programas para a conservação

- Tempo necessário para a coleta de informação antes dos processos administrativos

Conectância da rede social dos proprietários na comunidade

Proprietário participou de cursos semelhantes?

Quantidade de monitoramento e controle necessários para a implentação dos programas

Percentual de proprietários participando do grupo local Landcare (variável contínua transformada em categórica)

Existência de trusted peers

O bem-estar de sua família aumentou após a participação no programa de PSA?

O proprietério dompletou a educaçăo elementar?

ós participar do programa de PSA?

O proprietário se considera parte de um grupo indígena?

O proprietário considera que a gestão do programa de PSA deve ser feita pelo CONAFOR**

O proprietário pretende mudar o uso do solo após o término do programa de PSA?

O proprietário recebeu treinamento a respeito de Serviços Ambientais?

Mexico

O proprietário conhece as condições necessárias para a participação no programa de PSA?

O proprietário sabe a duração do programa de PSA?

O proprietário considera que o PSA tem um impacto positivo na gestão local de recursos hídricos?

Existem atividades organizadas na comunidade para a proteção e gestão das florestas?

- A comunidade toma decisoes a respeito do PSA por meio de consenso em assembléia?

Existem conflitos sobre os limites das propriedades dentro da comunidade?

* No caso, a instituição encarregada da execução do programa.

- Área da propriedade

O fazendeiro possui legalmente a titulação legal da terra?

dade do respondente

da família por hectare

Costa Rica

- Percentual da renda familiar proveniente de fora da fazenda

- Lucro líquido total proveniente da fazenda

- Família possui uma ou mais dívidas/empréstimos?

- Fazendeiro foi visitado por um agente técnico rura no último ano?

Fazendeiro participou de workshop sobre reflorestamento (antes da participação no programa de PSA)?

Percentual da fazenda com solo degradado de acordo com a percepção do proprietário

The money or the trees: What drives landholders' participation in biodivers carbon plantings?

like to conserve the forest, but I also like the cash". Socioeconomic factors influencing the motivation to be engaged Environmental Services

Programme

reforestation incentive

programs in Costa Rica

Percentual da fazenda com áreas íngremes de acordo com a percepção do proprietário 
O fazendeiro ofereceu terra para participar do WRP*?

- Área total possuída pelo fazendeiro

Area total de wetland possuída pelo fazendeiro

A renda média por hectare aumentou após a participação no Programa?

O respondente ficou sabendo do WRP por meio do serviço de extensão**

- O respondente possui bom conhecimento a respeito do WRP?

- O respondente possui wetlands alteradas para permitir o plantio agrícola?

O respondente cultiva soja?

Louisiana (Estados Unidos)

O respondente faz parte de uma organização ambiental

- Sexo do respondente

- Educação do respondent

Idade do respondente

Número de pessoas vivendo na casa do respondente

Renda do respondente

Atitude do respondente em relacão a participar com suas wetlands no WRP

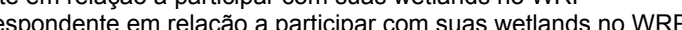

\section{*Wetland Reserve Program}

**Serviço de extensão se refere ao Louisiana Cooperative Extension Service

- Adequabilidade do solo para a agricultura

- Área total da propriedade

Presença de fatores ambientais (wetlands, vegetação endêmica etc.)

- Área predominantemente agrícola?

- Distância de áreas urbanas

- Existência de central de esgoto próxima à propriedade

O valor da terra agrícola ser igual ao da terra em desenvolvimento?

Delaware (Estados Unidos)

- $\mathrm{agricultor}$ planta na propriedade?

- Possui aves na propriedade?

- Possui milho ou soja na propriedade?

- Valor de vendas (acima de US\$30.000,00)

A preservação possui valor estético

- Média de horas de trabalho por semana do proprietário na propriedade

- O proprietário valoriza a terra pelas opções que ela providencia?

proprietário valoriza a terra por causa da preservação da natureza?

o proprietário valoriza a ter

- Tamanho da fazenda

Tazendeiro possui o título legal da terra?

- Tempo de trabalho da família na propriedade

Costa Rica

O proprietário realizou empréstimo nos últimos cinco anos?

Renda total proveniente da propriedade

Percentual da renda proveniente de fora da propriedade

Percentual da fazenda com solo de má qualidade, de acordo com a percepção do proprietário

Percentual da fazenda alta declividade, de acordo com a percepção do proprietário

O proprietário foi visitado por uma organização florestal ou um profissional para orientá-lo sobre o Programa?

Participation in the next generation of agriculture

conservation programs:

The role of environmenta attitudes

Participation in agricultural and preservatio

and a complex policy

Paying for Environmenta Services: An Analysis of Participation in Costa Rica' s PSA Program 
- Renda líquida do proprietário
- Percentual da renda proveniente de pensões

- Percentual da renda proveniente de fora da propriedade

- Percentual da renda proveniente da atividades realizadas dentro da propriedade

- Percentual da área alugada

- Total de horas trabalhadas na fazenda por ano [do proprietário ou terceiros]

- Horas de trabalho da família por hectare

- Percentual das áreas agricultáveis da propriedade em áreas montanhosas

- Existe área de pasto sem rebanho na propriedade?

- Nível de educação formal do fazendeiro

- Ocorrência de investimentos nos últimos 5 anos?

Norte da Itália

- A área total da propriedade cresceu nos últimos 5 anos?

- Opinião a respeito da propriedade no futuro

Atividades ambientais foram desenvolvidas anteriormente na propriedade sem a necessidade de pagamentos?

- Proprietário acredita que a imagem pública da agricultura influencia na sua decisão?

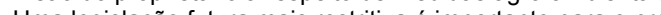

prietário ao avaliar sua decisão?

- A compensação financeira cobre integralmente os outros custos acarretados pelo Programa?

- O fazendeiro consegue aconselhamento técnico por outros proprietários?

- O fazendeiro lê revistas relacionadas à agricultura?

* Trata-se de um regulamento de programas agro-ambientais na Itália.

- Residente na propriedade em 1996 ?

- Tamanho da propriedade

Costa Rica

- Teve floresta desmatada nos últimos 50 anos?

- Idade do respondente

- Anos de educação formal do proprietário

Cidade de origem

Percentual da familia que é mulher

Duração do contrato

- Possui flexibilidade a respeito de qual área da terra entra no Programa?

Reino Unido (North East of England)

- Possui flexibilidade para fazer as medidas requeridas pelo Programa?

- Tempo médio gasto em trabalho administrativo ou burocrático

- Tempo médio gasto em trabalho administrativo ou burocrático

Holanda (Friesland)

Bèlgica (Flanders)

- Tempo medio gasto em trabalho adminis

- Idade do responsável pela fazenda

Itália (Emilia-Romagna e Veneto)

- Idade do responsável pela fazenda

- Nivel de educação formal

- Onsciência possui sucessor?

Área agricultável da prop

É uma grande propriedadedade (hectares)

República Tcheca

- Proporção da fazenda que é alugada

- Renda dependente da fazenda?

- Valor dos ativos em 1999

Custo de oportunidade da parcela

Declividade (três classes, variáveis binárias)

China

Benefício ambiental

Área total da propriedade

Distância da propriedade à casa

Número de moradores

Factors Affecting Farmers Participation in AgriPeasures: A Northern Italian

Combining qualitative an quantitative methods to costa rica's program if payments for

environmental services 
Cada grupo representa uma série de variáveis. Por exemplo no Grupo 2: opção de cancelamento de 5 em 5 ou 10 em 10 anos.

Agri-Environmental - Percentual da área agricultável localizada em moorlands

- Percentual da área de pasto fertilizada

- Percentual da área de pasto não fertilizada

- Número de ovelha

- Número de bois

Número de vacas leiteiras

Propriedade possui vacas e bois?

- Propriedade possui apenas bois?
- Propriedade possui apenas ovelhas?

Nidderdale Area of Outstanding

- Propriedade possui apenas ovelhas?

Contract Preferences

Natural Beauty (Reino Unido)

\section{- Área total}

- Uso de fertilizante artificial na propriedade?

Existe sucessão na família?

- Número de bois em menos de 6 mese

- Número de bois entre 6 e 18 meses

Número de bois em mais de 18 meses

Existência de grips na terra?

- Duração do contrato

Valor do contrato

Como o proprietário se sente em relação ao clima?

Como o proprietário se sente em relação ao preco de produtos primários?

Como o proprietario se sente em relação ao proprio nivel de plantação?

Renda total de 2011

dade do respondente

Número de membros da família

Tempo de trabalho da família na propriedade

- Como o proprietario se sente em relação ao suporte fiscal?

Como o proprietário se sente em relação ao efeito do $G G P^{\star}$ no meio ambiente?

nefícios do GGP o proprietário recebe?

obrevivência da floresta

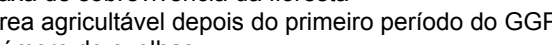

- Número de ovelhas

Como o proprietário se sente em relação às condiç̃̃es do solo?

Como o proprietário se sente em relação às condições do tráfeg?

Preço ofertado pela geração de carbono

A principal fonte de renda é a fazenda?

- Preocupado com as mudanças climáticas?
- Apoia políticas de mudanças climáticas?

Grupo* 1: Participa ou participou de programas para geração de carbono?

- Grupo 3: Experiência na produção

North Dakota (Estados Unidos)

Grupo 4: Educação formal

Grupo 5: Relação do proprietário com a terra (comprado, alugado etc.)

Grupo 6: Uso principal do solo

* Cada grupo representa uma série de perguntas com resposta binária.

Rural households'

rogram again: A case
tudy of Zhungeer, China

Producer preference for and-based biological carbon sequestration in agriculture: Some implications from a samp f North Dakota farmers 
- Renda da fazenda

Produção por hectare

Número de horas de trabalho por ano na propriedade

Idade do fazendeiro

Fazendeiro possui filhos?

Fazendeiro é casado?

Irlanda

Área da propriedade (hectares)

Nitrogênio orgânico

Grupo* 1: Tipo de solo

Grupo 2: Tamanho da propriedade

Grupo 3: Participações anteriores no Programa**

* Cada grupo representa uma série de variáveis. Por exemplo no Grupo 1: percentual da área da propriedade que tem um tipo específico de solo.

* Se aplica somente aos modelos para a fase 2 em diante do Programa em questão.

An investigation into the

to participate in Rural

Environment Protection

Scheme (REPS) and the

role of institutional chang

in influencing scheme

effectiveness 
APÊNDICE B - Variáveis candidatas 


\begin{tabular}{|c|c|c|c|c|c|}
\hline \multirow{2}{*}{$\begin{array}{l}\text { Dado original } \\
\text { encontrado }\end{array}$} & \multicolumn{3}{|r|}{ Variáveis obtidas } & \multirow{2}{*}{$\begin{array}{l}\text { Grupo adequado à variável } \\
\text { obtida }\end{array}$} & \multirow{2}{*}{ Fonte de obtenção } \\
\hline & Código & Tipo & Descrição & & \\
\hline \multirow{16}{*}{ Declaração no CAR } & area_prop_ha & contínua & Área total da propriedade, recalculada em hectares & Tamanho da propriedade & \multirow{16}{*}{ DataGEO (SÃO PAULO, 2016) } \\
\hline & area_disponivel & contínua & $\begin{array}{l}\text { Área disponível para a participação, calculada a partir da subtração espacial das } \\
\text { APPs hídricas, outras APPs, Reserva Legal e vegetação nativa da área total da } \\
\text { propriedade }\end{array}$ & Área agricultável & \\
\hline & area_nao_disponivel & contínua & $\begin{array}{l}\text { Área não disponível para a participação, calculada por: area_prop_ha - } \\
\text { area_disponivel }\end{array}$ & Área agricultável & \\
\hline & percentual_disponivel & contínua & $\begin{array}{l}\text { Percentual da propriedade disponível para a participação, calculada pela divisão } \\
\text { da area dísponivel pela área total da propriedade }\end{array}$ & Área agricultável & \\
\hline & possui_app & binária & Variável indicativa, de valor 1 caso a propriedade tenha APP e 0 , caso não tenha & Mata ciliar & \\
\hline & percentual_app & contínua & $\begin{array}{l}\text { Percentual de APP na propriedade, calculada como a área total da união entre } \\
\text { APPs hídricas e outras APPs, dividida pela área total da propriedade }\end{array}$ & $\begin{array}{l}\text { Mata ciliar, cumprimento da } \\
\text { lei }\end{array}$ & \\
\hline & percentual_RL & contínua & $\begin{array}{l}\text { Percentual de RL na propriedade, calculada como a área total de reserva legal } \\
\text { dividida pela área total da propriedade }\end{array}$ & Cumprimento da lei & \\
\hline & percentual_veg & contínua & $\begin{array}{l}\text { Percentual de vegetação na propriedade, calculada como a área declarada de } \\
\text { vegetação dividida pela área total da propriedade }\end{array}$ & Cumprimento da lei & \\
\hline & percentual_app_que_eh_RL & contínua & $\begin{array}{l}\text { Percentual da APP da propriedade que é considerada no cômputo da Reserva } \\
\text { Legal, calculada como a área da intersecção da união das APPs hídricas e outras } \\
\text { APPs com a Reserva Legal, divida pela área total de Reserva Legal }\end{array}$ & $\begin{array}{l}\text { Mata ciliar, cumprimento da } \\
\text { lei }\end{array}$ & \\
\hline & percentual_RL_vegetada & contínua & $\begin{array}{l}\text { Percentual da RL vegetada na propriedade, calculada como a área total da } \\
\text { intersecção da } R L \text { com a vegetação, dividida pela área total de } R L\end{array}$ & Cumprimento da lei & \\
\hline & percentual_app_vegetada & contínua & $\begin{array}{l}\text { Percentual da APP vegetada na propriedade, calculada como a área total da } \\
\text { intersecção entre a união das APPs hídricas e outras APPs com a vegetação } \\
\text { nativa, dividida pela área total da união das APPs hídricas e outras APPs }\end{array}$ & $\begin{array}{l}\text { Mata ciliar, cumprimento da } \\
\text { lei }\end{array}$ & \\
\hline & centroide_x & contínua & Longitude do centróide da propriedade & Localização & \\
\hline & centroide_y & contínua & Latitude do centróide da propriedade & Localização & \\
\hline & cod.Atividade & categórica & Atividade predominante na propriedade & Uso do solo & \\
\hline & tem_nascente & binária & $\begin{array}{l}\text { Variável indicativa, de valor } 1 \text { quando a propriedade possui nascente pontual e } 0 \text {, } \\
\text { quando não possui }\end{array}$ & Nascentes & \\
\hline & densidade_nascentes & contínua & $\begin{array}{l}\text { Medida da densidade das nascentes, calculada pelo número de nascentes dentro } \\
\text { da propriedade dividida pela sua área total }\end{array}$ & Nascentes & \\
\hline
\end{tabular}




\begin{tabular}{|c|c|c|c|c|c|}
\hline \multirow{2}{*}{$\begin{array}{l}\text { Dado original } \\
\text { encontrado }\end{array}$} & \multicolumn{3}{|r|}{ Variáveis obtidas } & \multirow{2}{*}{$\begin{array}{l}\text { Grupo adequado à variável } \\
\text { obtida }\end{array}$} & \multirow{2}{*}{ Fonte de obtenção } \\
\hline & Código & Tipo & Descrição & & \\
\hline \multirow{2}{*}{$\begin{array}{l}\text { Módulos fiscais por } \\
\text { município }\end{array}$} & modulos_fiscais_propriedade & contínua & $\begin{array}{l}\text { Número de módulos fiscais da propriedade, calculado pela área total da } \\
\text { propriedade dividida pela área do módulo fiscal no município }\end{array}$ & Tamanho da propriedade & \multirow{2}{*}{ INCRA (INCRA, 2017) } \\
\hline & grande_ou_pequena & binária & $\begin{array}{l}\text { Variável indicativa, de valor } 1 \text { caso a propriedade possua } \\
\text { modulos_fiscais_propriedade }>4 \text {, e valor } 0 \text { no caso contrário }\end{array}$ & Tamanho da propriedade & \\
\hline \multirow{10}{*}{ Rasters de solo } & pH_superficie & contínua & $\begin{array}{l}\text { pH na água da superfície do solo. Calculada a partir do raster de resolução de } \\
250 \mathrm{~m}\end{array}$ & Solo, produtividade & \multirow{10}{*}{ SoilGrids (HENGL et al., 2017 } \\
\hline & pH_30cm & contínua & $\begin{array}{l}\text { pH na água a } 30 \mathrm{~cm} \text { de profundidade do solo. Calculada a partir do raster de } \\
\text { resolução de } 250 \mathrm{~m}\end{array}$ & Solo, produtividade & \\
\hline & CTC_superficie_cmolc.kg & contínua & $\begin{array}{l}\text { Capacidade média de troca catiônica }(\mathrm{cmolc} / \mathrm{kg}) \text { na superficie do solo. Calculada a } \\
\text { partir do raster de resolução de } 250 \mathrm{~m}\end{array}$ & Solo, produtividade & \\
\hline & CTC_30cm_cmolc.kg & contínua & $\begin{array}{l}\text { Capacidade média de troca catiônica a } 30 \mathrm{~cm} \text { de profundidade do solo. Calculada } \\
\text { a partir do raster de resolução de } 250 \mathrm{~m}\end{array}$ & Solo, produtividade & \\
\hline & carbono_superficie_g.kg & contínua & $\begin{array}{l}\text { Teor médio de carbono orgânico }(\mathrm{g} / \mathrm{kg}) \text { na superfície do solo. Calculada a partir do } \\
\text { raster de resoluçâo de } 250 \mathrm{~m}\end{array}$ & Solo, produtividade & \\
\hline & carbono_30cm_g.kg & contínua & $\begin{array}{l}\text { Teor médio de carbono orgânico }(\mathrm{g} / \mathrm{kg}) \text { a } 30 \mathrm{~cm} \text { de profundidade do solo. } \\
\text { Calculada a partir do raster de resolução de } 250 \mathrm{~m}\end{array}$ & Solo, produtividade & \\
\hline & percentual_argila_superficie & contínua & $\begin{array}{l}\text { Fração média do solo, na superfície, composta por argila. Calculada a partir do } \\
\text { raster de resolução de } 250 \mathrm{~m}\end{array}$ & Solo, produtividade & \\
\hline & percentual_argila_30cm & contínua & $\begin{array}{l}\text { Fração média do solo, a } 30 \mathrm{~cm} \text { de profundidade, composta por argila. Calculada a } \\
\text { partir do raster de resolução de } 250 \mathrm{~m}\end{array}$ & Solo, produtividade & \\
\hline & grupo_solo & categórica & Classe de solo predominante na propriedade & Solo, produtividade & \\
\hline & grupo_solo_WRB & categórica & $\begin{array}{l}\text { Classe de solo predominante na propriedade, de acordo com a classificação da } \\
\text { World Reference Base }\end{array}$ & Solo, produtividade & \\
\hline \multirow[b]{4}{*}{$\begin{array}{l}\text { Modelo digital de } \\
\text { elevação }\end{array}$} & altitude_m & contínua & $\begin{array}{l}\text { Altitude média da propriedade. Calculada a partir do raster de resolução de } \\
\text { aproximadamente } 30 \mathrm{~m}\end{array}$ & Temperatura & \multirow[b]{4}{*}{ ASTER GDEM (USGS, 2017) } \\
\hline & declividade_radianos & contínua & $\begin{array}{l}\text { Declividade média da propriedade. Calculada a partir do raster de resolução de } \\
\text { aproximadamente } 30 \mathrm{~m}\end{array}$ & Declividade & \\
\hline & aspecto_graus & contínua & O ângulo médio para o qual aponta a declividade do terreno & Terreno & \\
\hline & seno_aspecto & contínua & $\begin{array}{l}\text { O seno do ângulo de aspecto médio do terreno. O seno atribui valores positivos } \\
\text { para propriedades viradas para a face norte e valores negativos para propriedades } \\
\text { viradas para a face sul }\end{array}$ & Terreno & \\
\hline
\end{tabular}




\begin{tabular}{|c|c|c|c|c|c|}
\hline \multirow{2}{*}{$\begin{array}{l}\text { Dado original } \\
\text { encontrado }\end{array}$} & \multicolumn{3}{|r|}{ Variáveis obtidas } & \multirow{2}{*}{$\begin{array}{l}\text { Grupo adequado à variável } \\
\text { obtida }\end{array}$} & \multirow{2}{*}{ Fonte de obtenção } \\
\hline & Código & Tipo & Descrição & & \\
\hline & insolacao_janeiro_kWh.m2 & contínua & $\begin{array}{l}\text { Insolação potencial ao meio dia de } 01 / 01 / 2017 \text {, calculada por meio do Modelo } \\
\text { Digital de Elevação e do módulo Potencial Incoming Solar Radiation, do SAGA } \\
\text { GIS. Calculada a partir do raster de resolução aproximadamente } 60 \mathrm{~m}\end{array}$ & Temperatura, produtividade & \\
\hline & insolacao_julho_kWh.m2 & contínua & $\begin{array}{l}\text { Insolação potencial ao meio dia de } 01 / 07 / 2017 \text {, calculada por meio do Modelo } \\
\text { Digital de Elevação e do módulo Potencial Incoming Solar Radiation, do SAGA } \\
\text { GIS. Calculada a partir do raster de resolução aproximadamente } 60 \mathrm{~m}\end{array}$ & Temperatura, produtividade & \\
\hline \multirow{6}{*}{ Erosões rurais } & tem_erosao & binária & Variável de valor 1 caso haja erosão dentro da propriedade e 0 , caso contrário & Erosão & \multirow{6}{*}{ DAEE/IPT (2012) } \\
\hline & tem_ravina & binária & Variável de valor 1 caso haja ravina dentro da propriedade e 0 , caso contrário & Erosão & \\
\hline & tem_bocoroca & binária & Variável de valor 1 caso haja boçoroca dentro da propriedade e 0 , caso contrário & Erosão & \\
\hline & densidade_erosao & contínua & $\begin{array}{l}\text { Medida da densidade de erosões das propriedades, calculada pelo número de } \\
\text { erosões dentro dos limites da propriedade dividido por sua área total }\end{array}$ & Erosão & \\
\hline & densidade_ravina & contínua & $\begin{array}{l}\text { Medida da densidade de ravinas das propriedades, calculada pelo número de } \\
\text { erosões dentro dos limites da propriedade dividido por sua área total }\end{array}$ & Erosão & \\
\hline & densidade_bocoroca & contínua & $\begin{array}{l}\text { Medida da densidade de boçorocas das propriedades, calculada pelo número de } \\
\text { erosões dentro dos limites da propriedade dividido por sua área total }\end{array}$ & Erosão & \\
\hline \multirow{2}{*}{$\begin{array}{l}\text { Área plantada e } \\
\text { rendimento médio das } \\
\text { lavouras temporárias e } \\
\text { permanentes }\end{array}$} & renda_bruta_freq & contínua & Renda bruta da cultura mais frequente no município da propriedade, em 2015 & Economia & \multirow{2}{*}{$\begin{array}{l}\text { Produção Agrícola Municipal } \\
\text { (IBGE, 2015c) }\end{array}$} \\
\hline & renda_bruta_maior & contínua & Renda bruta de maior valor no município da propriedade, em 2015 & Economia & \\
\hline \multirow{2}{*}{$\begin{array}{l}\text { Valor adicionado bruto } \\
\text { a preços correntes } \\
\text { total e por atividade } \\
\text { econômica }\end{array}$} & vadic_agrop_bruto & contínua & $\begin{array}{l}\text { Valor adicionado bruto da agropecuária no município da propriedade a preços } \\
\text { correntes (em } 1.000 \text { reais) }\end{array}$ & Economia & \multirow{2}{*}{$\begin{array}{l}\text { Produto Interno Bruto dos } \\
\text { Municípios (IBGE, 2012) }\end{array}$} \\
\hline & vadic_agrop_perc_total & contínua & $\begin{array}{l}\text { Percentual do valor adicionado bruto da agropecuária no município em relação ao } \\
\text { valor adicionado bruto total }\end{array}$ & Economia & \\
\hline \multirow{6}{*}{ Crédito rural } & cr2011 & contínua & Crédito rural no município da propriedade, em 2011 & Economia & \multirow{6}{*}{ SEADE (SÃO PAULO, 2016) } \\
\hline & cr2011_agr & contínua & Crédito rural para a agricultura no município da propriedade, em 2011 & Economia & \\
\hline & cr2011_pec & contínua & Crédito rural para a pecuária no município da propriedade, em 2011 & Economia & \\
\hline & cr2011_perc_agr & contínua & Percentual do crédito rural de 2011 destinado à agricultura & Economia & \\
\hline & cr2011_perc_pec & contínua & Percentual do crédito rural de 2011 destinado à pecuária & Economia & \\
\hline & emprego_agro & contínua & $\begin{array}{l}\text { Número de empregos formais da agricultura, pecuária, produção florestal, pesca e } \\
\text { aquicultura no município da propriedade }\end{array}$ & Economia & \\
\hline
\end{tabular}




\begin{tabular}{|c|c|c|c|c|c|}
\hline \multirow{2}{*}{$\begin{array}{l}\text { Dado original } \\
\text { encontrado }\end{array}$} & \multicolumn{3}{|r|}{ Variáveis obtidas } & \multirow{2}{*}{$\begin{array}{l}\text { Grupo adequado à variável } \\
\text { obtida }\end{array}$} & \multirow{2}{*}{ Fonte de obtenção } \\
\hline & Código & Tipo & Descrição & & \\
\hline \multirow[t]{2}{*}{$\begin{array}{l}\text { Empregos formais no } \\
\text { meio rural }\end{array}$} & emprego_agro_perc_total & contínua & $\begin{array}{l}\text { Percentual do número de empregos formais da agricultura, pecuária, produção } \\
\text { florestal, pesca e aquicultura em relação ao número de empregos formais total do } \\
\text { município da propriedade }\end{array}$ & Economia & \\
\hline & rend_emprego_agro & contínua & $\begin{array}{l}\text { Rendimento médio dos empregos formais da agricultura, pecuária, produção } \\
\text { florestal, pesca e aquicultura no município da propriedade }\end{array}$ & Economia & \\
\hline \multirow{2}{*}{$\begin{array}{l}\text { Autos de Infração } \\
\text { Ambiental (AIA), } 2016 \text { - } \\
\text { pontos válidos }\end{array}$} & tem_AlA_mun & binária & $\begin{array}{l}\text { Variável indicativa, de valor } 1 \text { quando o município da propriedade possui AIA e } 0 \text {, } \\
\text { quando não possui }\end{array}$ & Cumprimento da lei & \multirow{2}{*}{ DataGEO (SÃO PAULO, 2016) } \\
\hline & densidade_AIA_mun_n.km2 & contínua & $\begin{array}{l}\text { Medida da densidade de AIAs no município da propriedade, calculada como o } \\
\text { número de AIAs dentro de um município dividido por sua área total }\end{array}$ & Cumprimento da lei & \\
\hline \multirow{3}{*}{$\begin{array}{l}\text { Unidades de } \\
\text { Conservação }\end{array}$} & dentro_ou_fora_de_APA & binária & $\begin{array}{l}\text { Variável de valor } 1 \text {, caso a propriedade esteja com pelo menos } 50 \% \text { de sua área } \\
\text { dentro de uma Área de Proteção Ambiental, ou } 0 \text {, caso contrário }\end{array}$ & Áreas especiais & \multirow{3}{*}{ Sistema i3geo (MMA, 2017) } \\
\hline & dentro_ou_fora_de_UC_US & binária & $\begin{array}{l}\text { Variável de valor 1, caso a propriedade esteja com pelo menos } 50 \% \text { de sua área } \\
\text { dentro de uma Unidade de Conservação de Uso Sustentável, ou 0, caso contrário }\end{array}$ & Áreas especiais & \\
\hline & dentro_ou_fora_de_UC_PI & binária & $\begin{array}{l}\text { Variável de valor } 1 \text {, caso a propriedade esteja com pelo menos } 50 \% \text { de sua área } \\
\text { dentro de uma Unidade de Conservação de Proteção Integral, ou 0, caso contrário }\end{array}$ & Áreas especiais & \\
\hline Rodovias & distancia_rodovia_proxima_m & contínua & Distância do centroide da propriedade até a rodovia mais próxima & Distância & DNIT (2017) \\
\hline $\begin{array}{l}\text { Temperatura média } \\
\text { mensal }\end{array}$ & temperatura_media_10.celsius & contínua & $\begin{array}{l}\text { Temperatura média anual }\left(10^{\circ} \mathrm{C}\right) \text {. Calculada a partir do raster de resolução de } \\
\text { aproximadamente } 1 \mathrm{~km}\end{array}$ & Temperatura & WorldClim (FICK; HIJMANS, 2017) \\
\hline \multirow{2}{*}{$\begin{array}{l}\text { Precipitação média } \\
\text { mensal }\end{array}$} & precipitacao_media_mm & contínua & $\begin{array}{l}\text { Precipitação média anual }(\mathrm{mm}) \text {. Calculada a partir do raster de resolução de } \\
\text { aproximadamente } 1 \mathrm{~km}\end{array}$ & Produtividade & \multirow{2}{*}{ WorldClim (FICK; HIJMANS, 2017) } \\
\hline & precipitacao_acumulada_mm & contínua & $\begin{array}{l}\text { Precipitação acumulada anual }(\mathrm{mm}) \text {. Calculada a partir do raster de resolução de } \\
\text { aproximadamente } 1 \mathrm{~km}\end{array}$ & Produtividade & \\
\hline Biomas & bioma & binária & Variável de valor 1 para Mata Atlântica e 0 para Cerrado & Áreas especiais & Sistema i3geo (MMA, 2017) \\
\hline
\end{tabular}



APÊNDICE C - Lista dos principais arquivos 
$\$ l s-1$

arquivos \#arquivos de diferentes fontes incorporados ao banco de dados bin

concluidos \#trabalhos executados pelo Cluster

gdal-2.1.3 \#biblioteca necessária para a manipulação de dados espaciais geos-3.6.1 \#biblioteca necessária para a manipulação de dados espaciais include

lib

Modelo \#arquivos do modelo estatistico e dos graficos gerados

proj-4.9.3 \#biblioteca necessária para a manipulação de dados espaciais R

R.sh

saga-4.0.0 \#biblioteca necessária para a manipulação de dados espaciais share

$\$$ tree - $C$ arquivos Modelo

arquivos

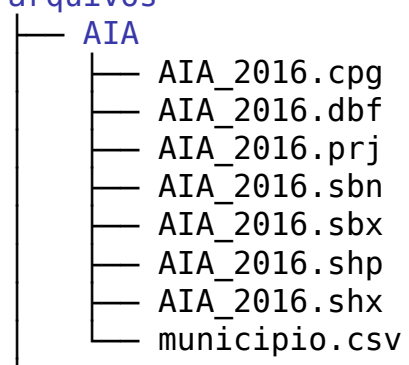

Areas

L areas municipios.csv

CAR

— app_buffer_publico.dbf

- app_buffer_publico.prj

- app buffer publico.sbn

- app_buffer_publico.sbx

- app_buffer_publico.shp

- app_buffer_publico.shx

- outras_apps.dbf

- outras apps.prj

- outras apps.sbn

- outras_apps.sbx

- outras apps.shp

outras apps.shx

- processados

- APP

- intersecao todas apps e rl.dbf

- intersecao_todas_apps_e_rl.prj

- intersecao todas apps e rl.shp

- intersecao todas apps e rl.shx

- intersecao_todas_apps_e_veg.dbf

- intersecao_todas apps_e_veg.prj

- intersecao todas apps e veg.shp

_ intersecao_todas_apps_e_veg.shx

- todas_apps.dbf

- todas apps.prj

_ todas_apps.shp

todas apps.shx

area disponivel

—_ disp_apph.dbf

- disp_apph.prj

- disp apph.shp

- disp_apph.shx

- disp apph veg.dbf

- disp apph veg.prj

_ disp_apph_veg_rl.dbf

- disp apph veg rl oapp.dbf

- disp apph veg rl oapp.prj

— disp_apph_veg_rl_oapp.shp 


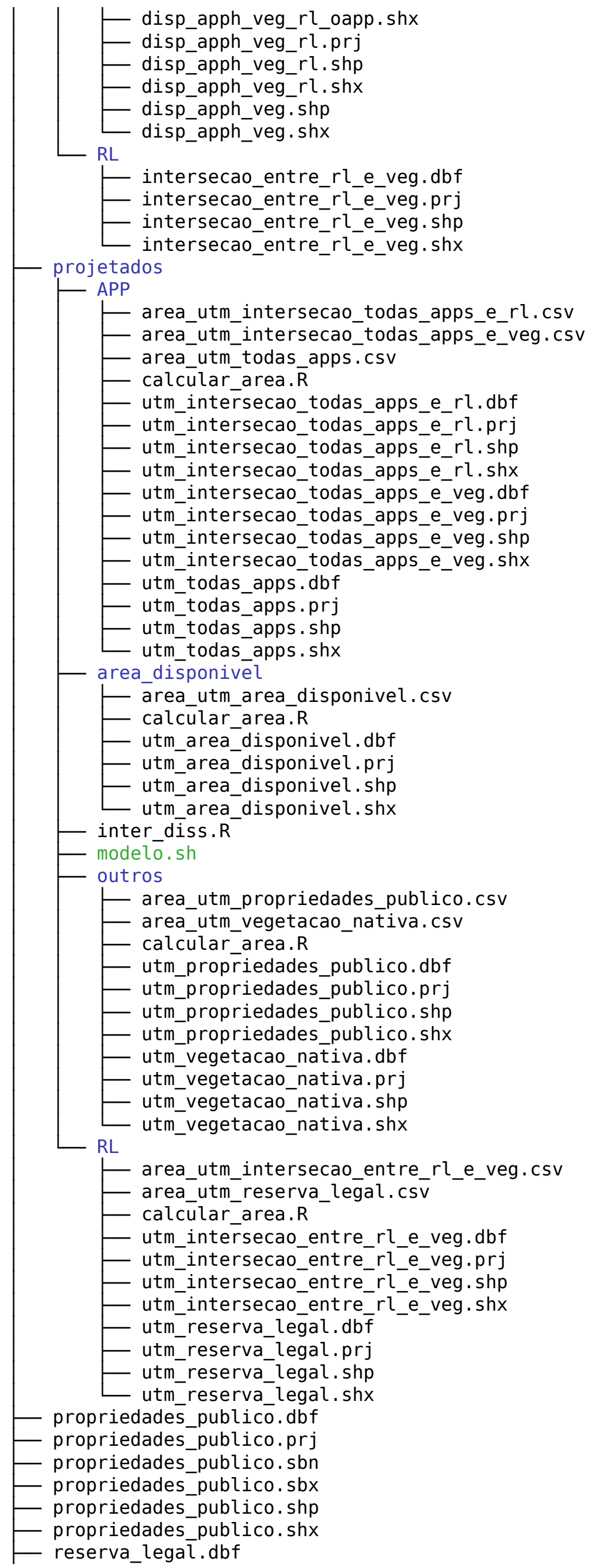




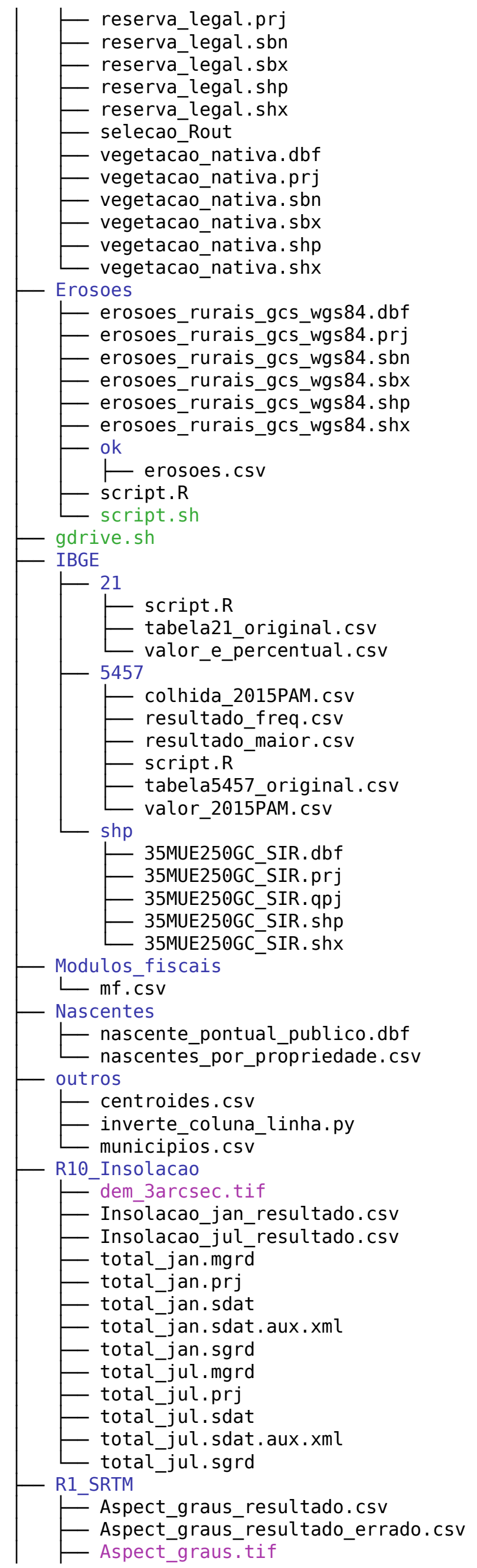




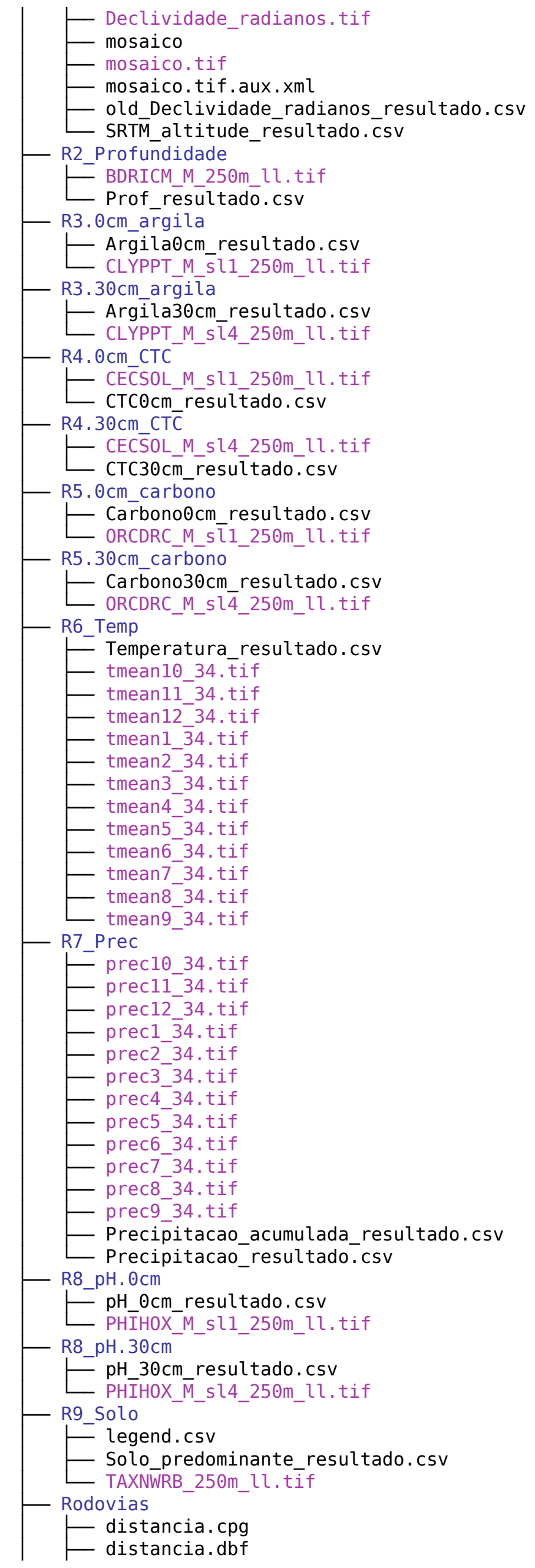




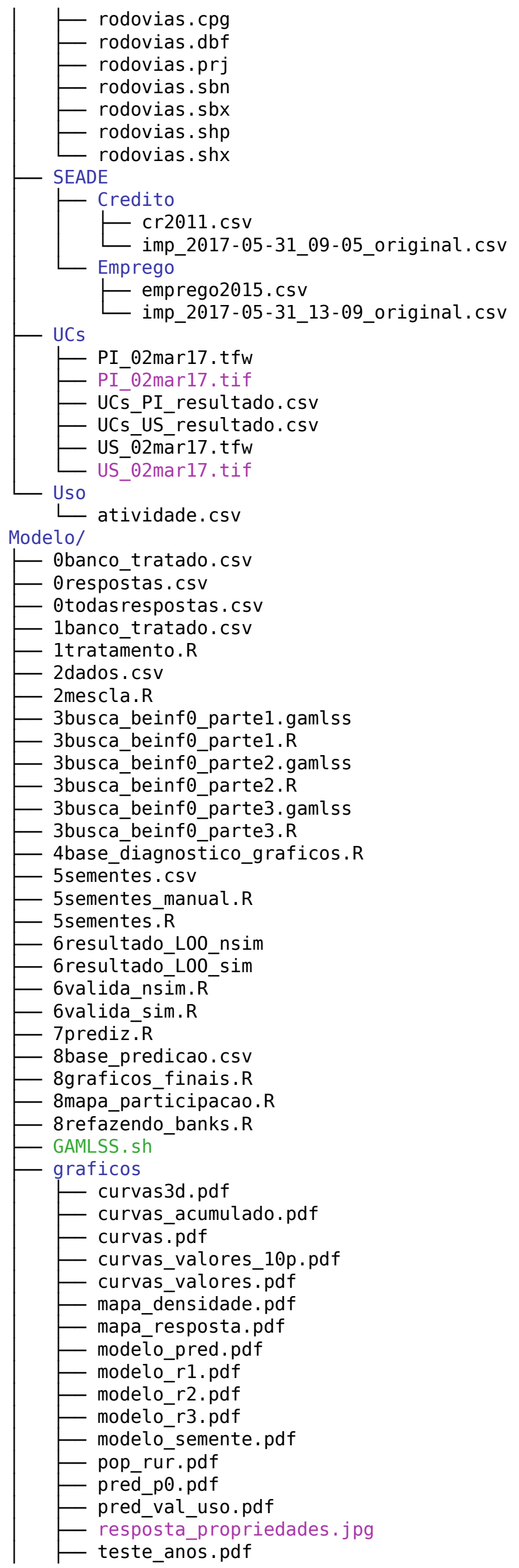


_teste_ativ_desm.pdf

teste_ativ.pdf teste_sexo.pdf

resultados

7p0_t5_p50
7p0_t5_p100
. .
7p0_t40_p1950
7p0_t40_p2000
7predicao_t5_p50
7predicao_t5_p100
. .
7predicao_t40_p1950
7predicao_t40_p2000

43 directories, 955 files 